\author{
Universidade de São Paulo \\ Instituto de Astronomia, Geofísica e Ciências Atmosféricas
}

Departamento de Astronomia

Rafael Miloni Santucci

\title{
Identificação de subestruturas no halo galáctico através de estrelas azuis tardias
}

São Paulo 



\section{Identificação de subestruturas no halo galáctico através de estrelas azuis tardias}

Tese apresentada ao Departamento de Astronomia do Instituto de Astronomia, Geofísica e Ciências Atmosféricas da Universidade de São Paulo como requisito parcial para a obtenção do título de Doutor em Ciências.

Área de Concentração: Astronomia Orientadora: Prof ${ }^{\mathrm{a}}$ Dr$^{\mathrm{a}}$ Silvia Rossi

São Paulo 

"Aos meus pais, obrigado pelo carinho e atenção, os quais nunca foram tardios nem pobres."

"Em memória de Maria Sônia, obrigado pela amizade e pelo exemplo, mesmo em épocas impossíveis." 



\section{Agradecimentos}

Aos meus pais, principais investidores do meu crescimento intelectual, vertical e horizontal;

À Elisa, por tudo;

Ao "Excelente" Professor Vini Placco, co-orientador e co-irmão. Um exemplo de dedicação, organização e competência;

À Prof ${ }^{\mathrm{a}}$. Silvia Rossi, que sempre me incentivou e acreditou no meu potencial (de longe, a melhor orientadora que eu já tive em toda vida);

Aos meus irmãos, Roginho e Rodrigo, por toda a diversão e cobrança;

Ao pesquisador, Timothy Beers por ter me apresentado ao tema das estrelas azuis tardias, e por todas as discussões científicas;

À Ana e à Luciene pela ajuda e companhia nesta jornada;

Ao observatório Abrahão de Moraes em Valinhos, que me proporcionou muita alegria e motivação;

À Dinah, que forneceu o computador que utilizei para realizar este trabalho; Ao Marco e ao Luis, que mantiveram o computador funcionando neste tempo;

Aos funcionários do IAG e equipes de apoio, por fornecer um ótimo ambiente de trabalho;

À CAPES e ao CNPq, pelo apoio financeiro;

À todos que eu não citei por problemas mentais momentâneos ou àqueles que deixei de dar a devida atenção enquanto estive realizando este trabalho, minhas sinceras desculpas e meu obrigado pela compreensão!

Esta tese foi escrita em $\mathrm{AT}_{\mathrm{E}} \mathrm{X}$ com a classe IAGTESE, para teses e dissertações do IAG. 

"Um cientista deve, acima de tudo, ser como uma criança [...]. Não dá pra ser um cientista se você vai ficar se preocupando se as pessoas vão ou não te achar bobo."

Douglas Adams

"O mundo te respeitará na exata proporção que você não tiver medo dele."

Clóvis de Barros Filho

"Ah - but I was so much older then; I am younger than that now."

Bob Dylan 



\section{Resumo}

Tudo que vive por muito tempo está apto a contribuir com boas histórias sobre o passado. Isto não é diferente com as estrelas azuis tardias que são encontradas em todos os ambientes estelares. Essas estrelas velhas mostram-se aparentemente muito jovens, e talvez por isso, nunca tenham sido ouvidas em um contexto maior que suas próprias vidas. Este trabalho interpreta a história que elas contam sobre a natureza do halo Galáctico, através de seus parâmetros físicos fundamentais: coordenadas, temperaturas, gravidades superficiais, metalicidades, cores, distâncias e idades.

Este trabalho utiliza dados do Sloan Digital Sky Survey para reunir candidatas a estrelas azuis tardias (BSSs) através de critérios espectrofotométricos. Ao todo, 8001 candidatas a BSSs sobreviveram aos diversos métodos de seleção aplicados, constituindo a base de dados deste estudo. Essa amostra permitiu estimar a frequência média de BSSs no halo em relação ao número de estrelas azuis do ramo horizontal (BHBs) em $\sim 2.15 \pm 0.13 \mathrm{BSS} / \mathrm{BHB}$, valor similar ao encontrado em galáxias anãs próximas $(\sim 2.24 \pm 0.17)$.

Verificou-se também que as BSSs apresentam um gradiente de cor em função da distância ao centro Galáctico, aparentemente independente da metalicidade. À variação de cor foi atribuída uma variação de idade, que forneceu um gradiente médio de $\sim-0.034 \pm 0.002$ Ganos/kpc no halo. Esse resultado mostra que as regiões mais velhas se concentram preferencialmente no centro da Galáxia, e ficam cada vez mais jovens para distâncias maiores.

O gradiente de cor das BSSs possibilitou a construção de mapas de idade do halo galáctico. Esses mapas foram superpostos às posições centrais de uma coleção de subestruturas encontrada na literatura. Aproximadamente $60 \%$ delas tem posições que concordam com as flutuações de cor observadas nos mapas, além de apresentarem propriedades cinemáticas e químicas similares às BSSs nessas regiões (em 2 $\sigma$ ). 



\section{Abstract}

Everything that lives long enough is able to contribute with good stories about the past. This statement also applies to the blue straggler stars (BSSs), which can be found in all stellar environments. These old stars appear to be very young and perhaps because of this have never been properly addressed in a context larger than their own lives. This work interprets the story they tell about the nature of the Galactic halo, through their fundamental physical parameters: coordinates, temperatures, surface gravities, metallicities, colors, distances and ages.

This work uses the Sloan Digital Sky Survey (SDSS) database to select BSS candidates through photometric and spectroscopic criteria. Altogether, 8001 BSS candidates survived the various selection methods applied and were used as the database for this study. This large sample allowed the determination of the average frequency of BSSs in the halo, compared to the number of blue horizontal branch stars (BHBs). The average frequency of BSS/BHB found in the galactic halo by this work is $2.15 \pm 0.13$, very similar to this ratio in nearby dwarf galaxies $(\sim 2.24 \pm 0.17)$.

In addition, this work verified that the BSSs show a color gradient as a function of distance to the galactic center, which appears to be independent from metallicity. To this color variation was assigned an age variation, yielding an average gradient of $-0.034 \pm 0.002$ Gyr/kpc in the halo. This result shows that the older regions preferentially occur in the center of the Galaxy and get younger for larger distances.

The BSSs color gradient allowed the construction of galactic halo age maps. These maps were superimposed to the central positions of a collection of substructures found in the literature. Approximately $60 \%$ of them have positions that agree with the color fluctuations observed in the maps, as well as having similar kinematic and chemical properties to the 
BSSs in those regions (within 2 $\sigma$ ). 


\section{Lista de Figuras}

1.1 Mapa do hemisfério norte celeste do halo galáctico construído com dados do Sloan Digital Sky Survey (SDSS) e apresentado em projeção Mercator. A variação de cor vista na figura está relacionada com a distância das estrelas. Assim, a coloração azul representa subestruturas mais próximas e as estrelas vermelhas as mais distantes, ao mesmo tempo que a intensidade das cores indica a densidade de objetos no céu. As subestruturas visíveis nessa figura são principalmente correntes de estrelas, onde a mais visível delas é a Correntes de Sagitário (Sagittarius stream), oriunda da ruptura da galáxia anã de Sagitário. Além dela, estão identificadas outras subestruturas menores como a Orphan stream ou "Corrente Órfã" que cruza a Corrente de Sagitário, o "Anel de Monoceros" (Monoceros Ring) que envolve o disco da Galáxia, rastros de estrelas sendo arrancadas do aglomerado globular Palomar 5 e sobredensidades de estrelas nas direções das constelações de Virgem (Virgo) e Hércules. Os círculos brancos marcam descobertas do SDSS de novos companheiros da Galáxia, sendo dois deles aglomerados globulares e os outros galáxias anãs. Créditos da imagem original: V. Belokurov e SDSS. 30 
1.2 Figura retirada de Slater et al. (2013), mostrando as posições de estrelas na corrente de Sagitário em coordenadas galácticas X vs Z (painel esquerdo) e $\mathrm{Y}$ vs Z (painel direito). Nota-se que o plano X-Z é praticamente o mesmo plano da corrente e, sendo assim, o plano Y-Z é praticamente perpendicular a sua órbita ao redor do centro da Galáxia. A posição do Sol está destacada por um X, e o centro da Galáxia é representado por um círculo preto, que é cruzado por um traço preto que representa o plano galáctico. No hemisfério sul galáctico $(Z<0)$ os círculos vermelhos e círculos azuis representam detecções de estrelas nos braços mais brilhantes e menos brilhantes da corrente, respectivamente. No hemisfério norte galáctico $(Z>0)$ são vistas as detecções da corrente usando dados do SDSS (Niederste-Ostholt et al., 2010) como círculos vermelhos e triângulos azuis, para o braço mais brilhante e para o menos brilhante da corrente, respectivamente. A posição da Corrente de Cetus também é identificada através de quadrados verdes (Newberg et al., 2009). Os pontos pretos são dados das simulações de Law e Majewski (2010) . . . . . . . . . . . . . . . . .

1.3 Diagrama cor-magnitude do aglomerado globular Palomar 5. As regiões azuis destacam as estrelas que podem (ou são) ser usadas como traçadoras de distâncias. Os mapeamentos de dados no céu são sempre limitados em dadas magnitudes e, como consequência disso, os objetos mais luminosos são preferencialmente usados como traçadores de longas distâncias. Entretanto, pode-se ver no diagrama que eles não são os mais abundantes. Figura adaptada de Newberg (2013) . . . . . . . . . . . . . .

1.4 Diagrama HR do aglomerado globular M55. As estrelas azuis tardias são encontradas na extensão da sequência principal, e suas posições estão destacadas no interior da elipse branca. Vê-se claramente que as estrelas BS localizam-se no prolongamento da sequência principal. Figura adaptada, criada por B.J. Mochejska e J. Kaluzny do "Nicolaus Copernicus Astronomical Center of the Polish Academy of Sciences", com o Telescópio Swope

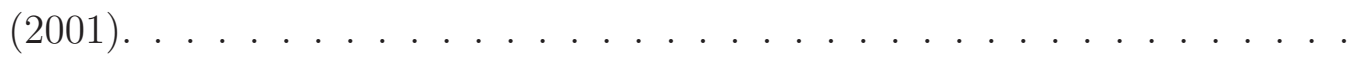


2.1 A figura mostra as diversas categorias de estrelas que podem ser selecionadas através de suas características fotométricas na base de dados do SDSS. As estrelas azuis tardias ocupam a região do cor-cor entre: $0.60<(u-g)<1.50$ e $-0.50<(g-r)<0.20$, juntamente com as BHBs. Além das descrições dos tipos estelares identificados nas legendas da figura, também são vistos círculos abertos na cor magenta, os quais representam anãs brancas mais frias. Figura retirada de Yanny et al. (2009a). . . . . . . . . . . . . . .

2.2 Região do diagrama cor-cor adotada para selecionar as candidatas a estrelas azuis tardias na base de dados do SDSS (DR8): $0.8<(u-g)_{0}<1.4$ e $-0.30<(g-r)_{0}<0.02$. A figura mostra os objetos que passaram por essa restrição e possuem informação espectroscópica associada ( 20 mil). . . .

2.3 Coordenadas celestes equatoriais dos dados deste trabalho. O SDSS faz seu mapeamento do céu a partir do hemisfério norte da Terra e, por essa razão, nota-se que o hemisfério norte celeste é melhor amostrado. Nenhuma restrição em coordenadas foi aplicada aos dados. . . . . . . . . . . . .

2.4 Relação entre a intensidade da linha K do Ca II (3933.7 Å) e a metalicidade estimada pelo SSPP. Nota-se que, quanto menor a metalicidade da estrela, menor a intensidade da linha $\mathrm{K}$ do Ca II. . . . . . . . . . . . . . . . .

2.5 Espectros normalizados de uma estrela BHB (em vermelho) e de uma estrela na sequência principal (BSS - em preto) para uma mesma temperatura efetiva ( $8100 \mathrm{~K})$. A linha tracejada em $80 \%$ de fluxo ressalta a diferença da largura das asas. Quanto maior a gravidade superficial da estrela, maior será a largura da asas das linha de Balmer. . . . . . . . . . . . . . 
3.1 Distribuição de $\mathrm{T}_{\text {eff }}$ vs. $\log (\mathrm{g})$ para estrelas com $g_{0}<18$. Há dois grupos concentrados em $\mathrm{T}_{\text {eff }} \geq 7500 \mathrm{~K}$ : um com $\log (\mathrm{g}) \sim 3.4$, que são as estrelas BHB (pontos vermelhos) e outro com $\log (\mathrm{g}) \sim 4.3$, que são as estrelas BSS (pontos pretos). Os pequenos quadrados em cinza são estrelas mais frias, que não são consideradas na análise adiante. Também estão destacadas as posições onde tipicamente são encontradas as estrelas RR Lyrae (retângulo azul) (Wilhelm et al., 1999b). O retângulo roxo mostra a localização das estrelas de sequência principal na região do turnoff (MSTO). A curva evolutiva em cinza é uma isócrona de Yale-Yonsei (Demarque et al., 2004), que identifica o caminho de uma estrela de $1 \mathrm{M}_{\odot}$, com $[\mathrm{Fe} / \mathrm{H}]=-2.0$, passados 12 bilhões de anos. . . . . . . . . . . . . . . . . . . .

3.2 Comparação entre os parâmetros $\mathrm{f}_{\mathrm{m} \delta}$ vs. $\mathrm{D}_{0.2 \delta}$. Os pontos estão coloridos de acordo com as restrições feitas pelos parâmetros do SSPP, vistas na Figura 3.1. As distribuições de estrelas BHBs e BSSs exibem uma ligeira sobreposição, indo até um pouco além dos limites adotados (linhas tracejadas). Os limites visuais adotados para selecionar as estrelas BSSs são: (i) $0.15<\mathrm{f}_{\mathrm{m} \delta}<0.27, \mathrm{D}_{0.2 \delta}>29$; (ii) $0.27<\mathrm{f}_{\mathrm{m} \delta}<0.40, \mathrm{D}_{0.2 \delta}>-90 \cdot \mathrm{f}_{\mathrm{m} \delta}+53$. Da mesma forma, os critérios para selecionar estrelas BHBs são: (i) $0.15<$ $\mathrm{f}_{\mathrm{m} \delta}<0.27,17<\mathrm{D}_{0.2 \delta}<29$; (ii) $0.27<\mathrm{f}_{\mathrm{m} \delta}<0.40,17<\mathrm{D}_{0.2 \delta}<-90 \cdot \mathrm{f}_{\mathrm{m} \delta}+$ 53

3.3 Comparação entre os parâmetros $c_{\beta \gamma \delta}$ e $b_{\beta \gamma \delta}$ da função de Sersic, coloridos de acordo com as restrições feitas na Figura 3.1. Assim como para o método $f_{\mathrm{m}}$ vs. $D_{0.2}$, novamente os limites fornecidos pelo SSPP para separar BHBs e BSSs concordam muito bem com o método de escala de forma e largura ( $\sim 95 \%$ das estrelas satisfazem ambas as restrições corretamente). A linha limitante entre os dois grupos neste método é definida por uma função de quarto grau, apresentada na Equação 3.3. . . . . . . . . . . . . . . 
3.4 Painel Superior: Distribuição de $\log (\mathrm{g})$ para estrelas com magnitudes $g_{0}<18$. O pico localizado em $\log (\mathrm{g})=3.38(\sigma=0.14 \mathrm{dex})$ representa a distribuição de BHBs, já o pico localizado em $\log (\mathrm{g})=4.34(\sigma=0.18 \mathrm{dex})$ mostra as BSSs. Painel inferior: Distribuição de $\log (\mathrm{g})$ para estrelas com magnitudes $g_{0}>18$. O pico centrado em $\log (\mathrm{g})=3.57(\sigma=0.33$ dex $)$ representa a distribuição de BHBs e o pico em $\log (\mathrm{g})=4.27$ ( $\sigma=0.20$ dex $)$ representa as BSSs. Esta figura também mostra que a fração de estrelas BHBs cai rapidamente se comparada as BSSs para os objetos mais fracos da amostra.

3.5 Região do diagrama cor-cor onde estão localizadas as BHBs (círculos vermelhos) e as BSSs (círculos pretos) selecionadas através das restrições espectroscópicas. Nota-se que a superposição dos dois grupos é grande, mas existem regiões do diagrama onde se encontram preferencialmente BHBs ou BSSs. . . . . . . . . . . . . . . . . .

3.6 Proporção de BHBs ou BSSs em pequenos intervalos do diagrama cor-cor. Cada quadrado contém ao menos 4 estrelas, e está colorido de acordo com a escala vista a direita da figura, quanto mais vermelho o quadrado, maior é a proporção de BHBs e, da mesma maneira, quanto mais preto, maior a frequência de BSSs. Os limites desenhados para isolar BHBs e BSSs foram resultados de ajustes de segundo grau (ver Equações 3.4 e 3.5, para limites de BHBs e BSSs, respectivamente) usando os quadrados que possuem entre $75 \%$ e $85 \%$ de proporção de cada tipo estelar, como destacam as linhas tracejadas na escala de cor. . . . . . . . . . . . . . . .

3.7 Seleção de dados fotométrica feita usando o SDSS (DR13). Os 100 mil objetos presentes na figura satisfizeram as seguintes restrições: (i) alvos únicos, (ii) $|b|>10^{\circ}$, (iii) erro na banda $u_{0}$ menor que $0.5 \%$, (iv) $-0.3<$ $(g-r)_{0}<0.0$ e $0.8<(u-g)_{0}<1.4$. As restrições de BHBs e BSSs $(3.4$ e 3.5, respectivamente) foram aplicadas à eles. 39372 candidatas a BSSs são vistas dentro dos limites das linhas pretas (proporção de 80.5\%) e 27568 BHBs estão presentes dentro dos limites das linhas vermelhas (proporção de

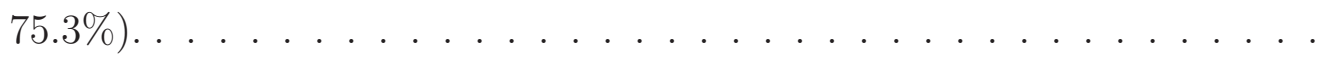


4.1 Painel (a): Comparação entre as distâncias estimadas com as calibrações de Deason et al. (2011) e Kinman et al. (1994) para BSSs. A linha sólida representa o valor onde $\mathrm{D}_{\mathrm{V}}=\mathrm{D}_{\mathrm{g}}$. A linha tracejada é o ajuste linear aplicado aos dados e a região com a sombra cinza representa o limite de $\pm 3 \sigma$ do ajuste. Os painéis (b) e (c) mostram, respectivamente, os resíduos da distribuição e sua dispersão, representados por um ajuste gaussiano. A região cinza escura indica o limite em $1 \sigma(1.15)$ do valor médio $(\sim 1.08 \mathrm{kpc})$ da distribuição. A região cinza mais clara é o limite em $2 \sigma$ da média. . . . . . . . . . . . . . 76

4.2 Painel (a): Comparação entre as distâncias estimadas com as calibrações de Deason et al. (2011) e Fermani e Schönrich (2013) para BHBs. A linha sólida (preta) representa o valor onde $\mathrm{D}_{\mathrm{gF}}=\mathrm{D}_{\mathrm{gD}}$. A linha tracejada é o ajuste linear aplicado aos dados e a região com a sombra cinza representa o limite de $\pm 3 \sigma$ do ajuste. Os painéis (b) e (c) mostram, respectivamente, os resíduos da distribuição e sua dispersão, representados por um ajuste gaussiano. A região cinza escura indica o limite em $1 \sigma(0.4)$ do valor médio $(\sim 0.35 \mathrm{kpc})$ da distribuição. A região cinza mais clara é o limite em $2 \sigma$ da média. . . . . . . . . . . . . . . . . . .

4.3 Distibruição de distâncias heliocêntricas de BSSs, vistas em cinza, usando a cabibração de Kinman et al. (1994) (Equação 4.3) e de BHBs, em vermelho, usando a calibração de Deason et al. (2011) (Equação 4.5). Para avaliar a frequência $\mathrm{F}_{\mathrm{BSS} / \mathrm{BHB}}$ no halo, foi considerado o intervalo de distâncias onde as contagens de ambas estrelas são as maiores possíveis, destacado pela área em verde. $\mathrm{O}$ valor médio para $\mathrm{F}_{\mathrm{BSS} / \mathrm{BHB}}$ obtido nesta região é igual a $2.15 \pm 0.13$, praticamente idêntico ao valor da frequência $\mathrm{F}_{\mathrm{BSS} / \mathrm{BHB}}$ encontrada em aglomerados abertos e galáxia anãs próximas $(2.24 \pm 0.17$ : Momany et al., 2007). . . . . . . . . . . . . . . . . 78

4.4 Distribruições de metalicidades de BSSs (cinza) e BHBs (vermelho). As curvas gaussianas ajustadas em ambas distribuições fornecem os valores centrais dos picos $(\mu)$ e suas dispersões $(\sigma)$, em preto para as BSS e em vermelho

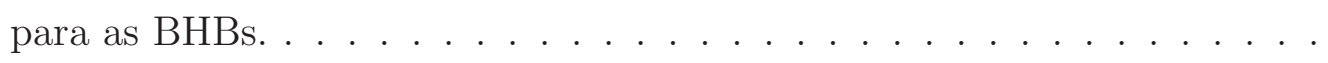


4.5 Distribruições de cores $(g-r)_{0}$ para BHBs (em vermelho) e BSSs (em cinza). A distribuição das BHBs apresenta um leve enviesamento para cores mais azuis. As BSSs, por conta do corte imposto em $(g-r)_{0}=0.02$ feito no início da seleção fotométrica, possuem um enviesamento ainda maior. . . .

4.6 Relação $[\mathrm{Fe} / \mathrm{H}]_{\mathrm{vs}}(g-r)_{0}$ para BHBs (pontos vermelhos) e BSSs (pontos pretos). Verifica-se que, assim como descrito por Deason et al. (2011) e Santucci et al. (2015b), não há relação evidente entre a metalicidade e a cor das BHBs, que possuem cores praticamente constantes $(\sim-0.156)$ no intervalo de metalicidades estudado. Entretanto, o mesmo não ocorre para as BSSs, as quais apresentam dependência da cor com a metalicidade, cujo comportamento pode ser descrito por uma função de segundo grau, com coeficientes exibidos na legenda da figura. Os pontos em cinza são BSSs que tiveram suas cores corrigidas dessa dependência com a metalicidade, usando a relação 4.9, e agora apresentam-se praticamente constantes em torno de $(g-r)_{0} \sim-0.073 \ldots \ldots \ldots \ldots \ldots \ldots$

4.7 Relação entre o índice de cor mediano das BSSs e médio das BHBs em relação a distância ao centro galáctico (r), a cada kpc. Nota-se que, independentemente da calibração de distância adotada, BSSs se tornam mais azuis com a distância, enquanto que as BHBs ficam mais vermelhas. A calibração de distância para BSSs usando a equação 4.4 (Deason et al., 2011) é mostrada em pontos pretos. Os pontos cinza são BSSs que tiveram distâncias (e cores) calculadas com a combinação das Equações 4.4 e 4.9, portanto corrigidas do desvio de cor associado a metalicidade. Os pontos azuis representam as BSSs com distâncias estimadas segundo a relação 4.3 (Kinman et al., 1994). Os coeficientes dos ajustes podem ser vistos no canto inferior direito da figura e seguem o mesmo esquema de cor descrito por suas distribuições. . . . . . . . . . . . . . . . . . . . . 
4.8 No painel superior esquerdo mostra-se a distribuição de metalicidades das BSSs, onde as várias cores representam os 7 intervalos considerados para análise nos outros painéis. As cores foram mantidas nos demais painéis para facilitar a associação com os intervalos de metalicidade avaliados. Os pontos coloridos são resultado da variação de cor (mediana) das BSSs com a distânca utilizando a Equação 4.3 para calibração das distâncias. Os pontos pretos foram calculados usando a Equação 4.4 e os pontos cinzas-claros são resultados vistos para distâncias que combinaram as equações Equações 4.4

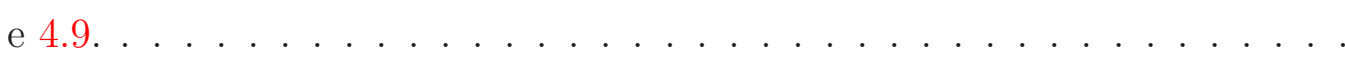

4.9 Variações de cor com a distância galactocêntrica, usando BHBs e BSSs tanto espectroscópicas como fotométricas, coloridas conforme visto na legenda da figura. As distâncias adotadas nesta figura foram calculadas usando calibrações de magnitudes absolutas baseadas somente em cores (Deason et al., 2011). A figura revela que os gradientes de cor das amostras fotométricas são mais sutis que os vistos nas amostras espectroscópicas. . . . . . . . . .

5.1 Região do plano $\mathrm{T}_{\text {eff }}$ vs $\log (\mathrm{g})$ ocupada por BSSs (pontos pretos). Sobrepostas a elas estão as trajetórias evolutivas YZVAR (Bertelli et al., 2008), para metalicidades constantes $([\mathrm{Fe} / \mathrm{H}]=-1.0)$ e diferentes massas $(1.2-1.6$ $\mathrm{M} \odot$ ) com passos de $0.1 \mathrm{M}_{\odot}$. Para mais detalhes, veja a legenda localizada canto inferior esquerdo da figura. . . . . . . . . . . . . .

5.2 Região do plano $\mathrm{T}_{\text {eff }}$ vs $\log (\mathrm{g})$ ocupada por BSSs (pontos pretos). Sobrepostas a elas estão as curvas evolutivas YZVAR (Bertelli et al., 2008) para massas constantes $(1.4 \mathrm{M} \odot)$ e diferentes metalicidades, cujos detalhes podem ser vistos na legenda, localizada canto superior esquerdo da figura. Os círculos vermelhos representam os pontos onde os índices de cor são obtidos através de isócronas. . . . . . . . . . . . . . . . . 
5.3 Diagrama de idades vs cores para modelos de estrelas de sequência principal, com $\mathrm{Y}=0.23$. As linhas horizontais tracejadas representam o limite de índice de cor da amostra de BSSs. Cada linha colorida representa uma metalicidade diferente, seguindo a divisão feita na distribuição de metalicidades das BSSs (ver Figura 4.8). Os valores vistos ao lado dos pontos mostram as massas de cada modelo. Os índices de cor e idades foram obtidos no ponto de saída da sequência principal, como destacado na Figura 5.2. $\Delta t_{9}$ é o intervalo de tempo em bilhões de anos associado a variação de cor de cada tendência. . . . . . . . . . . . . . . . . . . .

5.4 Comparação entre os diversos gradientes de idade obtidos para o halo em função da distância galactocêntrica. A linha preta representa o gradiente considerando a média dos ajustes da Figura 4.8. A linha verde representa o gradiente obtido com as idades individuais das BSSs (pontos verdes), segundo a Equação 5.1. A linha vermelha é o gradiente obtido por Santucci et al. (2015b), usando BHBs no halo. As áreas claras sombreadas limitam a região $3 \sigma$ de cada ajuste. . . . . . . . . . . . . . . . . . . . . 92

5.5 Variação da metalicidade $([\mathrm{Fe} / \mathrm{H}])$ em função da distância ao centro galáctico (em kpc) para BHBs (pontos vermelhos) e BSSs (pontos pretos). Notase que ambas as classes apresentam-se cada vez mais pobres em metais conforme as distâncias aumentam. . . . . . . . . . . . . . . . 
5.6 Mapa de idade do halo da Galáxia visto no plano de coordenadas galácticas XY. As distâncias foram calculadas usando a relação 4.3 e ambos painéis mostram a mesma região espacial. No painel esquerdo estão identificadas regiões onde as cores médias $\left(<(g-r)_{0}>\right)$ das BSSs foram medidas, considerando passos de $1 \mathrm{kpc}^{2}$. Nesse painel, os quadrados mostram as regiões onde estão presentes ao menos 3 BSSs, e os pontos são regiões com 2 ou menos estrelas. Cada quadrado fornece um valor médio de cor, correspondente a uma linha vertical preta na barra superior da figura. Além das médias de todos os quadrados do painel esquerdo, essa barra mostra uma linha vermelha representando a mediana dos valores dessas médias, além de uma região cinza indicando o limite $2 \sigma$ dela. A escala colorida destaca a variação $<(g-r)_{0}>$ encontrada em diferentes ambientes do halo e sua idade equivalente em bilhões de anos (valor entre parênteses). O painel direito mostra uma suavização gaussiana do painel esquerdo, feita apenas com os quadrados em intervalos de dados de 2 em 2. . . . . . . . . . . . .

5.7 Mapa de idade do halo da Galáxia visto no plano de coordenadas galácticas XZ. É nítida a presença de um gradiente de idade ( 1 bilhão de anos), que vai da região central da Galáxia, rejuvenescendo até $\sim 30 \mathrm{kpc}$ de distância. Em todos os mapas pode ser vista uma nítida concentração de "estrelas mais velhas" em um raio de $15 \mathrm{kpc}$ do centro da Galáxia. A escala de cor desta figura foi adotada como padrão para todos os mapas. . . . . . . . . . 96

5.8 Mapa de idade do halo da Galáxia visto no plano de coordenadas galácticas YZ. Através do mapa, assim como nos demais, é possível ver diversas (e nítidas) flutuações de cores-idades, as quais podem estar associadas à presença de subestruturas no halo. . . . . . . . . . . . . . . . . 96 
5.9 Posições galácticas (XYZ em kpc) e celestes (l,b em graus) das subestruturas presentes na Tabela 5.1. Tais subestruturas estão presentes nas regiões espaciais alcançadas pelos mapas de cor-idade. Os nomes das subestruturas estão centrados em áreas coloridas (cor púrpura) para facilitar suas identificações (estas áreas não representam seus limites espaciais). Foram escolhidas 3 posições da corrente de Sagitário (em cinza escuro), baseadas em observações do trabalho de Slater et al. (2013), para efeitos de comparação nos mapas. Como curiosidade, foi identicada a posição galáxia anã de Sagitário, progenitora da corrente de Sagitário, vista com o nome de

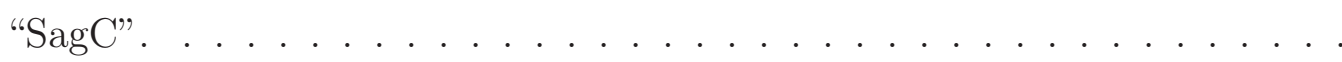

5.10 Combinação das posições centrais das subestruturas da Figura 5.9 com o mapa de idade do halo visto no plano XY. Os quadrados marcam as 3 posições escolhidas para a corrente de Sagitário (Slater et al., 2013). Os círculos marcam todas as subestruturas compiladas por Newberg e Carlin (2016), presentes nas áreas dos mapas. A posição da galáxia anã de Sagitário está marcada com um asterisco (Slater et al., 2013). Várias flutuações/extensões de cor coincidem com as posições centrais das subestruturas comparadas. . . . . . . . . . . . . . . . . .

5.11 Combinação das posições centrais das subestruturas da Figura 5.9 com o mapa de idade do halo visto no plano XZ. Novamente, várias flutuações/extensões de cor coincidem com as posições de subestruturas. A nuvem HerA não possui BSSs na sua posição central ( $\mathrm{X}=-5 \mathrm{kpc}$ e $\mathrm{Z}=0 \mathrm{kpc})$, mas ela está presente no mapa e é facilmente visível, pois se estende de $\mathrm{b}=-50^{\circ}$ até $\mathrm{b}=+50^{\circ}$. Note que existem duas flutuações de cor, bem avermelhadas, perpendiculares ao disco galáctico, na direção da sua posição central. . . . 100

5.12 Combinação das posições centrais das subestruturas da Figura 5.9 com o mapa de idade do halo visto no plano YZ. Neste plano de visada da Galáxia são vistas muitas flutuações de cor intensas que não possuem estruturas associadas, como nas regiões $(\mathrm{Y}, \mathrm{Z})$ iguais a $(-5,-8),(+8,+4),(+15,+15)$

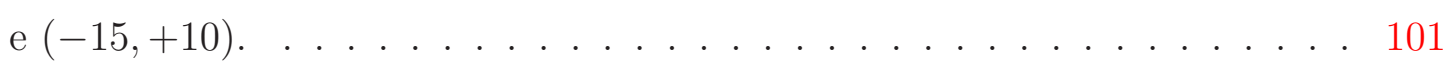





\section{Lista de Tabelas}

1.1 Parâmetros das estruturas encontradas no halo da Galáxia já descritas na literatura (ver Tabela 4.1 de Newberg e Carlin, 2016, para mais informações e referências). O termo corrente é tipicamente associado a sobredensidades que tenham comprimentos significativamente maiores que suas larguras. Já o termo nuvem é usado para grandes extensões de sobredensidades, onde não se nota uma dimensão preferencialmente muito maior que outra, e que possuem origens ainda a serem compreendidas. . . . . . . . . . . . . . .

5.1 Resumo e comparação entre os parâmetros físicos das subestruturas publicados na literatura Newberg e Carlin (2016), com os valores obtidos neste trabalho usando as BSSs. A coluna 1 fornece o nome abreviado da componente (apresentado por completo na Tabela 1.1). As colunas 3 e 5 mostram, respectivamente, metalicidades $([\mathrm{Fe} / \mathrm{H}])$ e velocidades radiais heliocêntricas $(\mathrm{em} \mathrm{km} / \mathrm{s})$ de membros das subestruturas já estimados na literatura. As colunas 4 e 6 mostram, respectivamente, metalicidades $([\mathrm{Fe} / \mathrm{H}])$ e velocidades radiais heliocêntricas $(\mathrm{em} \mathrm{km} / \mathrm{s}$ ) de membros das subestruturas estimadas por este trabalho, usando as BSSs. As colunas 7, 8 e 9 mostram, respectivamente, os valores centrais de cada subestrutura, e suas margens de erro, usados para calcular as metalicidades e velocidades das colunas 4 e 6 . A coluna 2 mostra o número de objetos encontrados nas posições centrais XYZ das subestrutura, dentro de suas margens de erro (ver colunas 7, 8 e 9). . . 103 



\section{Sumário}

1. Introdução . . . . . . . . . . . . . . . . . . . . . . . . . . . . . . . . . 29

1.1 A complexidade do halo despida pelos grandes mapeamentos de dados . . . 31

1.1.1 As subestruturas do halo da Galáxia . . . . . . . . . . . . . . . . . 32

1.1.1.1 Correntes associadas à aglomerados globulares . . . . . . . 33

1.1.1.2 Correntes associadas à galáxias anãs . . . . . . . . . . 35

1.1.1.3 Nuvens e outras subestruturas estelares difusas . . . . . 37

1.1.2 Técnicas de identificação de subestruturas . . . . . . . . . . . . . . 40

1.1.2.1 "Paralaxe" fotométrica . . . . . . . . . . . . . . . 40

1.1.2.2 Grupos com movimentos em comum . . . . . . . . . . 40

1.1.2.3 Composição química . . . . . . . . . . . . . . . . . . . 40

1.1.2.4 Mapas de idade cronográficos . . . . . . . . . . . . . . . . 41

1.1.2.5 Candidatas a velas-padrão no halo . . . . . . . . . . . . 41

1.2 Estrelas azuis tardias . . . . . . . . . . . . . . . . . . 44

1.2.1 A natureza das estrelas azuis tardias . . . . . . . . . . . . 45

1.3 Objetivos . . . . . . . . . . . . . . . . . . . . . . . . 48

2. Base de Dados . . . . . . . . . . . . . . . . . . . . . . . . . . . . . . . 51

2.1 SDSS e o Data-release $8 \ldots \ldots \ldots \ldots \ldots$. . . . . . . . . . . . . . . . .

2.2 Restrições no diagrama cor-cor . . . . . . . . . . . . . . . . . . . . 52

2.3 Características espectroscópicas . . . . . . . . . . . . . . . 53

2.3.1 As linhas de Balmer do Hidrogênio . . . . . . . . . . . . . . . . 55

3. Separações entre fases evolutivas . . . . . . . . . . . . . . . . . . . . 59

3.1 Análise da amostra com $g_{0}<18 \ldots \ldots \ldots$. . . . . . . . 60 
3.1.1 Restrições em $\mathrm{T}_{\text {eff }} \mathrm{e} \log (\mathrm{g}) \ldots \ldots$. . . . . . . . . . . 60

$3.1 .2 \mathrm{O}$ método $\mathrm{f}_{m}$ vs. $\mathrm{D}_{0.2} \ldots \ldots \ldots \ldots \ldots$

3.1.3 O método de escala de forma e largura: $c$ vs. $b$. . . . . . . . . 63

3.2 Análise da amostra com $18 \leq g_{0}<21 \ldots \ldots \ldots$. . . . . . . 65

3.3 Seleção fotométrica direta de BHBs e BSSs . . . . . . . . . . . . . . . . 66

4. Magnitudes absolutas, distâncias e cores . . . . . . . . . . . . . . . 71

4.1 Magnitudes absolutas das estrelas azuis tardias . . . . . . . . . . . . 71

4.2 Magnitudes absolutas de estrelas azuis no ramo horizontal . . . . . . . 73

4.3 Distâncias . . . . . . . . . . . . . . . . . . . . . . . . . . 74

4.3.1 Frequência média de BSSs no halo e suas implicações . . . . . . . . 75

4.4 Cores e metalicidades . . . . . . . . . . . . . . . . . 79

4.4.1 Variações de cor com a distância . . . . . . . . . . . . . . . . 81

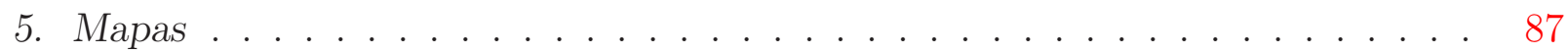

5.1 Relações entre cores, metalicidades e idades . . . . . . . . . . . . . . . 87

5.2 Mapas de idade do halo usando BSSs . . . . . . . . . . . . . . . . . . 94

5.3 Identificação de subestruturas no halo galáctico . . . . . . . . . . . . . . 97

6. Considerações finais . . . . . . . . . . . . . . . . . . . . 105

6.1 Interpretação dos resultados . . . . . . . . . . . . . . . . . . 105

6.2 Conclusões . . . . . . . . . . . . . . . . . . . . . 106

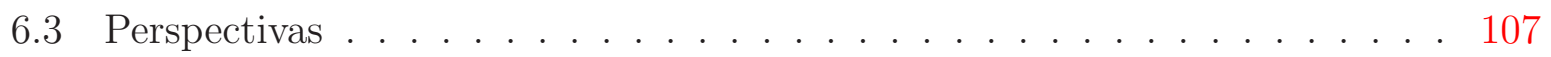

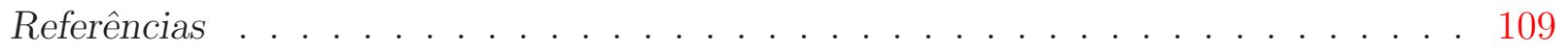


Capítulo 1

\section{Introdução}

O estudo de populações estelares na Via Láctea é um dos pilares para o entendimento de sua formação e evolução (Baade, 1958). De fato, a existência (ou não) de gradientes na idade, e/ou na metalicidade, de aglomerados globulares foram evidências cruciais usadas por Searle e Zinn (1978) para propor o cenário hierárquico de formação da Galáxia. Segundo essa perspectiva, o halo galáctico seria uma estrutura complexa que poderia conter estrelas de outras galáxias anãs, agregadas pela Via Láctea através de diversas fusões ao longo do tempo.

O cenário hierárquico é uma proposta contrária ao que afirma o modelo de colapso monolítico, descrito anos antes por Eggen et al. (1962, 1973). Nesse cenário, a Galáxia teria se formado através do rápido colapso gravitacional de uma enorme nuvem de gás primordial. Entretanto, depois de verificar que aglomerados globulares não possuem as mesmas idades, esse modelo não pôde mais ser sustentado.

Lee et al. (1994) publicaram um estudo sobre a morfologia do ramo horizontal (estágio da evolução estelar onde as estrelas fundem Hélio em Carbono em seus núcleos) em aglomerados globulares. Seus resultados indicaram que os aglomerados localizados entre 15 e 20 kpc de distância do centro galáctico, são cerca de 2 bilhões de anos mais velhos que outros aglomerados mais distantes. Leaman et al. (2013) fornecem uma discussão atualizada sobre a relação idade-metalicidade em aglomerados globulares e sua variação com a distância ao centro da Galáxia. Além das evidências observacionais, o cenário hierárquico de formação da Galáxia também tem sido corroborado por diversas simulações (Kauffmann et al., 1993; Springel et al., 2005; Bullock e Johnston, 2005; Cooper et al., 2010; Tumlinson, 2010) e pelo fato de que a acresção de pequenas galáxias no halo da Via Láctea (Ibata et al., 1994, 1995; Belokurov et al., 2006b) ainda é observada atualmente, conforme pode 
ser visto na Figura 1.1.

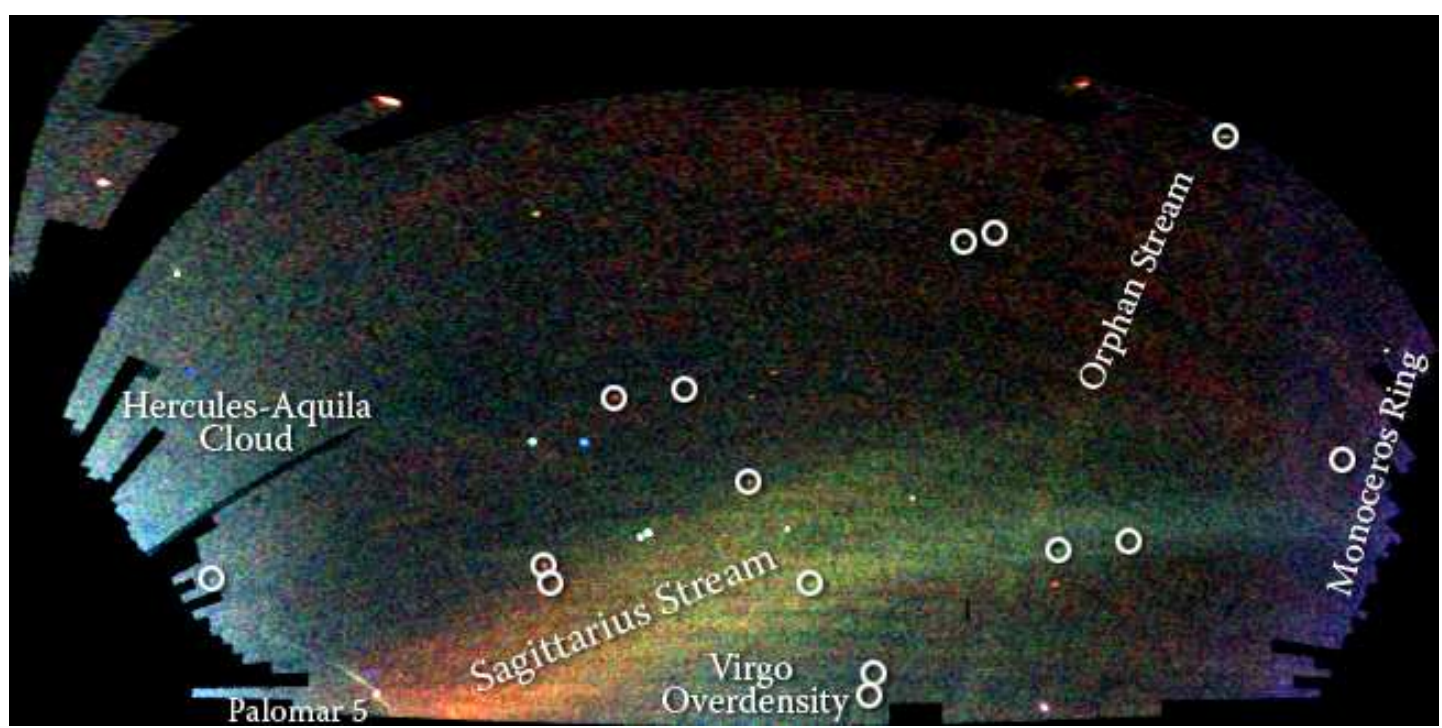

Figura 1.1: Mapa do hemisfério norte celeste do halo galáctico construído com dados do Sloan Digital Sky Survey (SDSS) e apresentado em projeção Mercator. A variação de cor vista na figura está relacionada com a distância das estrelas. Assim, a coloração azul representa subestruturas mais próximas e as estrelas vermelhas as mais distantes, ao mesmo tempo que a intensidade das cores indica a densidade de objetos no céu. As subestruturas visíveis nessa figura são principalmente correntes de estrelas, onde a mais visível delas é a Correntes de Sagitário (Sagittarius stream), oriunda da ruptura da galáxia anã de Sagitário. Além dela, estão identificadas outras subestruturas menores como a Orphan stream ou "Corrente Órfâ" que cruza a Corrente de Sagitário, o "Anel de Monoceros" (Monoceros Ring) que envolve o disco da Galáxia, rastros de estrelas sendo arrancadas do aglomerado globular Palomar 5 e sobredensidades de estrelas nas direções das constelações de Virgem (Virgo) e Hércules. Os círculos brancos marcam descobertas do SDSS de novos companheiros da Galáxia, sendo dois deles aglomerados globulares e os outros galáxias anãs. Créditos da imagem original: V. Belokurov e SDSS.

Enquanto os aglomerados globulares fornecem nítidas evidências para um gradiente de idade no halo galáctico, seria de extrema importância que o mesmo resultado tivesse suporte através do uso de estrelas de campo encontradas no mesmo ambiente, principalmente porque estes objetos estão disponíveis em amostragem maior.

A procura por essa corroboração encontrou suporte nos trabalhos recentes de Santucci et al. (2015b); Carollo et al. (2016), os quais forneceram os primeiros mapas de idade do halo da Galáxia usando, respectivamente, amostras espectroscópicas e fotométricas de estrelas azuis de ramo horizontal (blue horizontal branch stars - estrelas BHB ou BHBs).

Através das BHBs estudadas no campo do halo galáctico, identificou-se uma variação de suas cores com a distância em relação ao centro galáctico, indicando que as BHBs mais 
azuis encontram-se nas regiões centrais do halo e vão se tornando mais avermelhadas com a distância.

Essa variação de cor foi atribuída a uma variação de idade, resultando em um gradiente de cerca de 2.0 a 2.5 bilhões de anos, em uma região que se estende desde o centro galáctico até aproximadamente $40 \mathrm{kpc}$ de distância. Novamente, os objetos mais velhos são encontrados preferencialmente nas regiões centrais da Galáxia, em plena concordância com os resultados observados em aglomerados globulares e com as simulações anteriormente citadas.

\subsection{A complexidade do halo despida pelos grandes mapeamentos de dados}

Juntamente com a proposta hierárquica de formação da Galáxia, Searle e Zinn (1978) também sugeriram que o halo galáctico poderia ser um componente muito complexo, cuja forma seria influenciada por interações com galáxias anãs e aglomerados globulares, pois quando estes objetos se aproximam da Galáxia, eles podem sofrer rupturas devido à força gravitacional diferencial aplicada sobre eles, fazendo com que estrelas sejam arrancadas das galáxias anãs e orbitem a Galáxia. Este processo produz então as chamadas "correntes de maré de estrelas" (tidal stellar streams), ou somente "correntes de estrelas".

Atualmente, há cerca de 160 aglomerados globulares (Harris, 2010) e aproximadamente 30 galáxias anãs (McConnachie, 2012) identificadas na Galáxia. Esses números mostram que o halo não deve ser uma estrutura simples e pode conter muitas subestruturas. As principais evidências que reunidas para dar suporte a essas propostas ganharam força e número com o advento dos grandes mapeamentos de dados.

O Sloan Digital Sky Survey (SDSS; York et al., 2000) tem sido um dos principais levantamentos de dados astronômicos a contribuir na identificação de subestruturas presentes no halo galáctico. As primeiras observações do SDSS foram feitas em 1998, em uma região próxima ao equador celeste, e já nas primeiras imagens foram identificadas "inesperadas" sobredensidades (overdensities) de estrelas. Estas foram posteriormente descritas por Yanny et al. (2000) que mostraram a existência de duas sobredensidades de estrelas azuis $(-0.3<g-r<0.0)$, uma no hemisfério norte e outra no hemisfério sul galáctico.

Um ano depois, Ibata et al. (2001b) mostraram que essas sobredensidades faziam parte 
de uma mesma corrente de objetos, partilhando posições em comum com a trajetória da Galáxia anã de Sagitário, a qual, até hoje, é a corrente de estrelas mais proeminente identificada no halo da Galáxia. Essa mesma corrente de estrelas foi reidentificada dois anos mais tarde com uma amostra diferente de objetos. Dessa vez, utilizando o Two Micron AllSky Survey (2MASS), a subestrutura foi revelada por estrelas gigantes de tipo espectral K (Majewski et al., 2003). Tal confirmação juntamente com a observação contemporânea de uma grande corrente de estrelas na galáxia de Andrômeda (Ibata et al., 2001a) solidificaram o tema das subestruturas como um novo campo de estudo para a formação e evolução da Galáxia.

Mais recentemente, usando dados do SDSS, Belokurov et al. (2006b) publicaram um didático mapa de densidade de objetos, mostrando como o sistema de subestruturas presente no halo da Galáxia é complexo. Nesse mapa (Figura 1.1) são vistas estrelas coloridas qualitativamente de acordo com suas distâncias: as estrelas mais azuladas possuem magnitudes aparentes mais baixas que as estrelas mais avermelhadas. Na mesma figura, não somente a corrente de Sagitário (Sagittarius Stream) é facilmente identificada, como também outras subestruturas são vistas. A subseção a seguir mostra, de maneira resumida, uma compilação recente das subestruturas já identificadas no halo da Galáxia, extraída de Newberg e Carlin (2016).

\subsubsection{As subestruturas do halo da Galáxia}

As subestruturas encontradas no halo galáctico possuem tipicamente duas designações: corrente e nuvem. O termo corrente é comumente associado a sobredensidades que tenham comprimentos visualmente maiores que suas larguras. Segundo Newberg e Carlin (2016), o progenitor de uma corrente pode ser associado as suas principais caracteríscticas espaciais e cinemáticas: correntes largas (com mais de 500 pc) e "quentes" (dispersão de velocidades $\sigma_{\mathrm{v}} \geq 10 \mathrm{~km} / \mathrm{s}$ ) normalmente emergem de interações com galáxias anãs, enquanto correntes estreitas (menores que $100 \mathrm{pc})$ e "frias" $\left(\sigma_{\mathrm{v}} \leq 5 \mathrm{~km} / \mathrm{s}\right)$ podem surgir da interação com aglomerados globulares. Tais conclusões são resultantes da similaridade entre os tamanhos dos progenitores e seus rastros no halo, as correntes. 


\subsubsection{Correntes associadas à aglomerados globulares}

- Palomar 5 (Pal5): Esta corrente está associada ao aglomerado globular Palomar 5 (Pal5), sendo um dos exemplos mais representativos deste tipo de subestrutura, vista na Figura 1.1, como mostraram Belokurov et al. (2006b). Mais informações sobre esta subestrutura podem ser obtidas em Mastrobuono-Battisti et al. (2012); Küpper et al. (2012); Kuzma et al. (2015);

- NGC 5466: Como o próprio nome já sugere, trata-se de uma corrente relacionada ao aglomerado globular NGC 5466 (Lux et al., 2012). Também é uma subestrutura muito evidente e identificada na Figura 1.1. Mais informações sobre esta subestrutura estão disponíveis em Grillmair e Johnson (2006); Belokurov et al. (2006a);

- GD-1: Identificada por Grillmair (2006), é a corrente mais extensa (aproximadamente $80^{\circ}$ de extensão no hemisfério norte galáctico). Sua origem parecer estar relacionada a algum aglomerado globular, pois possui aproximadamente 70 pc de largura. Apesar de ainda não ter um progenitor estabelecido, Willett et al. (2009) definiram uma órbita para a corrente usando dados do SDSS, cujo pericentro galáctico é $\sim 14 \mathrm{kpc}$ e o apocentro $\sim 28 \mathrm{kpc}$, com inclinação de $\sim 35^{\circ}$. Mais informações sobre esta subestrutura podem ser encontradas em Koposov et al. (2010); Carlberg e Grillmair (2013);

- EBS: Abreviação de "Eastern Banded Structure", é uma corrente de cerca de $18^{\circ}$ de extensão identificada por Grillmair e Johnson (2006), a cerca de 10 kpc de distância do Sol. Mais informações sobre esta subestrutura podem ser obtidas em Li et al. (2012); Grillmair (2011);

- Pisces/Triangulum: Seu nome é duplo pois autores diferentes já se referiram a mesma estrutura por distintas razões. Descoberta por Bonaca et al. (2012b) esta subestrutura, estreita $\left(\sim 0.2^{\circ}\right.$ de largura) e com cerca de $5.5 \mathrm{kpc}$ de extensão, foi chamada de "Triangulum Stream" pois foi encontrada próxima à Galáxia do Triângulo (M33). Contemporaneamente, Martin et al. (2013) identificou, na mesma região, uma subestrutura cinemática em objetos na base de dados do SDSS, nomeando-a como "Pisces Stellar Stream", por estar na direção da constelação de Peixes. Mais informações sobre esta subestrutura podem ser vistas em Martin et al. (2014); 
- Acheron, Cocytos, Lethe, Hermus e Hyllus: Todas essas correntes, que carregam nomes de rios da mitologia grega, possuem características de subestruturas associadas à interação com aglomerados globulares, principalmente por serem estreitas. Entretanto, elas foram identificadas no limite de magnitude do SDSS, o que significa que ainda não há informações cinemáticas ou químicas associada a elas. Mais informações sobre Acheron, Cocytos e Lethe podem ser encontradas em LSST Science Collaboration et al. (2009) e sobre Hermus e Hyllus em Grillmair (2014);

- Alpheus: Essa subestrutura foi proposta por Grillmair et al. (2013) utilizando observações do 2MASS. Ela está relativamente próxima (menos que 2 kpc de distância do Sol) e, segundo os autores, poderia estar relacionada com o aglomerado globular NGC 288. Entretanto, novos levantamentos de dados devem ser feitos para estabelecer esta conexão, pois não há ainda informação cinemática ou química que os conectem;

- ATLAS stream: Esta corrente foi identificada por Koposov et al. (2014), utilizando o mapeamento de dados ATLAS (Shanks et al., 2015). Trata-se de uma subestrutura de cerca de $12^{\circ}$ de extensão no céu e aproximadamente $0.25^{\circ}$ de largura. Ela está 20 kpc de distância do Sol e sua origem pode estar relacionada ao aglomerado globular Pyxis (Koposov et al., 2014);

- Ophiuchus: É considerada uma corrente aparentemente pequena, pois sua extensão está ao longo da linha de visada. Identificada por Bernard et al. (2014), foi descrita como tendo apenas $2.5^{\circ}$ de extensão no céu, e assim foi associada à uma dimensão espacial de 1.6 kpc. Entretanto, seu comportamento cinemático indica uma trajetória bastante excêntrica, cujos pericentro e apocentro galácticos valem $3.5 \mathrm{kpc}$ e $17.5 \mathrm{kpc}$, respectivamente (Sesar et al., 2015).

- Virgo Stellar Stream: Essa corrente possui menos de $20^{\circ}$ de extensão no céu e provavelmente é originária da interação com o aglomerado globular NGC 2419 (Newberg et al., 2007). Está localizada a cerca de $20 \mathrm{kpc}$ de distância do Sol (Duffau et al., 2014). Para mais informações, além das referências já citadas, veja também Vivas et al. (2001). 


\subsubsection{Correntes associadas à galáxias anãs}

- Sagittarius Stream: A corrente de Sagitário é, sem dúvida, a maior corrente descoberta no halo galáctico até hoje. Sua progenitora foi descoberta por Ibata et al. (1994), e pouco tempo depois, já tinha sido verificado que se tratava de um satélite em processo de ruptura devido a forças de maré da Galáxia (Ibata et al., 1995). Poucos anos mais tarde, logo nas primeiras fases do SDSS, muitos trabalhos foram publicados, relatando sua enorme extensão, que chega a envolver o halo galáctico, provavelmente em mais de uma volta (Yanny et al., 2000; Newberg et al., 2002, 2003; Ivezić et al., 2000). A Figura 1.2, retirada de Slater et al. (2013), mostra em detalhes as posições de objetos identificados na corrente (pontos coloridos) no espaço tridimensional XYZ em coordenadas galácticas. Além disso, Ibata et al. (1995) também mostraram que a população estelar da galáxia anã progenitora era complexa, com um amplo intervalo de metalicidades e seu próprio sistema de aglomerados globulares;

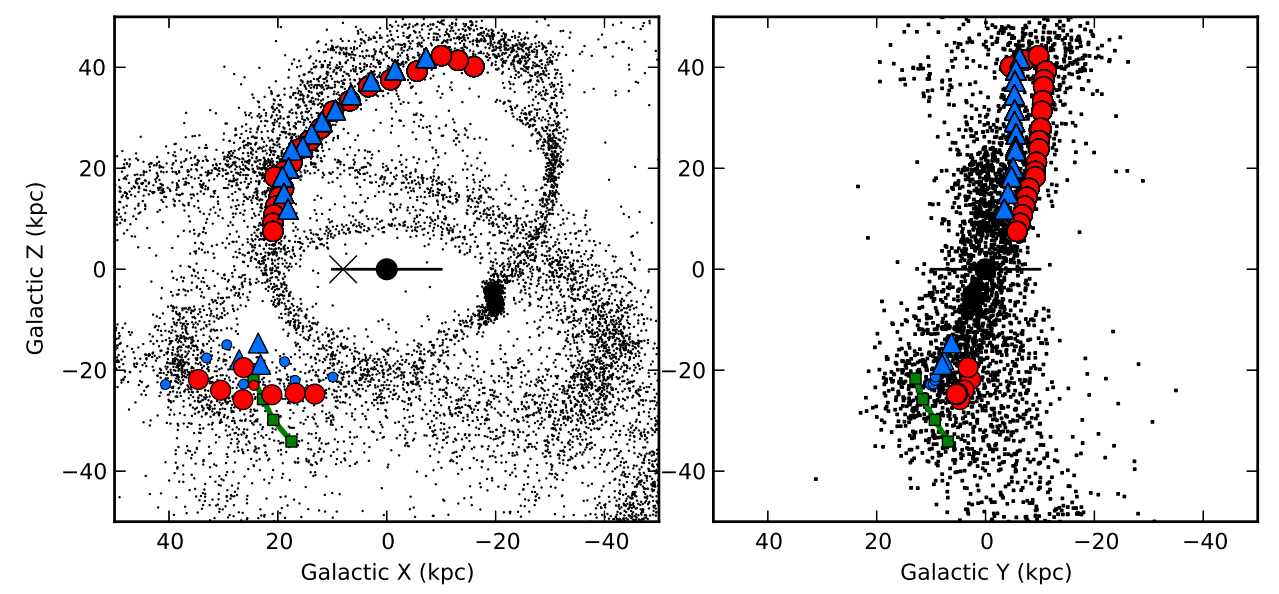

Figura 1.2: Figura retirada de Slater et al. (2013), mostrando as posições de estrelas na corrente de Sagitário em coordenadas galácticas X vs Z (painel esquerdo) e Y vs Z (painel direito). Nota-se que o plano X-Z é praticamente o mesmo plano da corrente e, sendo assim, o plano Y-Z é praticamente perpendicular a sua órbita ao redor do centro da Galáxia. A posição do Sol está destacada por um X, e o centro da Galáxia é representado por um círculo preto, que é cruzado por um traço preto que representa o plano galáctico. No hemisfério sul galáctico $(Z<0)$ os círculos vermelhos e círculos azuis representam detecções de estrelas nos braços mais brilhantes e menos brilhantes da corrente, respectivamente. No hemisfério norte galáctico $(\mathrm{Z}>0)$ são vistas as detecções da corrente usando dados do SDSS (NiedersteOstholt et al., 2010) como círculos vermelhos e triângulos azuis, para o braço mais brilhante e para o menos brilhante da corrente, respectivamente. A posição da Corrente de Cetus também é identificada através de quadrados verdes (Newberg et al., 2009). Os pontos pretos são dados das simulações de Law e Majewski (2010). 
- Orphan Stream: A "Corrente Órfã" (assim chamada pois sua progenitora não é conhecida), é uma subestrutura encontrada no hemisfério norte da Galáxia (Grillmair e Johnson, 2006; Belokurov et al., 2007b) e possui uma largura de cerca de $1^{\circ}$ a $2^{\circ}$ no céu. Identificada de $20 \mathrm{kpc}$ até cerca de $55 \mathrm{kpc}$ de distância do Sol (Sesar et al., 2013). Essa corrente foi analisada com espectroscopia de alta resolução, confirmando baixa dispersão de velocidades nos objetos avaliados (Casey et al., 2013) e padrões de abundância química compatíveis com a evolução de galáxias anãs esferoidais (Casey et al., 2014). Para mais informações sobre esta corrente, ver Fellhauer et al. (2007); Sales et al. (2008); Newberg et al. (2010);

- Cetus Polar Stream: A "Corrente Polar de Cetus" foi identificada pela primeira vez por Yanny et al. (2009b) como sendo uma estrutura justaposta no céu em relação a corrente de Sagitário, porém mais distante ( 30kpc do Sol). Yam et al. (2013) mostraram que o progenitor dessa subestrutura deve ser uma "galáxia anã ultrafraca" (ultra-faint dwarf galaxy), pois as distribuições de densidades, luminosidades e metalicidades $\left([\mathrm{Fe} / \mathrm{H}] \sim-2.2^{1}\right)$ observadas na corrente, só podem ser representadas por um progenitor com estas caracteristícas;

- PAndAS MW Stream: Encontrada por Martin et al. (2014), essa corrente está localizada na mesma linha de visada que M31. Acredita-se que sua progenitora seja uma galáxia anã dadas a largura da corrente e sua dispersão de velocidades. Trata-se também de uma subestrutura pobre em metais (ver Tabela 1.1), com componentes identificados a cerca de $17 \mathrm{kpc}$ de distância do Sol;

- AntiCenter Stream: A corrente do "anticentro galáctico" foi identificada pela primeira vez por Grillmair (2006). Esta subestrutura está localizada aproximadamente a 10 kpc de distância do Sol. Sua órbita é perpendicular ao plano galáctico na direção do seu anticentro. Seus parâmetros cinemáticos sugerem que sua progenitora pode ser uma galáxia anã, mas nenhuma galáxia anã já identificada pôde ser associada à órbita da subestrutura (Grillmair, 2006). Mais informações desta corrente podem ser obtidas em Grillmair et al. (2008); Li et al. (2012);

\footnotetext{
${ }^{1}$ A abundância relativa entre dois elementos é geralmente indicada através da comparação de suas razões numéricas relativas ao Sol, utilizando-se a notação: $[\mathrm{A} / \mathrm{B}]=\log \left(N_{A} / N_{B}\right)_{\star}-\log \left(N_{A} / N_{B}\right)_{\odot}$, onde $N_{A}$ e $N_{B}$ referem-se aos números de átomos dos elementos A e B na estrela $(\star)$ e no Sol $(\odot)$.
} 
- Styx: É uma estrutura distante, localizada a cerca de $46 \mathrm{kpc}$ de distância do Sol. Sua origem parece estar relacionada com uma galáxia anã, mas esta proposta foi baseada simplesmente pela proximidade que ela possui de Boötes III (LSST Science Collaboration et al., 2009). Entretanto, segundo Carlin et al. (2009), a velocidade medida para a galáxia anã não a qualifica como responsável por formar a corrente. Ainda são necessárias medidas de velocidades radiais de membros da corrente para obter comparações mais sólidas;

\subsubsection{Nuvens e outras subestruturas estelares difusas}

O termo nuvem é usado para grandes extensões de sobredensidades, onde não se nota uma dimensão preferencialmente muito maior que outra, cujos progenitores ainda são desconhecidos.

- Virgo overdensities: A sobredensidade de Virgo é uma enorme subestrutura identificada a distâncias entre 10 e $20 \mathrm{kpc}$, cobrindo uma área entre $1000^{\circ}$ quadrados (Jurić et al., 2008) e $3000^{\circ}$ quadrados do céu (Bonaca et al., 2012a). A subestrutura se parece com uma enorme nuvem de estrelas e há muita discusão sobre sua natureza, podendo ser entendida como um grupo complexo de subestruturas superpostas (Newberg et al., 2007; Vivas et al., 2008; Prior et al., 2009; Brink et al., 2010; Carlin et al., 2012), ou até mesmo restos de uma galáxia anã que, vindo em uma trajetória muito excêntrica, tenha se destruído ao passar perto demais do centro da Galáxia (Casetti-Dinescu et al., 2009; Carlin et al., 2012; Helmi et al., 2011).

- TriAnd1 e TriAnd2: Identificada por Rocha-Pinto et al. (2004) usando dados do 2MASS, a sobredensidade Triangulum-Andromeda teve sua distância ao Sol estimada entre $16 \mathrm{kpc}$ e $25 \mathrm{kpc}$. Estudos posteriores feitos por Martin et al. (2007) mostraram a existência de uma sequência principal secundária de objetos na mesma direção do céu, porém pouco mais distantes, entre 20 kpc e 28 kpc de distância. Assim, a estrutura original foi chamada de TriAnd1 e a nova de TriAnd2. Sheffield et al. (2014) fizeram um mapeamento espectroscópico de 200 estrelas nesta região e confirmaram que os dois grupos possuem picos de metalicidades ligeiramente diferentes em $\sim 0.1$ dex. Uma das propostas para explicar a natureza desta nuvem partiu de Deason et al. (2014), sugerindo que esta subestrutura provavelmente está associada, 
cinematicamente e espacialmente, a uma galáxia esferoidal anã ultra-fraca, denominada Segue 2. Novamente, como no caso da sobredensidade de Virgo, a origem para essa subestrutura também se mostra complexa e em aberto.

- Hercules-Aquila Cloud: Descoberta por Belokurov et al. (2007b), essa subestrutura está localizada na direção do disco galáctico, particularmente próxima ao centro, e se extende até latitudes de $\pm 50^{\circ}$. Sua distância média é de cerca de $20 \mathrm{kpc}$ do Sol (Belokurov et al., 2007b; Watkins et al., 2009; Larsen et al., 2011; Simion et al., 2014). A densidade de objetos vista na região desta nuvem é cerca de $60 \%$ maior que a densidade do halo na mesma região (Sesar et al., 2010a), fato que foi usado para estimar a magnitude absoluta da progenitora, a qual especula-se ser uma galáxia anã.

- Pisces Overdensity: Trata-se de uma sobredensidade distante notada pela primeira vez por Sesar et al. (2007), cuja localização foi estimada em 81 kpc de distância do Sol. Watkins et al. (2009) confirmaram que a subestrutura se estende até $100 \mathrm{kpc}$ de distância e propuseram que sua massa total está entre $10^{4}$ e $10^{5} \mathrm{M}_{\odot}$, com metalicidade média $[\mathrm{Fe} / \mathrm{H}] \sim-1.5$. Posteriormente, Sesar et al. (2010b) publicaram um trabalho mostrando que a distribuição de velocidades dos objetos nessa região possui dois picos separados por $100 \mathrm{~km} / \mathrm{s}$, indicando que essa subestrutura apresenta ao menos duas componentes superpostas. Entretanto, a natureza do(s) progenitor(es) ainda não é clara.

Além dessas subestruturas, a Galáxia possui outras sobredensidades que não exibem uma forma bem definida e, normalmente, são encontradas próximas ao disco, como é o caso da subestrutura conhecida como "Anel de Monoceros" ( "Monoceros Ring") (Newberg et al., 2002). Trata-se de outra grande subestrutura, com latitudes galácticas menores que $30^{\circ}$, na direção do anticentro galáctico. A origem dessa componente ainda é debatida amplamente na literatura, mas segundo Newberg e Carlin (2016), sua natureza parece estar restrita a duas propostas: (i) existência de uma galáxia anã progenitora do Anel de Monoceros, que formou essa sobredensidade devido a sua ruptura por forças de maré (Martin et al., 2004; Martínez-Delgado et al., 2005); (ii) parte de um braço espiral externo, e não de galáxia anã remanescente (Hammersley e López-Corredoira, 2011; Lopez-Corredoira et al., 2012). 
Tabela 1.1 - Parâmetros das estruturas encontradas no halo da Galáxia já descritas na literatura (ver Tabela 4.1 de Newberg e Carlin, 2016, para mais informações e referências). O termo corrente é tipicamente associado a sobredensidades que tenham comprimentos significativamente maiores que suas larguras. Já o termo nuvem é usado para grandes extensões de sobredensidades, onde não se nota uma dimensão preferencialmente muito maior que outra, e que possuem origens ainda a serem compreendidas.

\begin{tabular}{|c|c|c|c|c|c|c|}
\hline Abreviação & $\begin{array}{c}\text { Tipo de estrutura } \\
\text { Corrente }(\mathrm{C}) / \operatorname{Nuvem}(\mathrm{N})\end{array}$ & $\begin{array}{c}\text { Progenitor } \\
-\end{array}$ & $\begin{array}{c}\text { Extensão no céu } \\
\text { (A.R.,Dec) em graus }\end{array}$ & $\begin{array}{l}\text { Distância } \\
\mathrm{D}_{\odot}(\mathrm{kpc})\end{array}$ & $\begin{array}{c}\mathrm{V}_{\odot} \\
(\mathrm{km} / \mathrm{s})\end{array}$ & $\begin{array}{c}\text { Metalicidade } \\
{[\mathrm{Fe} / \mathrm{H}]}\end{array}$ \\
\hline $\mathrm{Sag}$ & Corrente de Sagitário (C) & galáxia anã de Sagitário & Circunda o céu & 7 a 100 & $-200,+200$ & $-1.15,-0.4$ \\
\hline Vir & Corrente de Virgo (C) & NGC $2419(?)$ & 180 a $195,-4$ a 0 & 19.6 & 128 & -1.8 \\
\hline Pal5 & Palomar $5(\mathrm{C})$ & Palomar 5 & 225 a $250,-3$ a 8.5 & 23 & -55 & -1.4 \\
\hline Mon & Anel de Monoceros (C) & galáxia anã (?) & 108 a $125,-3$ a -41 & 10.5 & 100 & -0.8 \\
\hline 5466 & NGC $5466(\mathrm{C})$ & NGC 5466 & 182 a 224,21 a 42 & 17 & 108 & -2.2 \\
\hline Orp & Orphan Stream (C) & galáxia anã (?) & 143 a $165,-17$ a 48 & 20 a 55 & $+95,+240$ & -2.1 \\
\hline GD1 & GD-1 (C) & aglomerado globular (?) & 134 a 218,14 a 58 & 7 a 10 & $-200,+100$ & -2.1 \\
\hline AntC & AntiCenter Stream (C) & galáxia anã (?) & 121 a $130,-3$ a 63 & 8 & $+050,+090$ & -1.0 \\
\hline EBS & $\operatorname{EBS}(\mathrm{C})$ & aglomerado globular (?) & 132 a $137,-3$ a 16 & 10 & $+071,+085$ & -1.8 \\
\hline Ach & Acheron (C) & aglomerado globular (?) & 232 a 258,3 a 20 & 3.5 a 3.8 & - & $-1.7(?)$ \\
\hline $\mathrm{Coc}$ & Cocytos (C) & aglomerado globular (?) & 197 a 257,8 a 30 & 11 & - & $-1.7(?)$ \\
\hline Let & Lethe (C) & aglomerado globular (?) & 176 a 252,22 a 37 & 13 & - & $-1.7(?)$ \\
\hline Sty & Styx $(C)$ & Bootes III (?) & 201 a 250,21 a 31 & 45 & - & $-2.2(?)$ \\
\hline Cet & Cetus Polar Stream (C) & NGC $5824(?)$ & 019 a $037,-11$ a 39 & 24 a 36 & $-200,-160$ & -2.1 \\
\hline Pis & Pisces/Triangulum (C) & aglomerado globular (?) & 021 a 024,23 a 40 & 35 & 120 & -2.2 \\
\hline Alp & Alpheus (C) & NGC $288(?)$ & 022 a $028,-69$ a -45 & 1.6 a 2.0 & - & $-1.0(?)$ \\
\hline Atlas & ATLAS stream $(\mathrm{C})$ & Pyxis (?) & 018 a $030,-32$ a -25 & 20 & - & $-1.4(?)$ \\
\hline PAn & PAndAS MW stream (C) & galáxia anã (?) & 000 a 022,40 a 48 & 17 & 127 & $-1.5(?)$ \\
\hline Her & Hermus $(\mathrm{C})$ & aglomerado globular (?) & 241 a 254,5 a 50 & 18.5 & - & $-2.3(?)$ \\
\hline Hyl & Hyllus $(\mathrm{C})$ & aglomerado globular (?) & 245 a 249,11 a 34 & 20 & - & $-2.3(?)$ \\
\hline Oph & Ophiuchus stream $(\mathrm{C})$ & aglomerado globular & 241 a $243,-7.2$ a 6.7 & 8.0 a 9.5 & 290 & -2.0 \\
\hline TA1 & Triangulum-Andromeda $1(\mathrm{~N})$ & galáxia anã (?) & -10 a 30,20 a 45 & 20 & $-200,-50$ & -0.6 \\
\hline HerA* & Hercules-Aquila* (N) & galáxia anã (?) & 0 a $80^{*},-50$ a $50^{*}$ & 10 a 25 & $-130,-120$ & $-2.2,-1.4$ \\
\hline $\mathrm{VO}$ & Virgo Overdensity $(\mathrm{N})$ & galáxia anã (?) & 180 a 200,0 a 10 & 6 a 20 & $+200,+360$ & $-2.0,-1.0$ \\
\hline TA2 & Triangulum-Andromeda $2(\mathrm{~N})$ & galáxia anã (?) & 3 a 23,28 a 42 & 28 & $-200,-50$ & -0.6 \\
\hline $\mathrm{PO}$ & Pisces Overdensity $(\mathrm{N})$ & galáxia anã (?) & 350 a $360,-1.3$ a 1.3 & 80 a 100 & -75 & -1.5 \\
\hline
\end{tabular}

*Extensão no céu desta subestrutura é fornecida em coordenadas celestes galácticas (l,b).

A Tabela 1.1, adaptada de Newberg e Carlin (2016), mostra as principais propriedades das subestruturas descritas anteriormente. As diferentes colunas apresentam: abreviação do nome da subestrutura adotada neste trabalho, nome da subestrutura comumente usado na literatura, progenitor da subestrutura (quando o símbolo de interrogação "?" está presente, significa que o progenitor é desconhecido, mas pode ter ligação com o tipo de objeto proposto), extensão no céu em coordenadas equatoriais (J2000), distâncias heliocêntricas (somente a estimativa mais recente para cada subestrutura foi considerada), velocidades heliocêntricas e estimativas de metalicidade $([\mathrm{Fe} / \mathrm{H}])$. 


\subsubsection{Técnicas de identificação de subestruturas}

Correntes e nuvens de sobredensidade de estrelas no halo são tipicamente encontradas quando se notam concentrações de objetos contrastantes com regiões menos densas próximas, conforme visto na Figura 1.1. Entretanto, mesmo que a presença de uma sobredensidade seja nítida, sempre existem outras técnicas usadas para confirmá-las, ou tentar isolar os objetos que as compõem.

\subsubsection{1 "Paralaxe" fotométrica}

A "paralaxe" fotométrica é uma técnica que consiste em conhecer uma determinada classe de estrelas através de suas caracteristícas fotométricas. É necessário que o tipo de estrela adotado possua magnitude absoluta conhecida, para que estimativas de distância sejam feitas comparando seus brilhos aparentes. Um excelente exemplo da aplicação desta técnica pode ser consultado no trabalho de Jurić et al. (2008), onde foi feita uma tomografia do halo galáctico, usando cerca de 48 milhões de estrelas do SDSS de tipo espectral G na sequência principal.

\subsubsection{Grupos com movimentos em comum}

Para aplicar esta técnica é necessário possuir informações espectroscópicas e astrométricas dos objetos (Klement et al., 2008; Smith, 2016), o que nem sempre é possível. As velocidades das estrelas de grupos com movimentos em comum precisam ser pouco dispersas em todas as direções espaciais. Portanto, é uma técnica normalmente utilizada para identificar "subestruturas" próximas do Sol (Proctor, 1869), onde os dados astrométricos são mais confiáveis, sendo muito difícil de ser usada para estudar objetos localizados a grandes distâncias no halo galáctico.

\subsubsection{Composição química}

Sabendo que a composição química de uma estrela está vinculada a nuvem que lhe deu origem, ao medir a composição química de um grupo de estrelas, infere-se então que objetos que tenham composição química semelhantes partilham uma origem em comum (Freeman e Bland-Hawthorn, 2002). Entretanto, este vínculo só é forte quando a abundância de vários elementos químicos pode ser estudada, requerendo espectroscopia de alta resolução, 
como tem feito o mapeamento GALAH ( GALactic Archaeology with HERMES - De Silva et al., 2015), na região do disco galáctico.

\subsubsection{Mapas de idade cronográficos}

Os mapas de idade produzidos por Santucci et al. (2015b), além de descreverem um gradiente de idade no halo, também são úteis para identificar algumas de suas subestruturas. Usando a variação de cor dos objetos como um fator de contraste, várias estruturas previamente descritas aqui, tais como a Corrente de Sagitário e a sobredensidade de Virgo, puderam ser identificadas.

Esta técnica possui potencial para identificar estruturas com base em gradientes de cor, mas não necessariamente no contraste de densidade, como outras técnicas anteriormente descritas. Ou seja, ela permite que uma subestrutura seja revelada mesmo que tenha densidade de estrelas igual ou até menor que o ambiente em que se encontra no halo galáctico.

A técnica foi descrita usando exclusivamente BHBs (Santucci et al., 2015b). Entretanto, não há razão pra acreditar que a variação na cor-idade de outros tipos de estrelas não forneçam o mesmo resultado, desde que sejam avaliadas da mesma maneira. Infelizmente, a escolha dos objetos que podem ser usados para essa análise é muito restrita, pois, além de ser necessário ter uma boa amostragem de estrelas, elas precisam estar em estágio evolutivo onde a variação de cor aparente possa ser vinculada a sua idade, e que também possam ser identificadas a grandes distâncias.

\subsubsection{Candidatas a velas-padrão no halo}

A maneira mais direta de identificar uma subestrutura no halo é através de sua densidade estelar, que seria perfeitamente descrita com a determinação completa da localização de suas estrelas constituintes, com posições marcadas em um espaço tridimensional, permitindo assim que sua densidade estelar fosse comparada com suas vizinhanças. Entretanto, para medir posições em um espaço tridimensional com confiança, é necessário conhecer as coordenadas e distâncias dos avlos com a máxima precisão possível. No caso das estrelas, os objetos que se mostram ideais para essas análises são aqueles que possuem magnitudes absolutas praticamente constantes, sendo também ao mesmo tempo muito luminosos, e por isso são chamados de velas-padrão. 
A Figura 1.3 apresenta o diagrama cor-magnitude do aglomerado globular Palomar 5 (Newberg, 2013). As estrelas amostradas estão dentro de uma região com 4 minutos de arco da posição central do aglomerado. Elas são, em geral, estrelas velhas e pobres em metais. As estrelas mais luminosas nesse diagrama são aquelas normalmente usadas como velas-padrão para estimar distâncias até subestruturas, ou então para estimar as próprias dimensões do halo (Deason et al., 2011). São elas: BHBs, RR Lyraes, gigantes de tipo espectral M e K, estrelas no turnoff e blue stragglers (que serão melhor descritas na subseção 1.2).

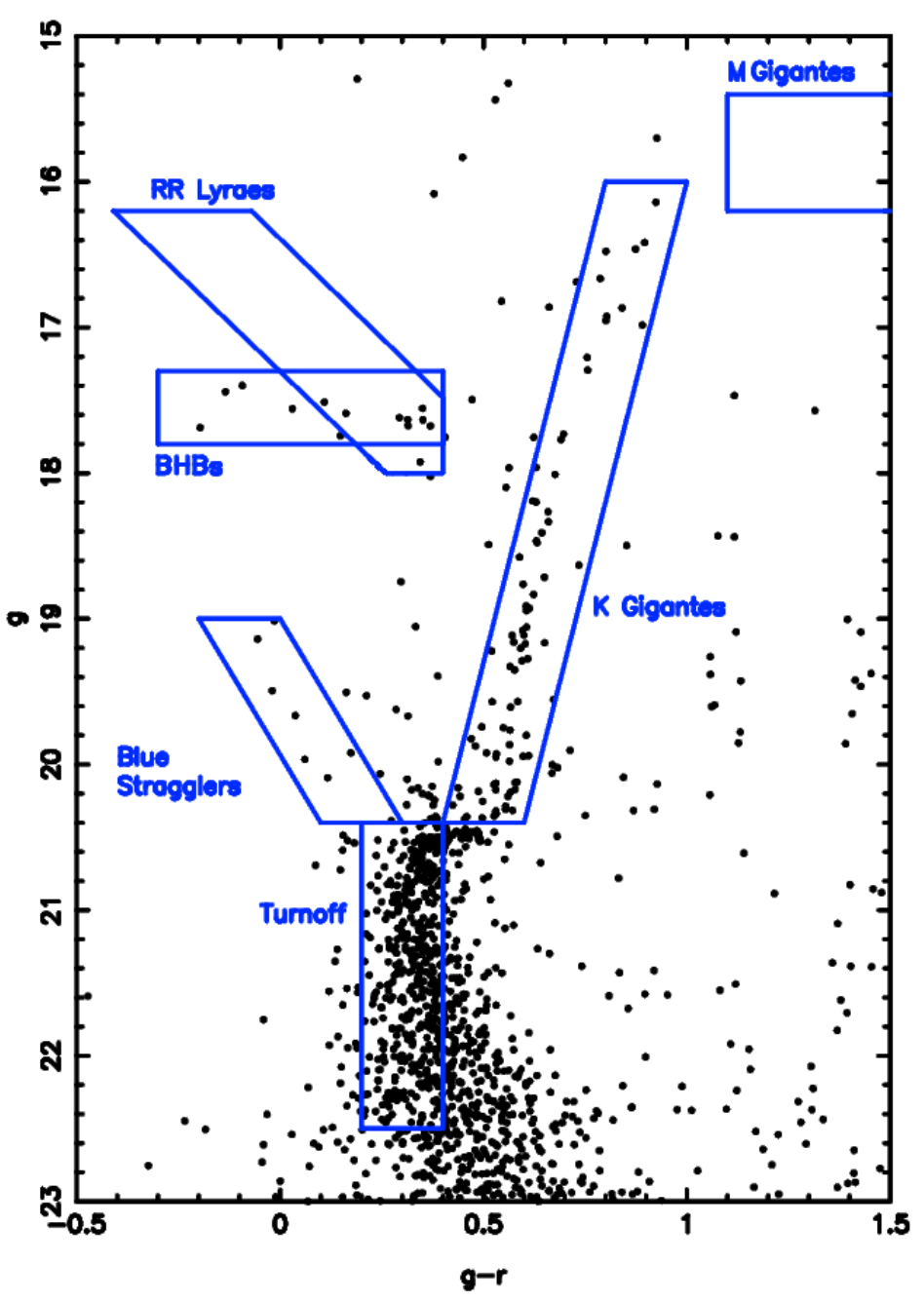

Figura 1.3: Diagrama cor-magnitude do aglomerado globular Palomar 5. As regiões azuis destacam as estrelas que podem (ou são) ser usadas como traçadoras de distâncias. Os mapeamentos de dados no céu são sempre limitados em dadas magnitudes e, como consequência disso, os objetos mais luminosos são preferencialmente usados como traçadores de longas distâncias. Entretanto, pode-se ver no diagrama que eles não são os mais abundantes. Figura adaptada de Newberg (2013). 
As estrelas azuis do ramo horizontal são boas traçadoras de distâncias porque possuem um intervalo estreito de magnitudes absolutas. Elas também são facilmente identificadas e selecionadas, mesmo usando somente suas características fotométricas (Deason et al., 2012; Carollo et al., 2016). Entretanto, a fotometria por si só não permite uma separação completa destes objetos, pois normalmente as blue stragglers ocupam uma região de cor superposta a elas. Além de estrelas azuis, o ramo horizontal também possui estrelas vermelhas. Entretanto, estas são ainda mais difíceis de se isolar fotometricamente, pois se confundem com outras gigantes e com estrelas mais frias da sequência principal.

As estrelas RR Lyrae são traçadoras de distâncias ainda melhores mas, por serem variáveis, precisam de observações em várias épocas para se obter a confirmação de seus períodos. Elas são tão brilhantes quanto as BHBs, mas não tão abundantes quanto elas.

As estrelas gigantes do tipo M são extremamente brilhantes, mas são encontradas preferencialmente em ambientes mais ricos em metais e, por isso, não são encontradas facilmente no halo e em aglomerados globulares (Sharma et al., 2010).

As brilhantes estrelas gigantes de tipo K são as escolhas mais frequentes para avaliação das densidades no halo, porque são mais abundantes em populações mais velhas do que as outras estrelas já citadas. O problema deste tipo estelar se resume na necessidade de possuir alguma informação espectral (ou fotométrica especial, com filtros que cobrem a região do tripleto do $\mathrm{MgI}$ e $\mathrm{MgH}$ em $\sim 5150 \AA$, pois são linhas sensíveis a gravidade superficial da estrela: Majewski et al., 2000) para que não sejam confundidas com estrelas anãs de mesmo tipo espectral. Além disso, suas magnitudes absolutas dependem de suas idades, metalicidades e ainda mais fortemente de suas cores (Newberg e Carlin, 2016).

As estrelas no turnoff são as mais abundantes de todas as traçadoras de distâncias aqui citadas, mas não são os objetos ideais para ser usados como velas-padrão, pois possuem luminosidades bem variadas, ocupando intervalo de $\sim 2$ magnitudes em um estrito intervalo de cor, como visto na Figura 1.3. Elas são consideradas principalmente quando é necessário quantificar a densidade de objetos em uma região de interesse.

Por sua vez, as blue stragglers podem ser melhor isoladas das BHBs através de seus espectros (Santucci et al., 2015a), mas também podem ser selecionadas fotometricamente (Deason et al., 2012; Carollo et al., 2016), pois são objetos de coloração mais azulada que são facilmente identificados em qualquer ambiente estelar velho. Suas magnitudes absolutas dependem fortemente de suas cores (Kinman et al., 1994; Deason et al., 2012), 
mas ao contrário do que a literatura as vezes pode afirmar (Newberg e Carlin, 2016), elas não são estrelas raras no halo. Preston et al. (1994) e mais recentemente Santucci et al. (2015a) mostraram que a frequência de blue stragglers no halo é, ao menos, duas vezes maior que o número de BHBs na mesma região, sendo que essa proporção varia com a distância e pode chegar até uma razão 4/1 nas regiões internas do halo.

O fato de suas magnitudes absolutas dependerem fortemente de suas cores, longe de ser um problema grave, acaba sendo útil quando há pouca, ou até nenhuma, informação espectroscópica presente. Por não serem tão luminosas quanto as BHBs, as blue stragglers não podem ser usadas como traçadoras de grandes distâncias e estão limitadas a regiões menores que 40kpc de distância do Sol (Santucci et al., 2015a). Por outro lado, como são estrelas de sequência principal, possuem também uma variação de cor ampla e atrelada a variação de suas massas e, consequentemente, de suas idades. Esta constatação as tornam excelentes candidatas para serem submetidas à técnica dos mapas de idade descrita anteriormente (Santucci et al., 2015b).

\subsection{Estrelas azuis tardias}

As estrelas "azuis tardias" (blue stragglers stars - BSSs ou estrelas BS) são estrelas de sequência principal (SP) que aparentam ser mais jovens que a população estelar da região onde se encontram, sendo excepcionalmente mais quentes que suas vizinhas. Apesar de seus nomes induzirem a ideia de cor, elas não são necessariamente estrelas azuis, mas receberam essa denominação quando foram observadas pela primeira vez por Sandage (1953) em um estudo sobre a idade do aglomerado globular M3. Sandage notou que existiam estrelas na extensão da sequência principal acima do turnoff e, portanto, eram mais azuis e, possivelmente, mais massivas que as demais estrelas na SP do aglomerado. Assim, apesar de não ser o foco de seu estudo, Sandage cunhou a expressão blue straggler e chamou a atenção para a necessidade de explicar o aparente atraso evolutivo dessas estrelas, as quais já deveriam ter deixado a SP.

Um bom exemplo para ilustrar a identificação feita por Sandage pode ser visto na Figura 1.4, que mostra o diagrama HR do aglomerado globular M55. Nesse gráfico, as estrelas azuis tardias identificadas na sequência principal aparecem dentro da elipse branca e são mais azuis que o ponto de turnoff. 


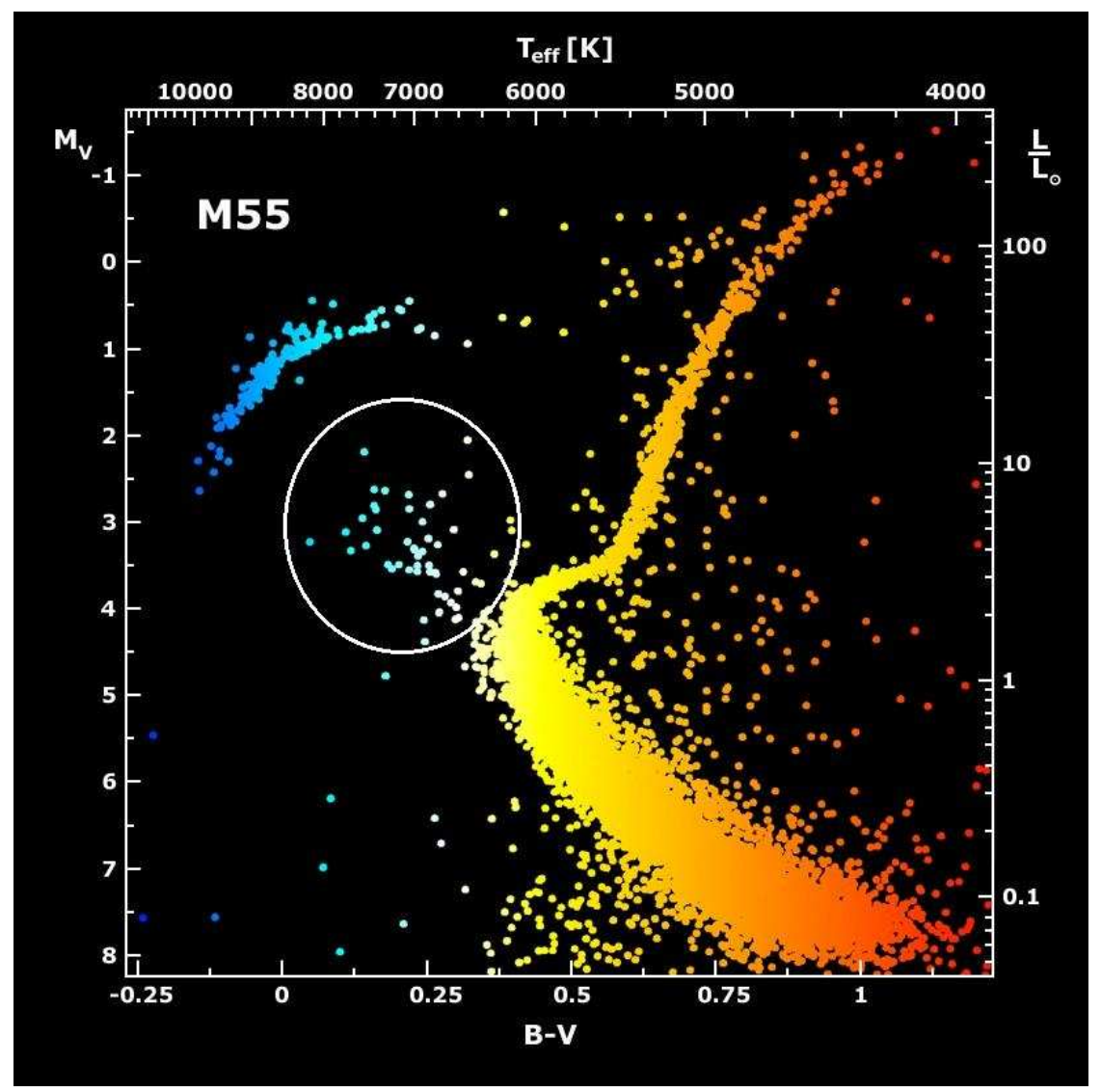

Figura 1.4: Diagrama HR do aglomerado globular M55. As estrelas azuis tardias são encontradas na extensão da sequência principal, e suas posições estão destacadas no interior da elipse branca. Vê-se claramente que as estrelas BS localizam-se no prolongamento da sequência principal. Figura adaptada, criada por B.J. Mochejska e J. Kaluzny do "Nicolaus Copernicus Astronomical Center of the Polish Academy of Sciences", com o Telescópio Swope (2001).

Desde sua descoberta, as estrelas BS têm sido identificadas em todos os ambientes e populações estelares: em populações estelares jovens no campo (Carney et al., 2005) e em aglomerados abertos de todas as idades (de Marchi et al., 2006), entre as estrelas do disco espesso (Fuhrmann e Bernkopf, 1999), assim como em populações estelares mais velhas, tanto no halo galáctico (Preston et al., 1994), como em aglomerados globulares (Piotto et al., 2004), e também no bojo da Galáxia (Clarkson et al., 2011) e em galáxias anãs no Grupo Local (Momany et al., 2007).

\subsubsection{A natureza das estrelas azuis tardias}

Muitos trabalhos foram publicados compilando as detecções, propriedades e várias hipóteses levantadas para justificar a existência das BSSs (Leonard, 1989; Stryker, 1993; 
Bailyn, 1995; Leonard, 1996; Preston, 2014). Somente dois mecanismos para explicar suas origens sobreviveram aos testes feitos ao longo do tempo: (i) colisões entre estrelas, resultando em um objeto mais massivo e aparentemente mais jovem (Hills e Day, 1976); e (ii) estrelas que coalesceram e/ou tiveram um processo de transferência de massa em um sistema binário, como proposto inicialmente por McCrea (1964). Este último cenário, no entanto, parece ser o principal meio de formação das BSSs, onde a estrela mais massiva de um sistema binário, ao evoluir primeiro e atingir a fase pós sequência principal, transfere parte de seu material para sua companheira (Boffin et al., 2014). A estrela companheira, agora mais massiva, aparentará ser anomalamente uma estrela mais jovem.

Fusi Pecci et al. (1992) foram um dos primeiros a propor que estrelas BSS em diferentes ambientes poderiam ter diferentes origens. Em aglomerados globulares, ambos os mecanismos citados parecem atuar. As colisões parecem dominar nas regiões centrais, onde a densidade de estrelas é maior, enquanto que a transferência de massa parece ser o principal mecanismo de formação em suas regiões periféricas (Mapelli et al., 2004). A frequência específica de estrelas BSS em aglomerados globulares é alta em seus centros, cai rapidamente até a metade de seus raios, e volta a crescer novamente nas regiões mais periféricas (Mapelli et al., 2004).

Uma tendência contrastante é encontrada quando se compara a frequência de estrelas azuis tardias em diferentes ambientes (Preston et al., 1994; Momany et al., 2007). Normalmente, verifica-se que quanto maior a densidade estelar, menor é a frequência de BSSs observada. Ou seja, a frequência de BSSs em aglomerados globulares e galáxias anãs compactas é sempre menor que em aglomerados abertos e no campo galáctico. Uma explicação para essa observação sugere que sistemas múltiplos de estrelas (os quais são presumidamente os progenitores de BSSs) podem ser mais facilmente destruídos quando sujeitos a mais interações gravitacionais (Preston e Sneden, 2000). Esse pode ser o caso dos aglomerados globulares, pois até mesmo sistemas de estrelas presentes em regiões periféricas menos densas podem estar, em algum momento, sujeitos a mudar suas trajetórias devido aos encontros com outras estrelas, e assim podem ser carregados até as regiões centrais, mais densas.

Cabe aqui ressaltar que a frequência de BSSs encontrada em aglomerados abertos e galáxias anãs $\left(\mathrm{N}_{\mathrm{BSS}} / \mathrm{N}_{\mathrm{BHB}}{ }^{2}=2.24 \pm 0.17\right.$; Momany et al., 2007) é diferente daquela

\footnotetext{
${ }^{2} \mathrm{~N}_{\mathrm{BSS}}$ e $\mathrm{N}_{\mathrm{BHB}}$ são os números de BSSs e BHBs encontrados nesses ambientes, respectivamente.
} 
estimada para o halo galáctico $\left(\mathrm{N}_{\mathrm{BSS}} / \mathrm{N}_{\mathrm{BHB}} \sim 4\right.$; Preston et al., 1994). Entretanto, como apontado por Momany et al. (2007), o valor proposto por Preston et al. (1994) foi estimado usando uma amosta de apenas 62 estrelas, distribuídas ao longo de muitas linhas de visada e em diferentes distâncias, onde nenhuma correspondência observacional direta da razão (BSS/BHB) pôde ser definida.

Preston e Sneden (2000) também argumentaram que as estrelas BSS de campo deveriam ser oriundas preferencialmente do processo de transferência de massa, pois não há densidade estelar suficiente no campo para justificar suas formações através colisões entre estrelas. Eles notaram também que as BSSs de campo são muito mais comuns que BSSs nas periferias de aglomerados globulares. Preston e Sneden (2000) observaram 62 estrelas azuis pobres em metais (de uma amostra de 84 estrelas de Preston et al. (1994)) com espectroscopia de alta resolução, e notaram que esses objetos possuiam gravidades superficiais e cores mais azuis que os turnoffs de aglomerados globulares $\left(0.15<(\mathrm{B}-\mathrm{V})_{0}<0.35\right)$.

Preston e Sneden (2000) também fizeram um monitoramento da velocidade radial da amostra reunida por Preston et al. (1994) ao longo de quase 10 anos. Como resultado, verificaram que mais de $60 \%$ da amostra era composta por sistemas binários, e mais de $70 \%$ deles eram BSSs. Esses números sugerem que as estrelas BSS são fortes indicadoras da presença de sistemas binários, e podem ser usadas como prova da existência de binaridade em populações estelares na Galáxia onde forem encontradas.

Como se não bastassem as evidências já apresentadas por Preston et al., Ryan et al. (2001) e Ryan et al. (2002) também argumentaram a favor da binaridade estar presente em muitas estrelas de campo no halo, baseando-se na observação de estrelas ultra deficientes em Lítio. Os autores propuseram que a depleção de Li observada em vários objetos analisados deveria estar relacionada ao processo de transferência de massa que produz as BSSs de campo. Além disso, as estrelas ultra deficientes em Li analisadas possuem rotação um pouco mais rápida que outras outras antigas pobres em metais. Este ganho de velocidade na rotação também foi atribuído ao processo de transferência de massa. Como as estrelas usadas em Ryan et al. eram mais frias que as estrelas no turnoff, eles se referiram a estes objetos como "quase blue stragglers", pois são estrelas de massa menor, mas vítimas do mesmo processo que forma as BSSs de campo mais azuis (Ryan et al., 2002). Além destes trabalhos, Rocha-Pinto et al. (2001) também notaram que a transferência de massa parece ser responsável por criar "BSSs mais frias", que poderiam ser chamadas de 
"amarelas tardias" ou "vermelhas tardias", mas foram descritas por esses autores como estrelas "cromosfericamente jovens e cinematicamente antigas". Também é válido lembrar que quase uma década antes de Ryan et al., Glaspey et al. (1994) já haviam obtido espectros em média resolução para avaliar a presença de Li em estrelas pobres em metais de campo. Várias estrelas dessa amostra mostraram depleção de Li, o que sugere novamente que esses objetos deveriam ter passado por um processo de mistura enorme, e assim foram associados com o mesmo mecanismo de formação de BSSs.

Gosnell et al. (2015) publicaram um estudo recente mostrando que existe um excesso de cor, no UV-distante, em cerca de $70 \%$ das 21 BSSs identificadas no aglomerado aberto NGC 188, usando dados fotométricos obtidos com o telescópio Hubble. Este excesso foi interpretado como sendo devido à presença de anãs brancas (muito quentes e portanto muito jovens) ao redor das BSSs.

A fração de sistemas binários confirmada em amostras de estrelas BSSs no campo é sempre muito alta. Mesmo assim, vários trabalhos já sugeriram a possibilidade de que as BSSs de campo não binárias possam ser oriundas de restos da acresção de satélites pela Galáxia (Preston et al., 1994; Preston e Sneden, 2000; Carney et al., 2001, 2005), tornando estes objetos ainda mais interessantes de serem usados na busca por subestruturas no halo.

\subsection{Objetivos}

Este trabalho tem o objetivo de fornecer evidências adicionais para respostas à algumas das questões supracitadas, visando ao mesmo tempo retirar o estigma de objetos "incompreendidos e problemáticos" geralmente atribuídos às estrelas azuis tardias, que normalmente são descritas como "poluidoras" de amostras por muitos autores (Marsteller et al., 2004; Xue et al., 2008; Parada et al., 2016). Estes termos tipicamente atribuídos à elas, mesmo que involuntariamente, quase sempre subestimam sua importância e as tornam tornam pouco interessantes aos olhos de quem as conhece pela primeira vez.

Assim, pretende-se neste trabalho reivindicar o papel de contribuição das BSSs em contextos maiores que a discussão de suas existências. Estas são estrelas que também possuem potencial para avaliar fenômenos como: o histórico de formação da Galáxia, a identificação de subestruturas no halo e sua frequência no halo. Com isso em mente, são utilizados neste trabalho dados espectrofotométricos do levantamento digital do céu SDSS 
("Sloan Digital Sky Survey" York et al., 2000), assim como os seus parâmetros atmosféricos obtidos através de seu sistema de análise automatizado ("Segue Stellar Parameter Pipeline" - SSPP York et al., 2000). Dentre os espectros estelares, busca-se a separação e classificação daqueles que possuam características físicas de estrelas azuis tardias no campo galáctico, que resumidamente são: estrelas de sequência principal de tipo espectral A, pobres em metais.

No Capítulo 2 são apresentados os critérios de seleção e a base de dados utilizada no trabalho. No Capítulo 3 são vistos os métodos para separar as estrelas azuis tardias segundo critérios espectrais e fotométricos. As estimativas de magnitude absoluta, distâncias e frequências encontram-se no Capítulo 4. O Capítulo 5 mostra aplicações para os mapas de idade feitos com as estrelas azuis tardias no halo, tais como a identificação de subestruturas. Finalmente, no Capítulo 6 são apresentadas as principais conclusões e perspectivas do trabalho. 
Capítulo 2

\section{Base de Dados}

Este capítulo apresenta a base de dados utilizada na análise do trabalho. Inicialmente são descritos os critérios de seleção fotométrica de BSSs através do diagrama cor-cor. Em seguida, discute-se o limite de $[\mathrm{Fe} / \mathrm{H}]$ adotado para as estrelas pobres em metais da amostra. Por fim, mostra-se a essência da separação espectroscópica entre as BHBs e BSSs.

\subsection{SDSS e o Data-release 8}

O "Sloan Digital Sky Survey" (SDSS) é um grande mapeamento espectroscópico e fotométrico (York et al., 2000) que cobre cerca de 1/4 do céu. Os dados de imageamento são obtidos pela instrumentação de dois conjuntos de matrizes de CCDs acoplados ao telescópio de 2.5m (Gunn et al., 1998, 2006) situado no Apache Point Observatory, Novo México - EUA.

O imageamento é feito simultaneamente em cinco bandas: $u, g, r, i$ e $z$, centradas em $3551 \AA, 4686 \AA, 6166 \AA, 7480 \AA$ e $8932 \AA$, respectivamente (Veja: Fukugita et al., 1996, para mais detalhes). Para falicitar o acesso aos dados, e principalmente para separar estrelas de outros astros difusos, foi desenvolvida uma plataforma de tratamento dos dados automatizada que adota diversos métodos fotométricos, astrométricos e espectrais, para classificar os alvos de acordo com suas naturezas. Esse conjunto de métodos de análise, voltada para os dados estelares do SDSS, é conhecida como SSPP (SEGUE Stellar Parameter Pipeline - Lupton et al., 2001; Stoughton et al., 2002; Pier et al., 2003; Ivezić et al., 2004; Tucker et al., 2006; Lee et al., 2008; Allende Prieto et al., 2008).

Este trabalho faz uso da oitava fase de disponibilização dados do SDSS (data-release 8 - DR8). Nesta fase, o mapeamento cobre $\sim 14000^{\circ 2}$ do céu, principalmente no hemisfério 
norte celeste, na direção do halo galáctico (Aihara et al., 2011).

O SDSS fornece espectros e dados com magnitudes aparentes no intervalo $13<g<21$. Neste trabalho, somente alvos com erros fotométricos menores que 1\% (banda $g$ ) foram considerados. Além disso, os mapas de Schlegel et al. (1998) são adotados para corrigir os dados fotométricos do avermelhamento. Todas magnitudes e índices de cor vistos neste trabalho estão corrigidas pelo avermelhamento segundo esses mapas.

\subsection{Restrições no diagrama cor-cor}

Yanny et al. (2009a) publicaram um trabalho importante que resume a localização fotométrica de tipos estelares, identificados espectroscopicamente, no SDSS. Estas posições são vistas no diagrama cor-cor presente na Figura 2.1. Através dela é possível ver que vários tipos de estrelas consideradas traçadoras de distâncias (velas-padrão) podem ser isoladas usando somente seus índices de cor. Entretanto, como os limites entre os tipos espectrais, e/ou fases evolutivas, não são bem definidos usando somente suas cores, muitas vezes é necessário obter também seus espectros para selecionar o tipo estelar desejado.

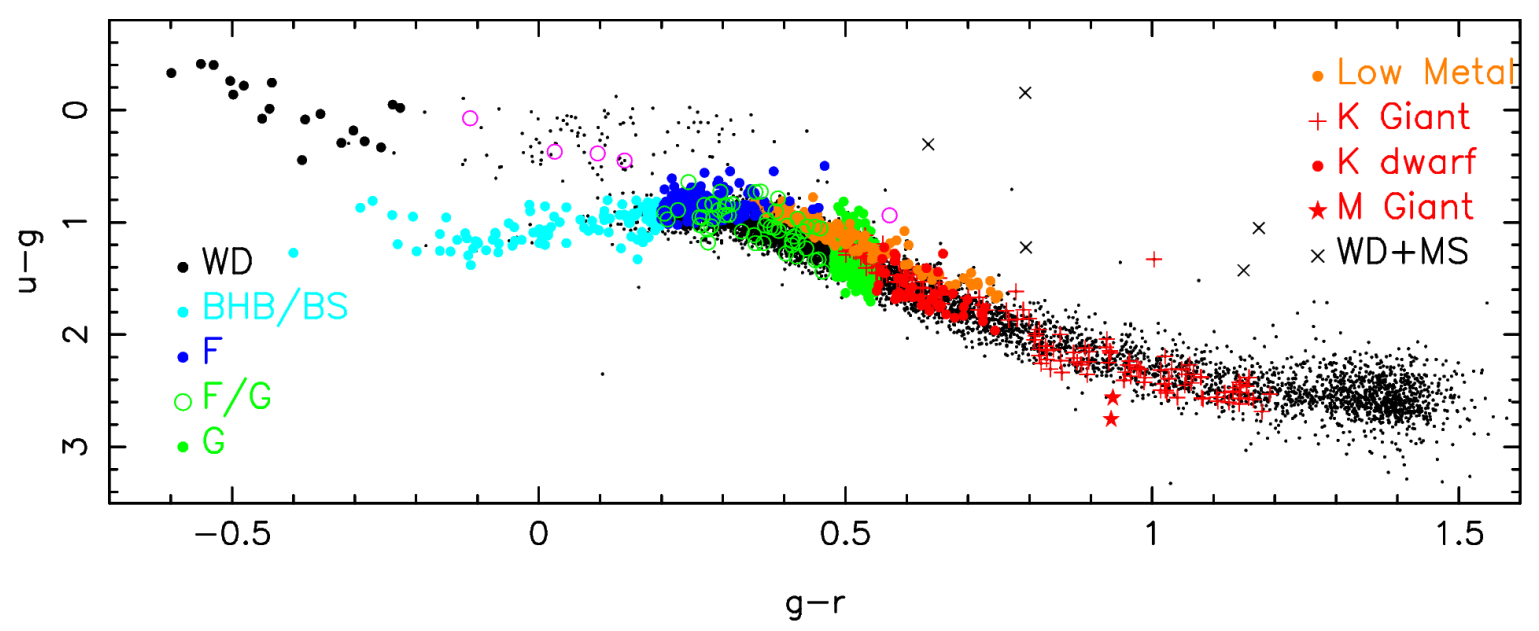

Figura 2.1: A figura mostra as diversas categorias de estrelas que podem ser selecionadas através de suas características fotométricas na base de dados do SDSS. As estrelas azuis tardias ocupam a região do cor-cor entre: $0.60<(u-g)<1.50$ e $-0.50<(g-r)<0.20$, juntamente com as BHBs. Além das descrições dos tipos estelares identificados nas legendas da figura, também são vistos círculos abertos na cor magenta, os quais representam anãs brancas mais frias. Figura retirada de Yanny et al. (2009a).

Através da Figura 2.1, nota-se que as candidatas a estrelas azuis tardias (BSSs) estão localizadas na região cor-cor aproximadamente entre: $0.6<(u-g)_{0}<1.5$ e $-0.5<(g-r)_{0}$ 
$<0.2$, juntamente com as BHBs. Esta é a região no diagrama cor-cor onde estão as estrelas quentes do tipo espectral A. Entretanto, somente com a fotometria não é possível distinguir claramente as estrelas na sequência principal (BSSs), daquelas presentes no ramo horizontal (BHBs). Na verdade, nessas faixas de cores, as estrelas de tipo A podem ser confundidas até mesmo com estrelas mais frias, de tipo espectral F e G.

Desta maneira, este trabalho faz uso de uma amostra espectrofotométrica, ou seja, somente dados com contrapartida espectroscópica foram selecionados na base de dados do SDSS. Segundo Yanny et al. (2009a), cerca de 25 mil alvos espectroscópicos habitam a região onde BSSs e BHBs são encontradas.

A seleção fotométrica feita para selecionar BSSs neste trabalho segue critérios ligeiramente diferentes daqueles comumente usados na literatura $\left(0.8<(u-g)_{0}<1.4 \mathrm{e}\right.$ $-0.3<(g-r)_{0}<0.0$. Veja Xue et al., 2008; Deason et al., 2011, para mais detalhes), adotando um intervalo pouco maior para as cores $(g-r)_{0}$, com o intuito de incluir mais objetos: $-0.30<(g-r)_{0}<0.02$, como mostra a Figura 2.2. Esta sutil extensão tem a finalidade de incluir mais candidatas a BSSs na amostra, pois é justamente na região $(g-r)_{0} \sim 0$ que elas são mais frequentes que as BHBs (Deason et al., 2011). Entretanto, ao tentar selecionar mais BSSs aumentando o intervalo de cor $(g-r)_{0}$, aumenta-se também as chances de contaminação de estrelas de sequência principal mais frias. Portanto, esse limite não pode ser muito maior do que o valor considerado (Yanny et al., 2009a).

O mapeamento do SDSS não deixa lacunas entre os campos observados no céu. Para tanto, o imageamento perfaz uma superposição nas bordas dos campos observados, resultando muitas vezes em objetos idênticos que são classificados com nomes distintos em placas diferentes. Portanto, todas as multiplicidades excedentes de dados foram removidas, resultando em 20526 espectros estelares únicos.

A Figura 2.3 mostra a distribuição celeste dos dados utilizados neste trabalho, os quais estão presentes em todas as regiões do mapeamento do SDSS. Nenhuma restrição em coordenadas foi adotada no trabalho.

\subsection{Características espectroscópicas}

Os espectros únicos, presentes na região cor-cor adotada na seção anterior, foram então inspecionados visualmente com a finalidade de garantir que somente alvos que possuíssem 


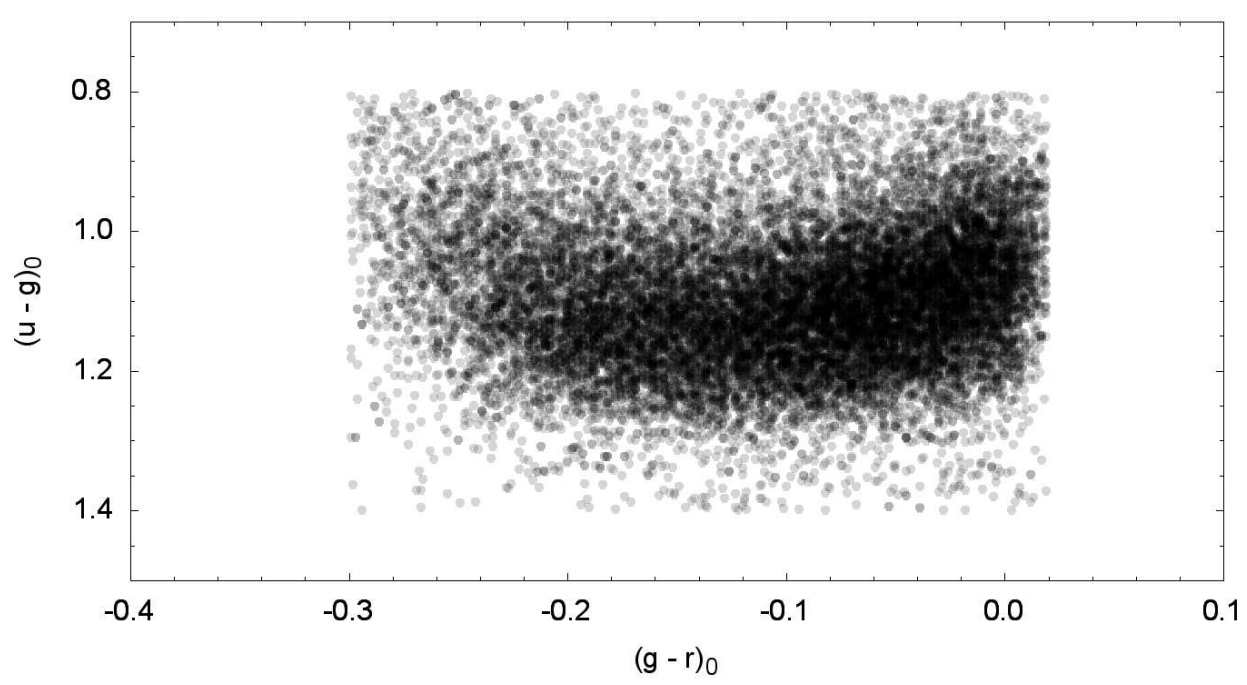

Figura 2.2: Região do diagrama cor-cor adotada para selecionar as candidatas a estrelas azuis tardias na base de dados do SDSS (DR8): $0.8<(u-g)_{0}<1.4 \mathrm{e}-0.30<(g-r)_{0}$ $<0.02$. A figura mostra os objetos que passaram por essa restrição e possuem informação espectroscópica associada $(\sim 20$ mil).

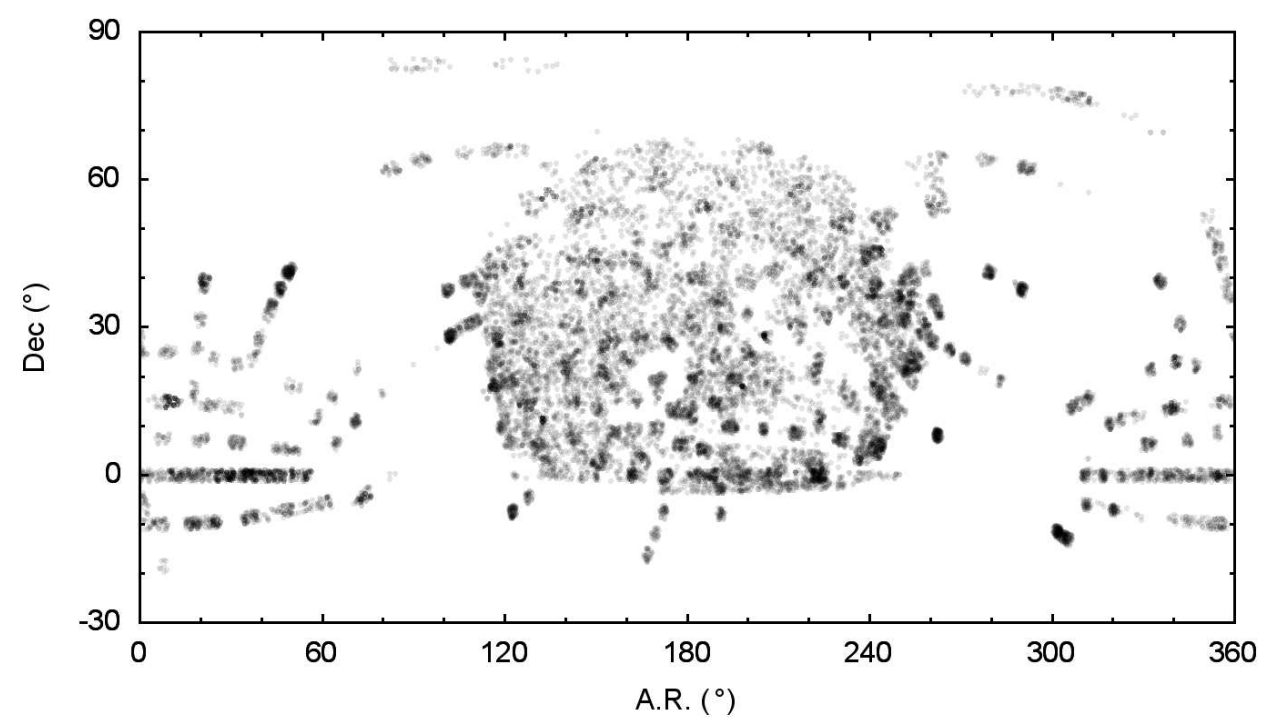

Figura 2.3: Coordenadas celestes equatoriais dos dados deste trabalho. O SDSS faz seu mapeamento do céu a partir do hemisfério norte da Terra e, por essa razão, nota-se que o hemisfério norte celeste é melhor amostrado. Nenhuma restrição em coordenadas foi aplicada aos dados.

espectros estelares fossem considerados. Cerca de 500 espectros inspecionados possuíam problemas ou não pareciam ser de estrelas do interesse deste trabalho e foram excluídos.

Os dados avaliados tiveram parâmetros atmosféricos estelares estimados pelo sistema automatizado do SSPP, fornecendo valores para temperatura efetiva $\left(\mathrm{T}_{\text {eff }}\right)$, logarítmo da 
gravidade superficial - $\log (\mathrm{g})$, metalicidade $([\mathrm{Fe} / \mathrm{H}])$ e velocidade radial heliocêntrica $\left(\mathrm{V}_{\odot}\right)$.

Através das metalicidades fornecidas pelo SSPP, a amostra pôde ser restrita a $[\mathrm{Fe} / \mathrm{H}]<$ -0.4. Para selecionar as melhores candidatas a BSSs do halo, excluiu-se os objetos mais ricos em metais, os quais podem pertencer ao disco galáctico. O valor de -0.4 foi escolhido pois, para $[\mathrm{Fe} / \mathrm{H}]>-0.4$, há um aumento drástico do número de estrelas na amostra, possivelmente devido à contaminação por regiões mais jovens. Este corte reduziu a amostra para cerca de 18 mil objetos. Nenhuma restrição em latitudes galácticas foi aplicada para diminuir ainda mais a possibilidade de contaminação por membros do disco, porque isso reduziria desnecessariamente o número de objetos na amostra. Além disso, o limite em metalicidade considerado parece ser mais eficiente em excluir os objetos desta região mais jovem, pois existem objetos pobres em metais do halo passando pelo disco.

BSSs com diferentes metalicidades fornecidas pelo SSPP podem ser vistas na Figura 2.4. Os espectros apresentados na figura possuem metalicidades no intervalo $-3.0<[\mathrm{Fe} / \mathrm{H}]<$ -0.4 e temperaturas em torno de $\sim 8600 \mathrm{~K}$. Um dos métodos de estimaviva de metalicidade considerado pelo SSPP usa uma relação empírica baseada na linha K do Ca II (3933.7 A). Essa técnica foi descrita inicialmente por Beers et al. (1990) e revisada em um estudo posterior Beers et al. (1999). A Figura 2.4 mostra que, quanto menor a metalicidade da estrela, menos intensa é a linha K do Ca II para uma dada temperatura. O SSPP fornece um erro médio de 0.2 dex na metalicidade para estrelas com magnitudes $g_{0}<18$.

\subsubsection{As linhas de Balmer do Hidrogênio}

A série de Balmer do Hidrogênio é a principal característica vista nos espectros da amostra. As linhas do Hidrogênio são usadas para distinguir as estrelas de tipo A em diferentes fases evolutivas. A temperatura da estrela modifica a profundidade da linha de absorção do Hidrogênio, enquanto que o efeito de diferentes gravidades superficiais altera a largura de suas asas (Mihalas, 1982). Assim, estrelas na sequência principal e no ramo horizontal possuem propriedades físicas que produzem diferenças em seus espectros, conforme pode ser visto na Figura 2.5. Através desta figura, pode-se notar que, para mesma temperatura, as linhas de Balmer de estrelas com gravidade superficial maior $(\log (\mathrm{g}) 4.3$ - BSS, em preto) possuem asas mais largas que estrelas de gravidade superficial menor $(\log (\mathrm{g}) 3.4$ - BHB, em vermelho).

Entretanto, para que diferenças nos espectros de BHBs e BSSs sejam perceptíveis, 


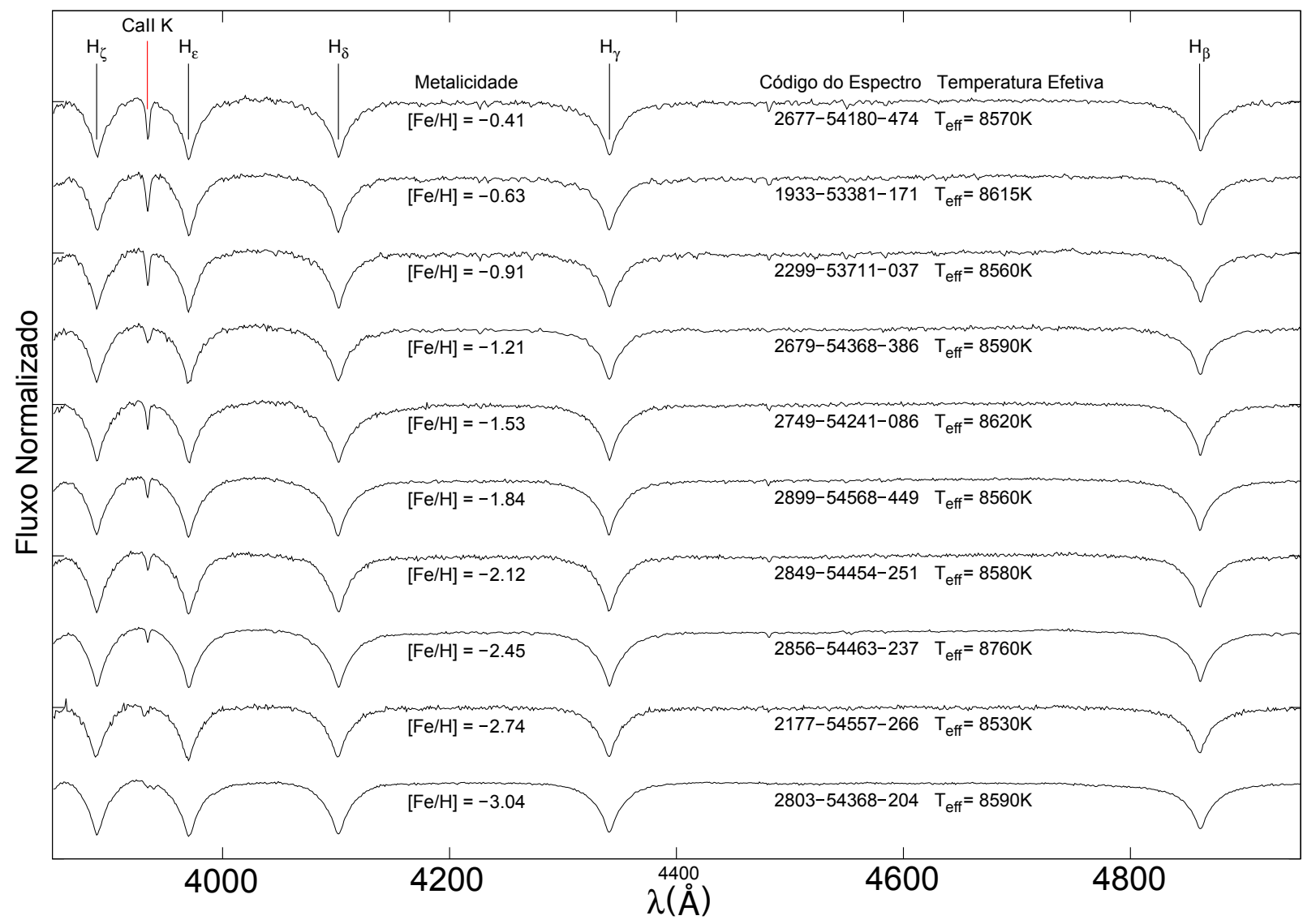

Figura 2.4: Relação entre a intensidade da linha K do Ca II (3933.7 Å) e a metalicidade estimada pelo SSPP. Nota-se que, quanto menor a metalicidade da estrela, menor a intensidade da linha K do CaII.

é necessário estabelecer um valor mínimo da razão sinal/ruído (S/R) para os espectros. Segundo Deason et al. (2012), os espectros desses objetos começam a mostrar distinção confiável a partir da razão $\mathrm{S} / \mathrm{R}>5$. Entretanto, para razão $\mathrm{S} / \mathrm{R}>9$ (veja a Figura 3 de Deason et al., 2012, para mais detalhes), a separação entre ambas é feita com mais facilidade. Portanto, esse limite foi imposto aos espectros selecionados neste trabalho, os quais serão analisados no capítulo a seguir, onde são apresentados os métodos espectroscópicos utilizados para selecionar BHBs e BSSs. 


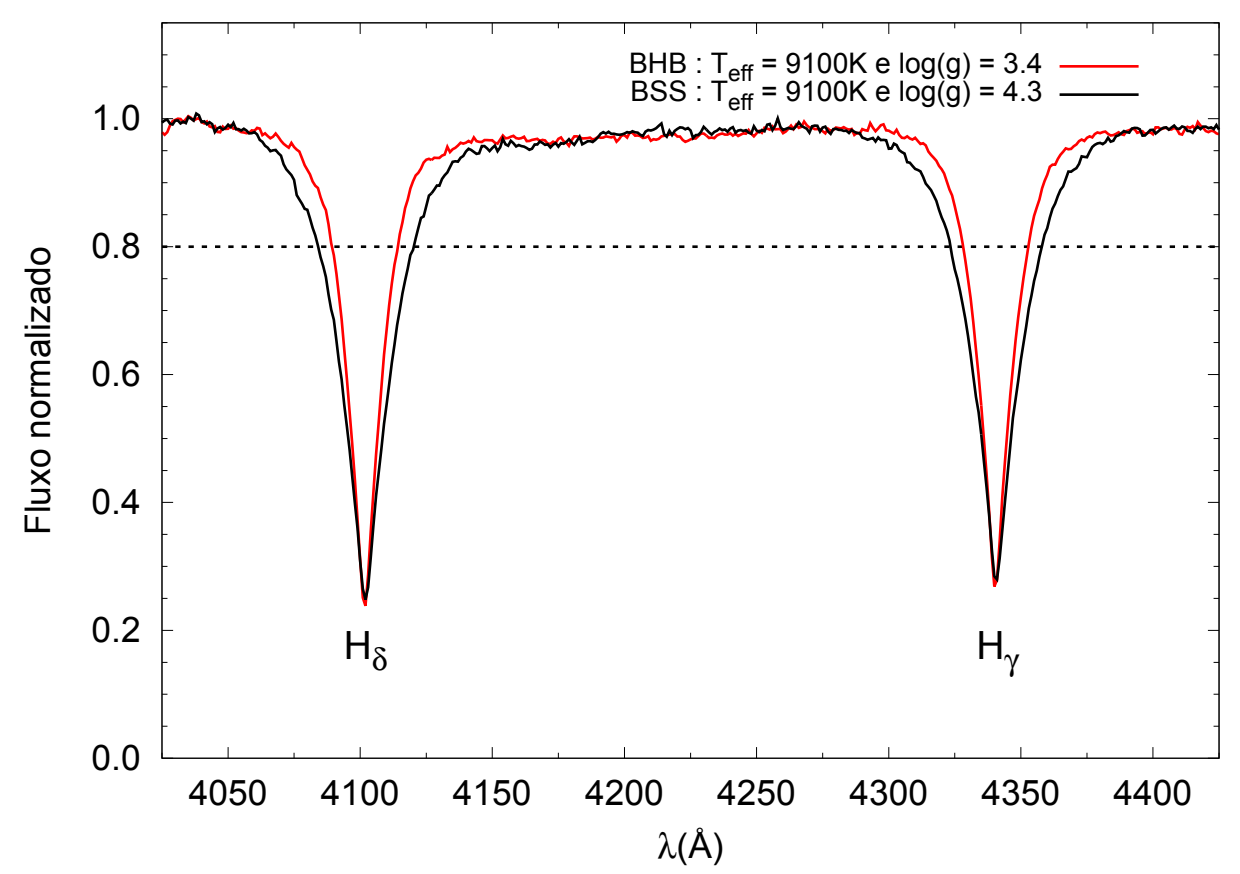

Figura 2.5: Espectros normalizados de uma estrela BHB (em vermelho) e de uma estrela na sequência principal (BSS - em preto) para uma mesma temperatura efetiva ( 8100 K). A linha tracejada em 80\% de fluxo ressalta a diferença da largura das asas. Quanto maior a gravidade superficial da estrela, maior será a largura da asas das linha de Balmer. 
Capítulo 3

\section{Separações entre fases evolutivas}

Neste capítulo são apresentados os métodos adotados para separar BHBs e BSSs usando dados espectroscópicos do SDSS em média resolução. As estrelas que passaram por todas as restrições dos métodos de seleção aplicados são avaliadas no Capítulo 4. Apesar das BHBs não serem o foco deste trabalho, é importante identificá-las corretamente no decorrer da análise, pois elas são usadas para avaliar a frequência de BSSs no halo, além de fornecerem margens de erros nas seleções adotadas. No final deste Capítulo, também são definidas novas restrições para a seleção fotométrica destes tipos estelares.

Através dos parâmetros atmosféricos calculados pelo SSPP é possível comparar diretamente gravidades superficiais e temperaturas de BSSs e BHBs (Wilhelm et al., 1999b; Deason et al., 2012; Santucci et al., 2015a). Entretanto, o intervalo de temperaturas onde estas estrelas se encontram ainda não foi validado com comparações em alta resolução (7500 $\left.\mathrm{K}<\mathrm{T}_{\text {eff }}<10000 \mathrm{~K}\right)$. Dessa maneira, deve ser feita uma validação de seus parâmetros, mesmo que qualitativa (Santucci et al., 2015a).

A tarefa de validação pode ser feita comparando-se os resultados do SSPP com resultados de outros métodos usados na literatura para separar BHBs e BSSs (Clewley et al., 2002; Sirko et al., 2004). Entretanto, tais métodos requerem espectros de razão S/R maior que o limite mínimo adotado na amostra. O limite de S/R necessário para usá-las é alcançado em objetos com magnitude $g_{0}<18$ (Sirko et al., 2004). A razão S/R média da amostra espectroscópica neste intervalo de magnitudes é aproximadamente 38.

Mesmo que os objetos com magnitude $g_{0}>18$ não possam ser avaliados satisfatoriamente por alguns dos métodos apresentados a seguir, eles ainda possuem informações que podem ser usadas para distinguí-los entre BHBs e BSSs (Santucci et al., 2015a). Portanto, para a análise seguinte, são seguidos os mesmos passos descritos por Santucci et al. (2015a). 
A amostra foi divida então em duas partes: uma mais brilhante com $g_{0}<18$, e outra menos brilhante com $g_{0} \geq 18$.

\subsection{Análise da amostra com $g_{0}<18$}

Como esta amostra possui os espectros com melhores razões $\mathrm{S} / \mathrm{R}$, é possível aplicar uma série de testes para isolar BHBs e BSSs, como exemplificado a seguir.

\subsubsection{Restrições em $T_{\text {eff }}$ e $\log (g)$}

Através dos parâmetros fornecidos pelo SSPP, pode-se comparar diretamente suas temperaturas e gravidades superficiais, assim como feito por Wilhelm et al. (1999b), Deason et al. (2012) e Santucci et al. (2015a). Para esta parte da amostra com alta razão S/R é possível distinguir claramente BHBs e BSSs através destes parâmetros (Santucci et al., 2015a).

A Figura 3.1 resume os limites de temperatura e gravidade superficial adotados para selecionar BSSs e BHBs na amostra mais brilhante, segundo os parâmetros fornecidos pelo SSPP. Estes limites são os mesmos obtidos por Santucci et al. (2015a). A linha que separa os dois grupos estelares marca a melhor região onde os grupos se separam, estando localizada em $\log (\mathrm{g})=3.8$ (ver o painel superior da Figura 3.4). Esse valor limitante entre os dois tipos estelares representa o local onde, estatisticamente, a contaminação de estrelas BSS devido às BHBs é mínima, e vice-versa. Isto porque o limite definido está $3 \sigma$ distante dos picos de ambas as distribuições (Figura 3.4), centradas em $\log (\mathrm{g})=3.38 \pm 0.14$ dex e $\log (\mathrm{g})=4.34 \pm 0.18$ dex, para BHBs e BSSs, respectivamente.

Assim como visto na Figura 3.1, todas as demais figuras deste trabalho que comparam BHBs e BSSs foram coloridas marcando BHBs em vermelho e BSSs em preto. Além disso, para comparar com mais facilidade a congruência dos métodos de seleção descritos a seguir com os critérios estabelecidos através dos parâmetros do SSPP, as codificações de cores segundo as restrições da Figura 3.1 foram mantidas nas Figuras 3.2 e 3.3.

\subsubsection{O método $f_{m}$ vs. $D_{0.2}$}

Os parâmetros usados nos próximos métodos desta análise foram obtidos através de ajustes da função de Sersic (Sersic, 1968), vista na Equação 3.1, que é capaz de descrever 


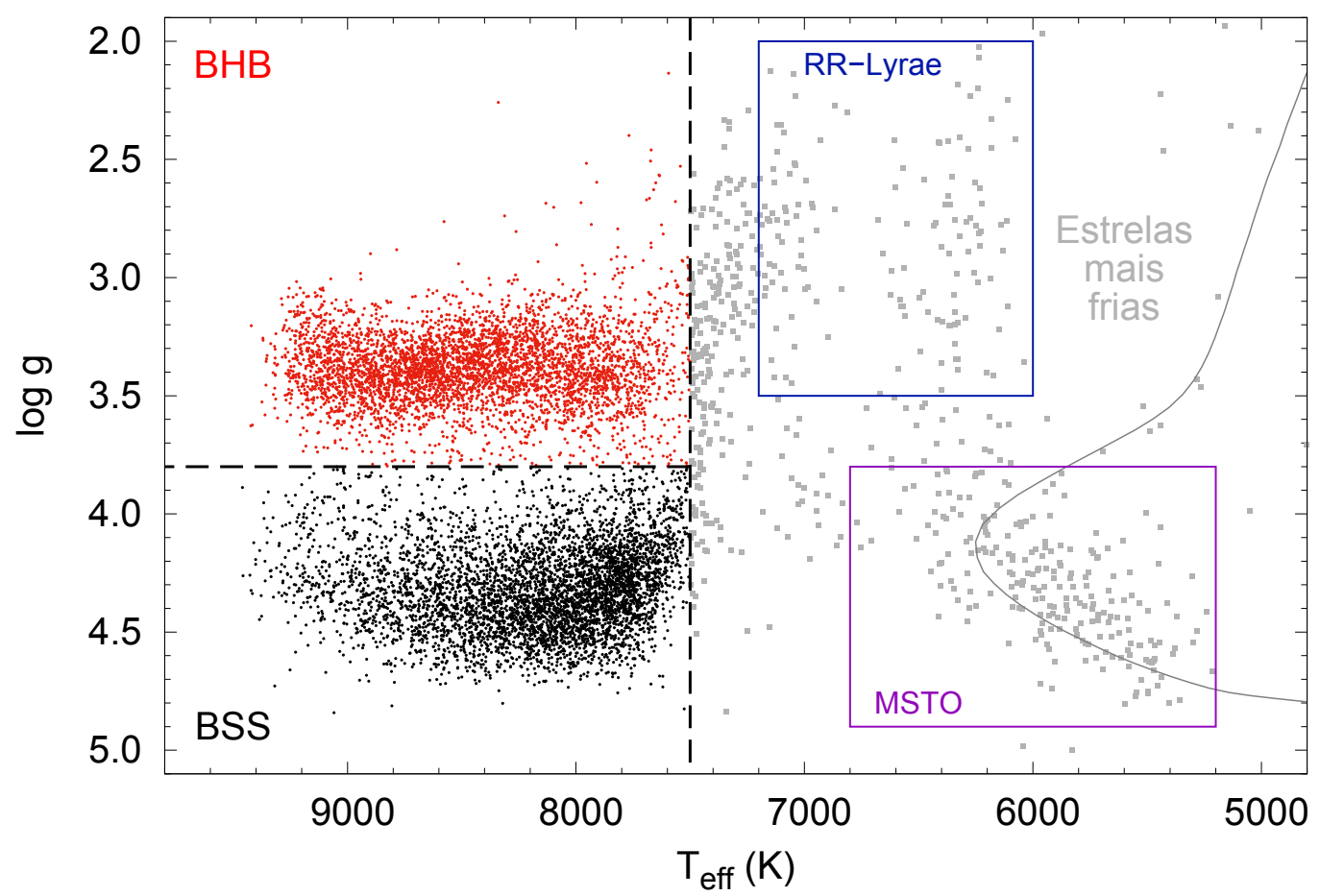

Figura 3.1: Distribuição de $\mathrm{T}_{\text {eff }}$ vs. $\log (\mathrm{g})$ para estrelas com $g_{0}<18$. Há dois grupos concentrados em $\mathrm{T}_{\text {eff }} \geq 7500 \mathrm{~K}$ : um com $\log (\mathrm{g}) \sim 3.4$, que são as estrelas BHB (pontos vermelhos) e outro com $\log (\mathrm{g}) \sim 4.3$, que são as estrelas BSS (pontos pretos). Os pequenos quadrados em cinza são estrelas mais frias, que não são consideradas na análise adiante. Também estão destacadas as posições onde tipicamente são encontradas as estrelas RR Lyrae (retângulo azul) (Wilhelm et al., 1999b). O retângulo roxo mostra a localização das estrelas de sequência principal na região do turnoff (MSTO). A curva evolutiva em cinza é uma isócrona de Yale-Yonsei (Demarque et al., 2004), que identifica o caminho de uma estrela de $1 \mathrm{M}_{\odot}$, com $[\mathrm{Fe} / \mathrm{H}]=-2.0$, passados 12 bilhões de anos.

a forma de uma linha da série de Balmer do Hidrogênio, usando o menor número de parâmetros livres possível (Clewley et al., 2002):

$$
S(x)=n-a \cdot \exp \left[-\left(\left|\lambda-\lambda_{0}\right| / b\right)^{c}\right]
$$

onde, $n, a, b$, e $c$ são parâmetros livres. O parâmetro $n$ se ajusta ao nível do contínuo $(\sim 1$ neste caso pois os espectros estão normalizados), $\lambda_{0}$ é o comprimento de onda do centro da linha e $a$ define o parâmetro de escala da profundidade da linha. Os parâmetros $b$ (define uma escala de largura) e $c$ (define uma escala de formato) são avaliados na análise do próximo método, chamado método de escala de forma e largura (Clewley et al., 2002), descrito na Subseção 3.1.3. 
Não há relação fundamental entre o parâmetro $a$ e os outros parâmetros do perfil de Sersic. Além disso, os valores do parâmetro $a$ são praticamente constantes (cada linha de Balmer possui um valor preferencial do parâmetro a). Portanto, eles são fixados de acordo com seus valores médios, que nesta amostra valem: $\left\langle\mathrm{a}_{\beta}\right\rangle=0.709,\left\langle\mathrm{a}_{\gamma}\right\rangle=0.694$, e $\left\langle\mathrm{a}_{\delta}\right\rangle=$ 0.769. Assim, é possível refinar ainda mais os demais parâmetros de Sersic, reajustando a função vista na Equação 3.1 com o valor $\langle a\rangle$ fixado para cada linha.

O método $\mathrm{f}_{m}$ vs $\mathrm{D}_{0.2}$ foi proposto pela primeira vez por Pier (1983). Ele compara $\mathrm{T}_{\text {eff }}$ e $\log (\mathrm{g})$ indiretamente, pois o parâmetro $\mathrm{f}_{m}$ é o menor fluxo da linha em relação ao contínuo, geralmente encontrado em seu centro, sendo portanto um parâmetro sensível à temperatura. O parâmetro $\mathrm{D}_{0.2}$ é simplesmente a largura da linha medida em um nível $20 \%$ abaixo do contínuo normalizado do espectro (ou a $80 \%$ de fluxo) (Beers et al., 1992; Sirko et al., 2004) e é, portanto, um indicador da gravidade superficial da estrela, como pôde ser exemplificado na Figura 2.5: quando o $\log (\mathrm{g})$ é maior, também será maior o valor de $\mathrm{D}_{0.2}$. Para calcular o valor de $\mathrm{D}_{0.2}$, deve-se subtrair as raízes da função inversa do perfil de Sersic, no nível de $80 \%$ do fluxo $(S(x)=0.8 n)$, como feito por Clewley et al. (2002). Isso resulta na seguinte relação:

$$
D_{0.2}=2 \cdot b \cdot\left[\log (n /(5 \cdot\langle a\rangle)]^{\frac{1}{c}} .\right.
$$

Adota-se aqui a linha $\mathrm{H}_{\delta}$ da série de Balmer para a comparação entre os parâmetros $\mathrm{f}_{\mathrm{m}}$ e $\mathrm{D}_{0.2}$ deste método, indicada por um símbolo $\delta$ nos parâmetros que ela fornece (ver Sirko et al., 2004, para mais detalhes). A Figura 3.2 mostra o comportamento do parâmetro $D_{0.2 \delta}$, em função de $\mathrm{f}_{\mathrm{m} \delta}$, para estrelas com magnitudes $g_{0}<18$. Nesta figura, as estrelas concentradas na região $\left(f_{\mathrm{m} \delta} ; D_{0.2 \delta}\right) \sim(0.26 ; 25)$ são candidatas a BHBs e o outro grupo com valores maiores de $D_{0.2 \delta}$ são candidatas a BSSs. Os outros objetos são estrelas de tipos espectrais mais frios.

Lembrando que, para comparar os resultados do método $f_{m}$ vs. $D_{0.2}$ com os valores obtidos pelo SSPP, os dados da Figura 3.2 foram coloridos de acordo com as restrições vistas na Figura 3.1. Assim, os pontos pretos representam as BSSs, os pontos vermelhos as BHBs e os demais quadrados cinzas são as estrelas mais frias. É nítido que as divisões adotadas em $\mathrm{f}_{\mathrm{m} \delta}$ e $\mathrm{D}_{0.2 \delta}$ possuem ótima concordância com a separação feita com os parâmetros estelares do SSPP, sendo que $\sim 92 \%$ das estrelas satisfazem corretamente ambas as restrições. 


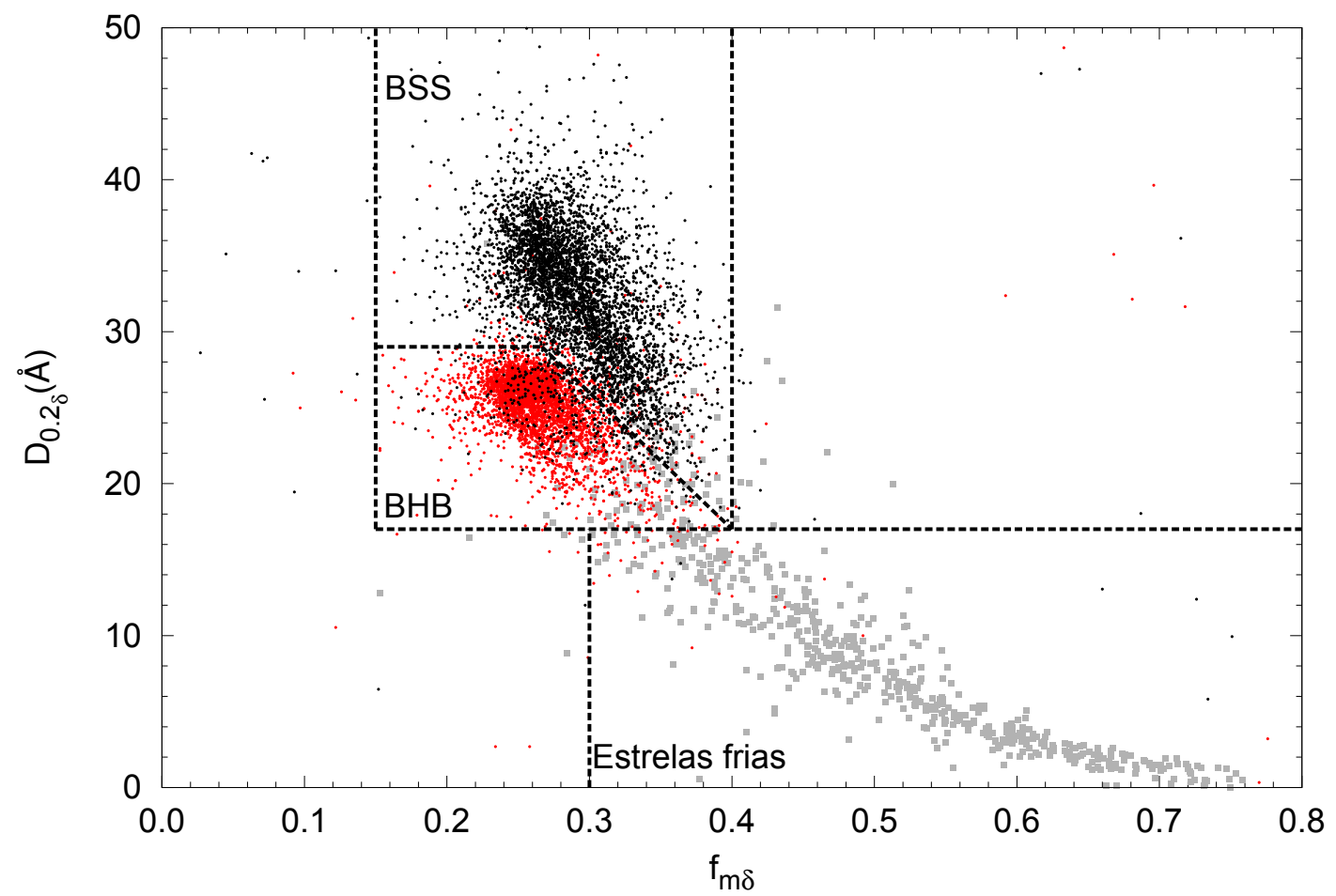

Figura 3.2: Comparação entre os parâmetros $\mathrm{f}_{\mathrm{m} \delta}$ vs. $\mathrm{D}_{0.2 \delta}$. Os pontos estão coloridos de acordo com as restrições feitas pelos parâmetros do SSPP, vistas na Figura 3.1. As distribuições de estrelas BHBs e BSSs exibem uma ligeira sobreposição, indo até um pouco além dos limites adotados (linhas tracejadas). Os limites visuais adotados para selecionar as estrelas BSSs são: (i) $0.15<\mathrm{f}_{\mathrm{m} \delta}<0.27, \mathrm{D}_{0.2 \delta}>29$; (ii) $0.27<\mathrm{f}_{\mathrm{m} \delta}<0.40, \mathrm{D}_{0.2 \delta}>-90 \cdot \mathrm{f}_{\mathrm{m} \delta}$ + 53. Da mesma forma, os critérios para selecionar estrelas BHBs são: (i) $0.15<\mathrm{f}_{\mathrm{m} \delta}<0.27$, $17<\mathrm{D}_{0.2 \delta}<29$; (ii) $0.27<\mathrm{f}_{\mathrm{m} \delta}<0.40,17<\mathrm{D}_{0.2 \delta}<-90 \cdot \mathrm{f}_{\mathrm{m} \delta}+53$.

\subsubsection{O método de escala de forma e largura: $c$ vs. $b$}

O método de escala de forma e largura é um método adicional para separar BHBs e BSSs. Ele foi descrito pela primeira vez por Clewley et al. (2002) e usa os parâmetros $c$ e $b$, da função de Sersic, como critério de separação e seleção dos objetos. Mais uma vez, é importante ressaltar que os valores de $c$ vs. $b$ só podem ser comparados neste método se, primeiramente, forem fixados os valores dos parâmetros a para cada linha.

Seguindo os trabalhos de Deason et al. (2011); Santucci et al. (2015a), adotou-se a média dos parâmetros $c$ e $b$ para três linhas da série de Balmer: $\mathrm{H}_{\beta}, \mathrm{H}_{\gamma}$ e $\mathrm{H}_{\delta}$, tornando a separação entre BHBs e BSSs ainda mais evidente. O resultado é visto na Figura 3.3, onde os pontos $c_{\beta \gamma \delta}$ e $b_{\beta \gamma \delta}$ também estão coloridos de acordo com os limites vistos na Figura 3.1.

Como pode ser visto na Figura 3.3, há uma excelente concordância entre os grupos 
separados por este método com os limites adotados através dos parâmetros do SSPP ( 95\% das estrelas satisfazem corretamente ambas as restrições). Nota-se também que o método de separação através dos parâmetros $c$ e $b$ pode, a princípio, ser usado sozinho para separar BHBs e BSSs (Preston, 2014), pois através dele também é possível ver uma clara separação entre estes tipos estelares. O limite entre os grupos de estrelas BSSs e BHBs está definido por um polinômio de quarto grau, o qual possui os seguintes parâmetros:

$$
\begin{array}{r}
b_{\beta \gamma \delta}=+9.20-46.32 \cdot\left(c_{\beta \gamma \delta}\right)+82.24 \cdot\left(c_{\beta \gamma \delta}\right)^{2} \\
-23.36 \cdot\left(c_{\beta \gamma \delta}\right)^{3}-10.82 \cdot\left(c_{\beta \gamma \delta}\right)^{4} .
\end{array}
$$

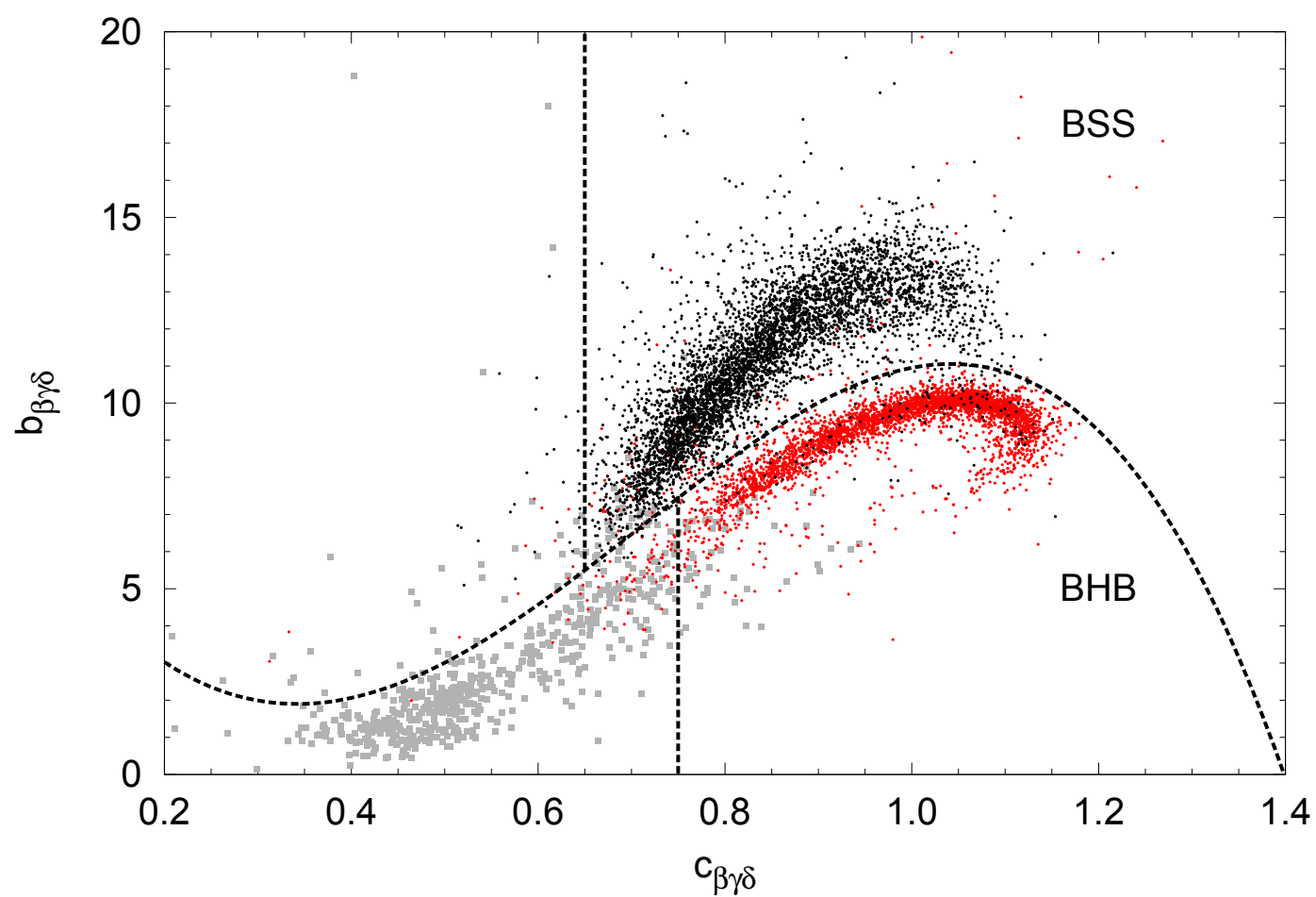

Figura 3.3: Comparação entre os parâmetros $c_{\beta \gamma \delta}$ e $b_{\beta \gamma \delta}$ da função de Sersic, coloridos de acordo com as restrições feitas na Figura 3.1. Assim como para o método $f_{\mathrm{m}}$ vs. $D_{0.2}$, novamente os limites fornecidos pelo SSPP para separar BHBs e BSSs concordam muito bem com o método de escala de forma e largura ( $~ 95 \%$ das estrelas satisfazem ambas as restrições corretamente). A linha limitante entre os dois grupos neste método é definida por uma função de quarto grau, apresentada na Equação 3.3.

Portanto, as BSSs e BHBs com magnitudes $g_{0}<18$ consideradas nas amostras finais foram aquelas que passaram, satisfatoriamente, pelas restrições impostas pelos três métodos de seleção. 
O erro médio da temperatura efetiva fornecido pelo SSPP é aproximadamente 150K (Lee et al., 2008), um pouco maior do que o erro médio encontrado nos parâmetros destas amostras $(\sim 130 \mathrm{~K})$. Portanto, para evitar ainda mais as contaminações de objetos mais frios, considerou-se um limite inferior de temperatura $\left(\mathrm{T}_{\text {eff }} \geq 7650 \mathrm{~K}\right)$, reduzindo as amostras a 4838 BSSs e 4380 BHBs.

\subsection{Análise da amostra com $18 \leq g_{0}<21$}

Os métodos tradicionais descritos anteriormente ( $f_{\mathrm{m}}$ vs. $D_{0.2}$ e $c$ vs. $\left.b\right)$ não conseguem separar satisfatoriamente as estrelas da amostra com $g_{0} \geq 18$, pois estes objetos possuem baixas razões S/R em seus espectros (Clewley et al., 2002; Sirko et al., 2004). São cerca de 5 mil estrelas que deixariam de ser avaliadas pelos métodos tradicionais, mas foram avaliadas novamente segundo os parâmetros do SSPP, com diferentes limites em $\log (\mathrm{g})$, como mostra o painel inferior da Figura 3.4.

A distribuição dos valores de $\log (\mathrm{g})$ da amostra com $g_{0} \geq 18$ tem um pico localizado em $\sim 3.57$, com alta dispersão $(\sigma=0.33$ dex $)$, o qual representa as BHBs. Por causa desta alta dispersão, a região de superposição entre os picos é muito maior que a da amostra mais brilhante (veja a Figura 3.4). Esta dispensão é tão maior que, se considerado o mesmo limite de $3 \sigma$ para separar BHBs e BSSs, quase todas as BSSs seriam excluídas, pois estão centradas em $\log (\mathrm{g})=4.27$, com dispensão $\sigma=0.20$ dex.

As distribuições de $\log (\mathrm{g})$ de todos os painéis da Figura 3.4 podem ser descritas por funções gaussianas. Então pode-se atribuir a elas uma probabilidade de encontrar BHBs e BSSs em intervalos de $\log (\mathrm{g})$, usando os valores centrais de seus picos e suas dispersões como intervalos de probabilidade. Portanto, considera-se como limite seguro para encontrar

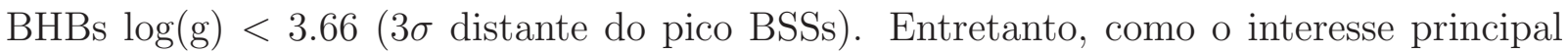
deste trabalho é selecionar as BSSs, é adotado um critério mais flexível para sua seleção, mesmo que isso forneça uma contaminação maior de BHBs nessa amostra. Este limite foi estabelecido para $\log (\mathrm{g})>3.92$, o qual é $1 \sigma$ distante do pico das estrelas BHBs, resultando em uma probabilidade de $\sim 88 \%$ de encontrarmos uma BSS neste limite.

Combinando as amostras, obtém-se um total de 8001 candidatas a estrelas BSSs, com uma probabilidade média de $\sim 95 \%$, e também 4796 candidatas a BHBs, com uma probabilidade média de $~ 98 \%$. 


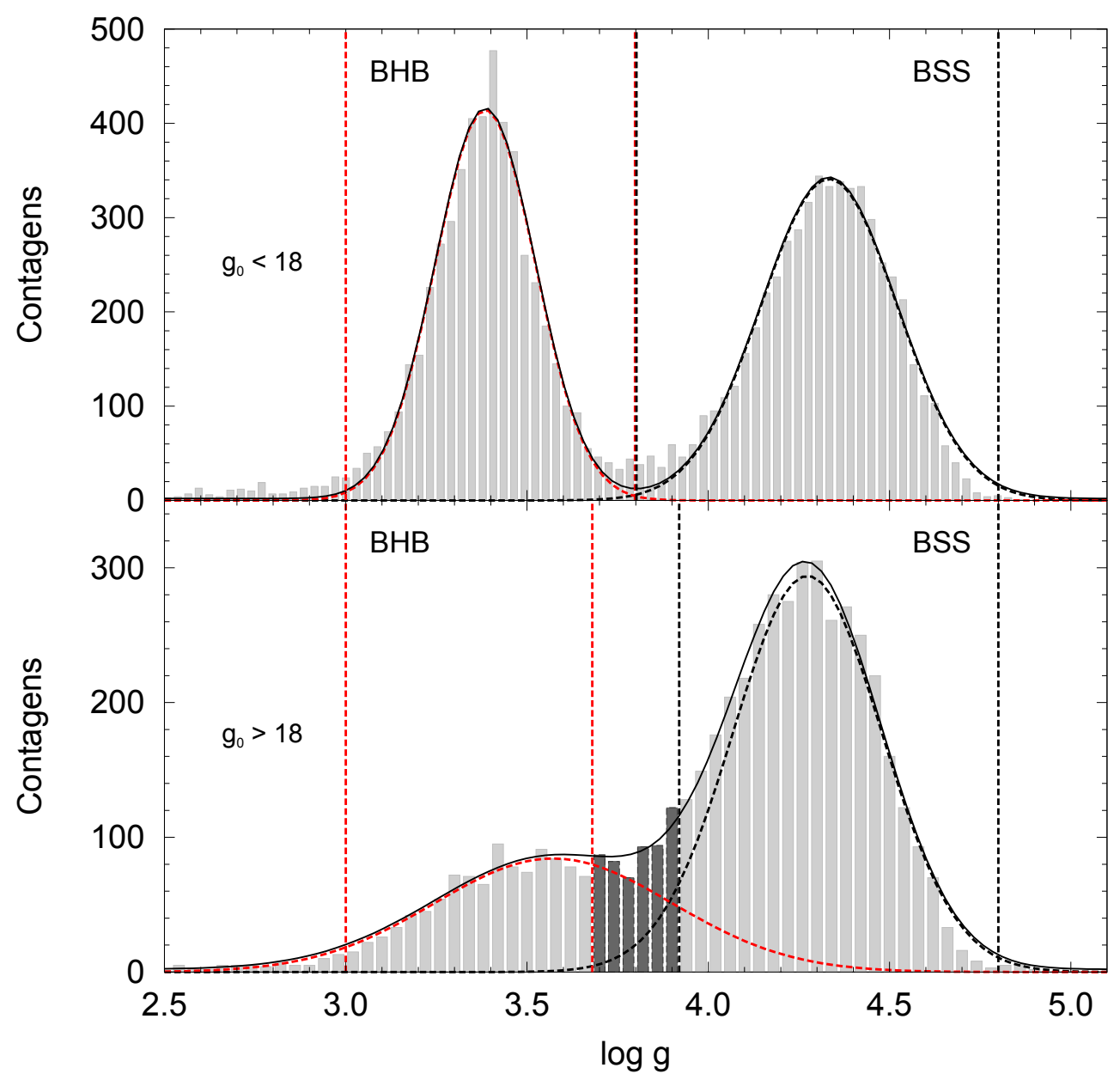

Figura 3.4: Painel Superior: Distribuição de $\log (\mathrm{g})$ para estrelas com magnitudes $g_{0}<18$. O pico localizado em $\log (\mathrm{g})=3.38(\sigma=0.14 \mathrm{dex})$ representa a distribuição de BHBs, já o pico localizado em $\log (\mathrm{g})=4.34(\sigma=0.18 \mathrm{dex})$ mostra as BSSs. Painel inferior: Distribuição de $\log (\mathrm{g})$ para estrelas com magnitudes $g_{0}>18$. O pico centrado em $\log (\mathrm{g})=3.57(\sigma=0.33$ dex) representa a distribuição de BHBs e o pico em $\log (\mathrm{g})=4.27(\sigma=0.20 \mathrm{dex})$ representa as BSSs. Esta figura também mostra que a fração de estrelas BHBs cai rapidamente se comparada as BSSs para os objetos mais fracos da amostra.

\subsection{Seleção fotométrica direta de BHBs e BSSs}

Utilizando as amostras selecionadas pelos métodos espectroscópicos, foi possível avaliar novamente a região do diagrama cor-cor, onde BHBs e BSSs foram inicialmente selecionadas, da mesma maneira que fizeram Deason et al. (2011); Carollo et al. (2016).

A Figura 3.5 mostra a região $(g-r)_{0}$ vs. $(u-g)_{0}$ onde BHBs (círculos vermelhos) e BSSs (círculos pretos) resultantes da seleção espectroscópica estão localizadas. Nota-se que mesmo existindo uma intensa superposição entre os dois tipos estelares, ainda podem ser vistas regiões preferencialmente vermelhas, que possuem muitas BHBs, ou preferenci- 


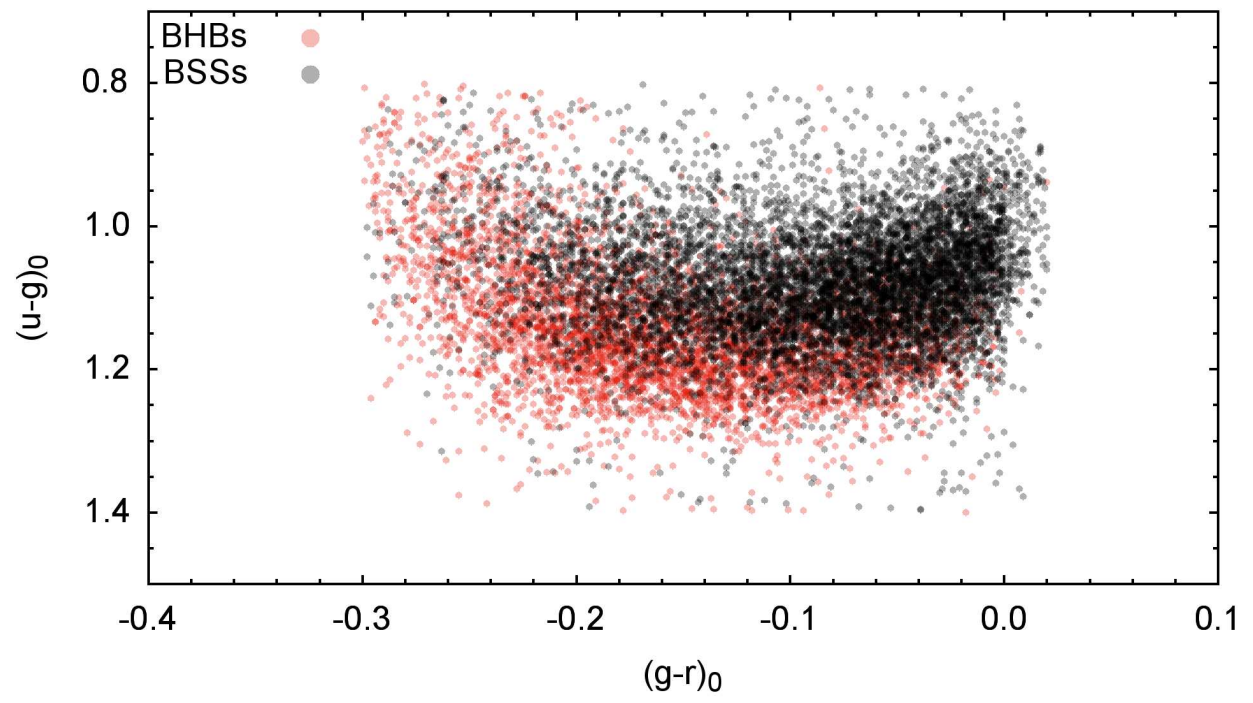

Figura 3.5: Região do diagrama cor-cor onde estão localizadas as BHBs (círculos vermelhos) e as BSSs (círculos pretos) selecionadas através das restrições espectroscópicas. Nota-se que a superposição dos dois grupos é grande, mas existem regiões do diagrama onde se encontram preferencialmente BHBs ou BSSs.

almente pretas, onde as BSSs dominam.

Buscando estabelecer um limite para que BHBs e BSSs possam ser identificadas fotometricamente com boa probabilidade, foram avaliadas as frequências dos dois grupos em pequenas áreas do diagrama cor-cor. Esta "grade de contagens" foi limitada à região $0.8<(u-g)_{0}<1.4$ e $-0.30<(g-r)_{0}<0.0$, dividida em intervalos de 0.005 dex em $(g-r)_{0}$ e 0.01 dex em $(u-g)_{0}$. O resultado das proporções de BHBs e BSSs nesta região é visto na Figura 3.6. Nesta figura, cada pequeno quadrado colorido possui ao menos 4 estrelas. Os quadrados estão coloridos de acordo com a proporção de estrelas encontradas, segundo a escala vista do lado direito da figura. Através dela, é possível distinguir a distribuição da proporção de cada tipo de estrela do diagrama cor-cor.

Ainda na Figura 3.6, são vistas duas curvas que limitam BHBs e BSSs. Elas foram ajustadas com a intenção de estabelecer o limite onde cada tipo estelar tenha $80 \%$ ou mais de frequência média. Para isso, dois ajustes de segundo grau foram aplicados sobre os quadrados que possuem entre $75 \%$ e $85 \%$ de proporção de cada tipo estelar. Os resultados destes ajustes, assim como os limites fotométricos considerados para BHBs e BSSs são apresentados a seguir: 


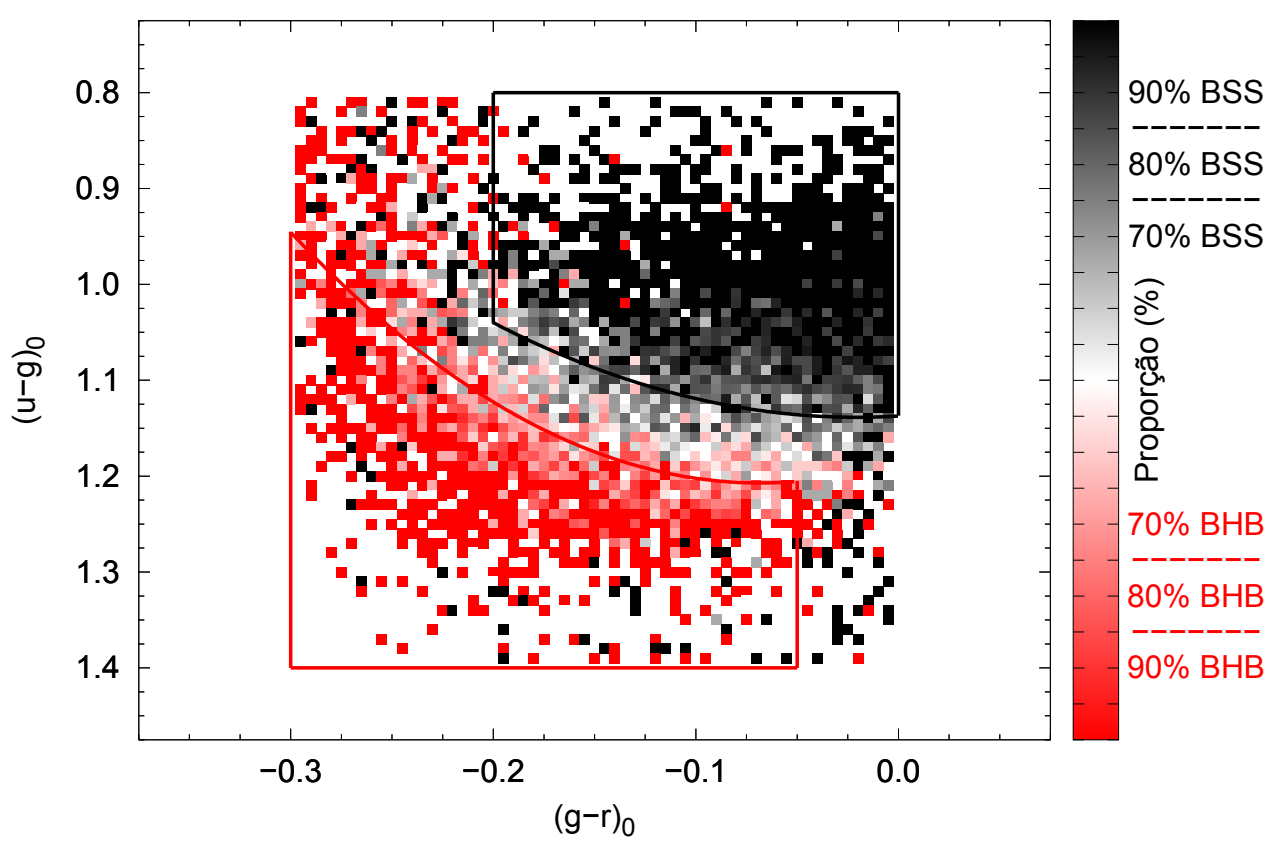

Figura 3.6: Proporção de BHBs ou BSSs em pequenos intervalos do diagrama cor-cor. Cada quadrado contém ao menos 4 estrelas, e está colorido de acordo com a escala vista a direita da figura, quanto mais vermelho o quadrado, maior é a proporção de BHBs e, da mesma maneira, quanto mais preto, maior a frequência de BSSs. Os limites desenhados para isolar BHBs e BSSs foram resultados de ajustes de segundo grau (ver Equações 3.4 e 3.5, para limites de BHBs e BSSs, respectivamente) usando os quadrados que possuem entre $75 \% \mathrm{e}$ $85 \%$ de proporção de cada tipo estelar, como destacam as linhas tracejadas na escala de cor.

BHBs :

$$
-0.3<(g-r)_{0}<-0.05
$$

$$
1.184-0.667 \cdot(g-r)_{0}-4.876 \cdot(g-r)_{0}^{2}<(u-g)_{0}<1.40 .
$$

BSSs :

$$
-0.2<(g-r)_{0}<0.0
$$

$$
0.8<(u-g)_{0}<1.137-0.123 \cdot(g-r)_{0}-3.050 \cdot(g-r)_{0}^{2} .
$$

Para testar a contaminação de cada tipo estelar dentro dos limites definidos pela seleção fotométrica, vinculou-se a amostra espectroscópica a eles. Admitindo que a amostra espectroscópica inicial, fornecida pela base de dados do SDSS, tenha a mesma proporção de objetos que uma seleção puramente fotométrica na mesma região cor-cor, os limites descritos pelas Equações 3.4 e 3.5 fornecem as seguintes proporções:

- Na região fotométrica BHB (limites 3.4): 75.3\% de BHBs, 19.5\% de BSSs e $5.2 \%$ de estrelas mais frias. 
- Na região fotométrica BSS (limites 3.5): 11.4\% de BHBs, $80.5 \%$ de BSSs e $8.1 \%$ de estrelas mais frias.

Utilizando novamente a base dados do SDSS, desta vez considerando a última (décima terceira) fase de disponibilização de dados (DR13), foi feita uma nova seleção fotométrica com os seguintes critérios:

- (i): alvos únicos com fotometria limpa, ou seja, pontuais e não extensos;

- (ii): $|b|>10^{\circ}$, para diminuir a contaminação de objetos do disco;

- (iii): erro da fotometria na banda $u_{0}$ menor que $0.5 \%$. Essa banda é a chave para separação fotométrica, já que a gravidade superficial é medida usando as linhas de Balmer e esse filtro abrange o maior número delas;

- (iv): $-0.3<(g-r)_{0}<0.0$ e $0.8<(u-g)_{0}<1.4$.

Os dados conseguidos com estas restrições foram submetidos às classificações fotométricas 3.4 e 3.5, como visto na Figura 3.7. Ao final foram obtidas 39372 candidatas a BSSs (proporção de $80.5 \%$ ) e 27568 BHBs (proporção de $75.3 \%$ ).

Essas amostras foram reunidas para comparações em análises futuras. Além disso, os critérios descritos para suas seleções servem de referência para outros trabalhos que envolvam esses tipos estelares, baseados somente em suas propriedades fotométricas, como fizeram Deason et al. (2011) e Carollo et al. (2016). 


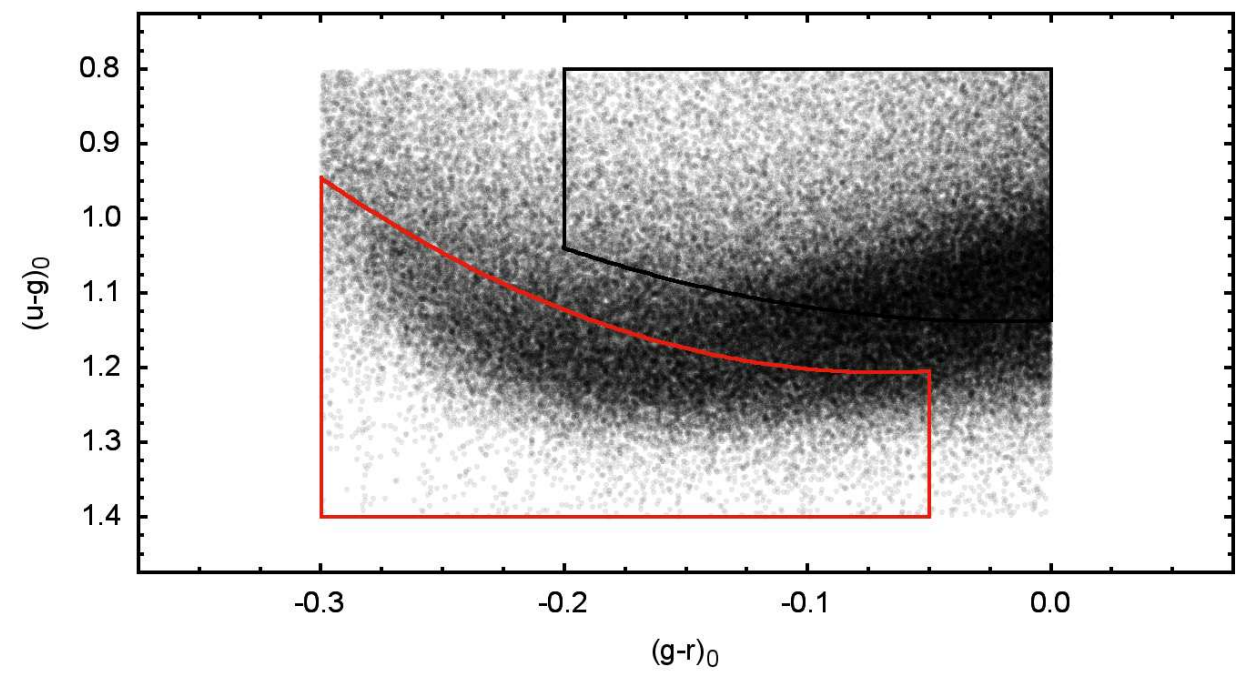

Figura 3.7: Seleção de dados fotométrica feita usando o SDSS (DR13). Os 100 mil objetos presentes na figura satisfizeram as seguintes restrições: (i) alvos únicos, (ii) $|b|>10^{\circ}$, (iii) erro na banda $u_{0}$ menor que $0.5 \%$, (iv) $-0.3<(g-r)_{0}<0.0$ e $0.8<(u-g)_{0}<1.4$. As restrições de BHBs e BSSs (3.4 e 3.5, respectivamente) foram aplicadas à eles. 39372 candidatas a BSSs são vistas dentro dos limites das linhas pretas (proporção de 80.5\%) e 27568 BHBs estão presentes dentro dos limites das linhas vermelhas (proporção de 75.3\%). 
Capítulo 4

\section{Magnitudes absolutas, distâncias e cores}

Muitos estudos fornecem (ou adotam) calibrações para magnitudes absolutas de BHBs e BSSs em sistemas fotométricos diferentes do SDSS (Kinman et al., 1994; Preston et al., 1994; Preston e Sneden, 2000; Carney et al., 2001, 2005). Portanto, para que seja possível comparar as calibrações de distâncias fornecidas por diferentes trabalhos, foram utilizadas as transformações de cores e magnitudes descritas por Zhao e Newberg (2006). Essas calibrações foram derivadas de estrelas do SDSS com fotometria já conhecida nos filtros $U B V R I$, incluindo BHBs e BSSs. São elas:

$$
\mathrm{V}_{0}=g-0.561 \cdot(g-r)-0.004
$$

e

$$
(B-V)_{0}=0.916 \cdot(g-r)+0.187 .
$$

Segundo Beers et al. (2012), o intervalo de cor válido para aplicar estas transformações é $-0.5<(g-r)_{0}<1.0$, consistente com os índices de cor das estrelas usadas neste estudo.

\subsection{Magnitudes absolutas das estrelas azuis tardias}

Baseando-se na magnitude da banda $V$, é possível estimar a magnitude absoluta de BSSs usando a relação descrita por Kinman et al. (1994) abaixo:

$$
\mathrm{M}_{\mathrm{V}_{\mathrm{BSS}}}=1.32+4.05 \cdot(B-V)_{0}-0.45 \cdot[\mathrm{Fe} / \mathrm{H}] .
$$


Essa calibração foi concebida valendo-se de BSSs observadas em aglomerados globulares, reunidas nos estudos de Sarajedini $(1993,1994)$. Utilizando valores típicos de cores e metalicidades das BSSs presentes na amostra deste trabalho (veja as Figuras 4.4 e 4.5, respectivamente), verificou-se que as BSSs de campo do SDSS possuem magnitudes absolutas médias $\mathrm{M}_{\mathrm{V}} \approx 2.39 \pm 0.39$. Esse valor está em concordância com os valores observados para as BSSs em aglomerados globulares e galáxias anãs (Sarajedini, 1993; Momany et al., 2007), como pode ser visto também na Figura 1.4.

Deason et al. (2011) também publicaram uma calibração de magnitudes absolutas para BSSs, mas usaram o sistema fotométrico do SDSS e estrelas presentes na chamada "faixa" 82 (Stripe 82). Esta região tem sido intensamente observada pelo SDSS, principalmente para identificar estrelas variáveis e, portanto, possui uma fotometria considerada muito confiável (erros menores que 0.01 dex: Ivezić et al., 2007).

A faixa 82 abrange uma área do céu que contém parte da Corrente de Sagitário. Assim, Deason et al. (2011) combinaram resultados de magnitudes aparentes e distâncias de estrelas RR-Lyrae na corrente, publicados por Watkins et al. (2009), para propor distâncias até as BSSs presentes nessa região, através da seguinte relação:

$$
\mathrm{M}_{\mathrm{g}_{\mathrm{BSS}}}=3.108+5.495 \cdot(g-r)_{0} .
$$

Esta calibração fornece um valor médio de $\mathrm{M}_{\mathrm{g}}=2.62 \pm 0.39$ para magnitudes absolutas das BSSs. Este valor, quando convertido em $M_{V}$ através da calibração 4.1, fornece $\mathrm{M}_{\mathrm{V}}=$ $2.66 \pm 0.39$ (adotando o índice de cor mediano $\left.(g-r)_{0}=-0.075\right)$. Ou seja, estas magnitudes absolutas são 11\% maiores que as fornecidas pela calibração 4.1, sendo compatíveis no intervalo de $1 \sigma$.

Nota-se então que, ao contrário de Kinman et al. (1994), Deason et al. (2011) não encontraram dependência da magnitude absoluta com a metalicidade para sua calibração. Muito provavelmente isso ocorreu porque as estrelas da corrente de Sagitário não apresentaram amplas variações de abundâncias na região adotada em seus estudos. A Figura 4.1 mostra a comparação das distâncias obtidas com as duas calibrações de magnitudes absolutas. Pode-se notar que as distâncias são sistematicamente maiores para a calibração usando aglomerados globulares $(\sim 10 \%)$, mas ambas concordam em $3 \sigma$. As duas calibrações são consideradas neste trabalho, principalmente para avaliar os erros nas análises futuras. Entretanto, a calibração que usa metalicidade é usada preferencialmente até a 
análise final, enquanto a calibração que usa somente cores é útil para estimar distâncias da amostra fotométrica.

\subsection{Magnitudes absolutas de estrelas azuis no ramo horizontal}

Da mesma maneira que foram avaliadas as magnitudes absolutas das BSSs, também foram comparadas duas calibrações de magnitudes absolutas para BHBs: (1) Deason et al. (2011) derivaram uma relação de magnitude absoluta $\left(\mathrm{M}_{\mathrm{g}}\right)$ usando dados fotométricos de 10 aglomerados globulares do estudo de An et al. (2008). Essa calibração é vista na Equação 4.5 e usa somente os índices de cor de BHBs. O intervalo de magnitudes $\left(\mathrm{M}_{\mathrm{g}}\right)$ para BHBs em aglomerados globulares, avaliado por Deason et al. (2011), é $0.45<\mathrm{M}_{\mathrm{g}}<0.65$, e suas metalicidades ocupam o intervalo entre -2.3 e -1.3 . Os autores foram enfáticos ao afirmar que nenhuma dependência significativa de $[\mathrm{Fe} / \mathrm{H}]$ foi verificada em $\mathrm{M}_{\mathrm{g}}$; (2) Fermani e Schönrich (2013) propuseram uma calibração mais complexa para magnitudes absolutas de BHBs, dependente de cores e metalicidades, argumentando ferozmente que a calibração proposta por Deason et al. (2011) fornece magnitudes absolutas sistematicamente menos brilhantes para estrelas mais pobres em metais e, da mesma maneira, mais brilhantes para estrelas com metalicidades mais altas. A calibração é vista na Equação 4.6. De acordo com Fermani e Schönrich (2013), a ausência de dependência na metalicidade relatada por Deason et al. (2011) ocorreu porque: (i) os autores adotaram incertezas erradas em seus módulos de distância; (ii) foram utilizados mapas para correção de avermelhamento pouco precisos; (iii) não consideraram que BHBs de campo podem ser sistematicamente diferentes de BHBs em aglomerados globulares por razões ainda desconhecidas. As calibrações de magnitude absoluta para BHBs de Deason et al. (2011) e Fermani e Schönrich (2013) são vistas, respectivamente, nas equações 4.5 e 4.6 a seguir:

$$
\begin{array}{r}
\mathrm{M}_{\mathrm{gD}}=0.434-0.169 \cdot(g-r)+2.319 \cdot(g-r)^{2} \\
+20.449 \cdot(g-r)^{3}+94.517 \cdot(g-r)^{4}
\end{array}
$$

$\mathrm{e}$

$$
\mathrm{M}_{\mathrm{gFS}}=0.0075 \cdot e^{-14.0 \cdot(g-r)}+0.04 \cdot([\mathrm{Fe} / \mathrm{H}]+3.5)^{2}+0.25
$$


Apesar de todos os argumentos usados por Fermani e Schönrich (2013) a favor de sua calibração, ao se comparar os resultados de magnitudes de ambos autores (veja a Figura 4.2), não foi verificada nenhuma diferença significativa que justificasse os argumentos de Fermani e Schönrich (2013), tampouco o uso de sua calibração de magnitudes absolutas, que é desnecessariamente mais complexa e fornece os mesmos resultados $\left(\mathrm{M}_{\mathrm{gFS}}=0.49 \pm 0.27\right.$ e $\left.\mathrm{M}_{\mathrm{gD}}=0.54 \pm 0.16\right)$.

\subsection{Distâncias}

Conhecer a frequência de BSSs no halo galáctico é importante para comparar quão comuns elas são em diversos ambientes (Momany et al., 2007). Ao contrário do que afirmaram Newberg e Carlin (2016), as BSSs não são estrelas raras no halo galáctico. Esse fato pôde ser verificado, mesmo que superficialmente, com os números de BSSs (8001) e BHBs (4796) obtidos nas amostras espectroscópicas.

Para determinar a frequência de BSSs em um ambiente é necessário comparar o seu número de ocorrências com outro tipo estelar. Neste caso, as estrelas BHBs são normalmente usadas nas comparações (Mapelli et al., 2004). Portanto, para avaliar a frequência de estrelas azuis tardias no halo, é necessário fazer a razão entre BSSs e BHBs presentes nesse meio $\left(\mathrm{F}_{\mathrm{BSS} / \mathrm{BHB}}\right)$. Para tanto, é necessário obter as distâncias até essas estrelas. Através das magnitudes absolutas estimadas anteriormente, as distâncias até BHBs e BSSs podem ser calculadas usando a seguintes relações:

$$
D=10^{[(\mathrm{m}-\mathrm{M}) / 5-2]},
$$

e

$$
r^{2}=X^{2}+Y^{2}+Z^{2}=\left(r_{\odot}-D \cos b \cos l\right)^{2}+(D \cos b \sin l)^{2}+(D \sin b)^{2}
$$

onde $b$ e $l$ são, respectivamente, latitude e longitude celestes galácticas, $r_{\odot}$ é a distância do Sol ao centro galáctico, cujo valor adotado foi $r_{\odot}=(8.5,0,0) \mathrm{kpc}$, consistente com o trabalho recente de Carollo et al. (2010).

A Figura 4.1 compara as distâncias heliocêntricas das BSSs obtidas usando as calibrações de Deason et al. (2011) ( $\mathrm{D}_{\mathrm{g}}$ ) e Kinman et al. (1994) ( $\left.\mathrm{D}_{\mathrm{V}}\right)$. As distâncias $\mathrm{D}_{\mathrm{V}}$ são, 
em média, $\sim 10 \%$ maiores que as distâncias $\mathrm{D}_{\mathrm{g}}$, mas ambas são compatíveis em $3 \sigma$. O painel (b) da Figura 4.1 mostra que o espalhamento entre as calibrações aumenta consideravelmente para distâncias maiores que 15 kpc. Já o painel (c) mostra que, em média, as distâncias estimadas com a calibração que usa a metalicidade são 1.08 kpc maiores e a dispersão entre elas é de $1.15 \mathrm{kpc}$.

A Figura 4.2 compara as distâncias heliocêntricas das BHBs, obtidas usando as calibrações $4.5\left(\mathrm{D}_{\mathrm{gD}}\right)$ e $4.6\left(\mathrm{D}_{\mathrm{gF}}\right)$. As distâncias $\mathrm{D}_{\mathrm{gF}}$ são, em média, somente $\sim 2.5 \%$ maiores que as distâncias $\mathrm{D}_{\mathrm{gD}}$, o que fica absolutamente dentro das margens de erro de ambas. A partir dos painéis (b) e (c) da Figura 4.2, é possível ver que o espalhamento entre as calibrações fica maior para distâncias maiores que $30 \mathrm{kpc}$, mas não há diferenças sistemáticas significativas entre ambas. O deslocamento entre as duas distribuições é de $0.35 \mathrm{kpc}$, com desvio padrão de $0.40 \mathrm{kpc}$.

\subsubsection{Frequência média de BSSs no halo e suas implicações}

Uma análise detalhada sobre as frequências de BSSs e BHBs no halo pode ser vista no trabalho de Santucci et al. (2015a). Nesse estudo, os autores também fazem comparações detalhadas entre os diferentes métodos adotados para calibrar as distâncias até ambos os tipos estelares, mostrando que os resultados obtidos para $\mathrm{F}_{\mathrm{BSS} / \mathrm{BHB}}$ não dependem das calibrações de distâncias adotadas.

Entretanto, diferentemente do critério adotado por Santucci et al. (2015a), foi definido aqui um critério mais simples para avaliar a frequência média $\mathrm{F}_{\mathrm{BSS} / \mathrm{BHB}}$ no halo, pois essa fração não pode ser avaliada em qualquer intervalo de distância, devido às distribuições de BSSs, que estão preferencialmente mais próximas, e BHBs, que estão preferencialmente mais distantes.

A divergência nas distribuições de distâncias pode ser vista na Figura 4.3, onde as BSSs são encontradas em grande número logo a poucos kpc de distância do Sol, enquanto que as BHBs só são vistas a partir de 5 kpc de distância. Essas diferenças ocorrem por causa de dois fatores: o limite de magnitudes do mapeamento do SDSS $(\sim 13<\mathrm{g}<\sim 22)$ e o fato das BHBs serem mais luminosas que as BSSs, cerca de $2.01 \pm 0.16$ magnitudes mais brilhantes para as amostras espectroscópicas deste trabalho.

Através dessa diferença de magnitudes absolutas $\left(\mathrm{M}_{\mathrm{BHB}}-\mathrm{M}_{\mathrm{BSS}}=-2.01\right)$, pode-se dizer que a luminosidade média de uma BSS da amostra espectroscópica vale aproximadamente 

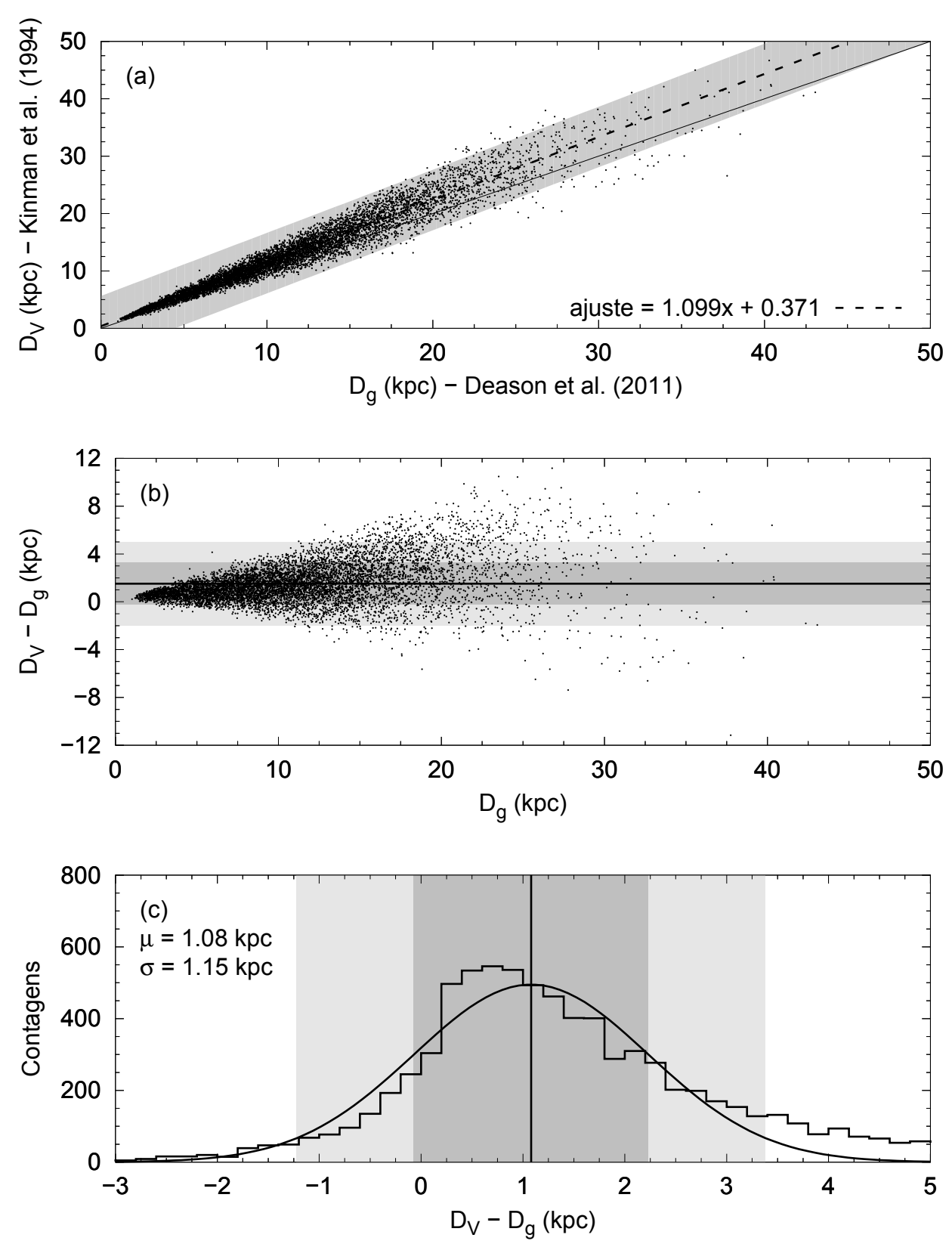

Figura 4.1: Painel (a): Comparação entre as distâncias estimadas com as calibrações de Deason et al. (2011) e Kinman et al. (1994) para BSSs. A linha sólida representa o valor onde $\mathrm{D}_{\mathrm{V}}=\mathrm{D}_{\mathrm{g}}$. A linha tracejada é o ajuste linear aplicado aos dados e a região com a sombra cinza representa o limite de $\pm 3 \sigma$ do ajuste. Os painéis (b) e (c) mostram, respectivamente, os resíduos da distribuição e sua dispersão, representados por um ajuste gaussiano. A região cinza escura indica o limite em $1 \sigma(1.15)$ do valor médio $(\sim 1.08 \mathrm{kpc})$ da distribuição. A região cinza mais clara é o limite em $2 \sigma$ da média.

16\% da luminosidade média de uma BHB: $-2.01=-2.5 \log \left(\mathrm{L}_{\mathrm{BHB}} / \mathrm{L}_{\mathrm{BSS}}\right)$. Portanto, para que ambas sejam vistas com a mesma magnitude aparente (por exemplo, $g_{0}=13$, que é o limite superior de brilho do SDSS), a BSS deve estar muito mais próxima que a BHB. 

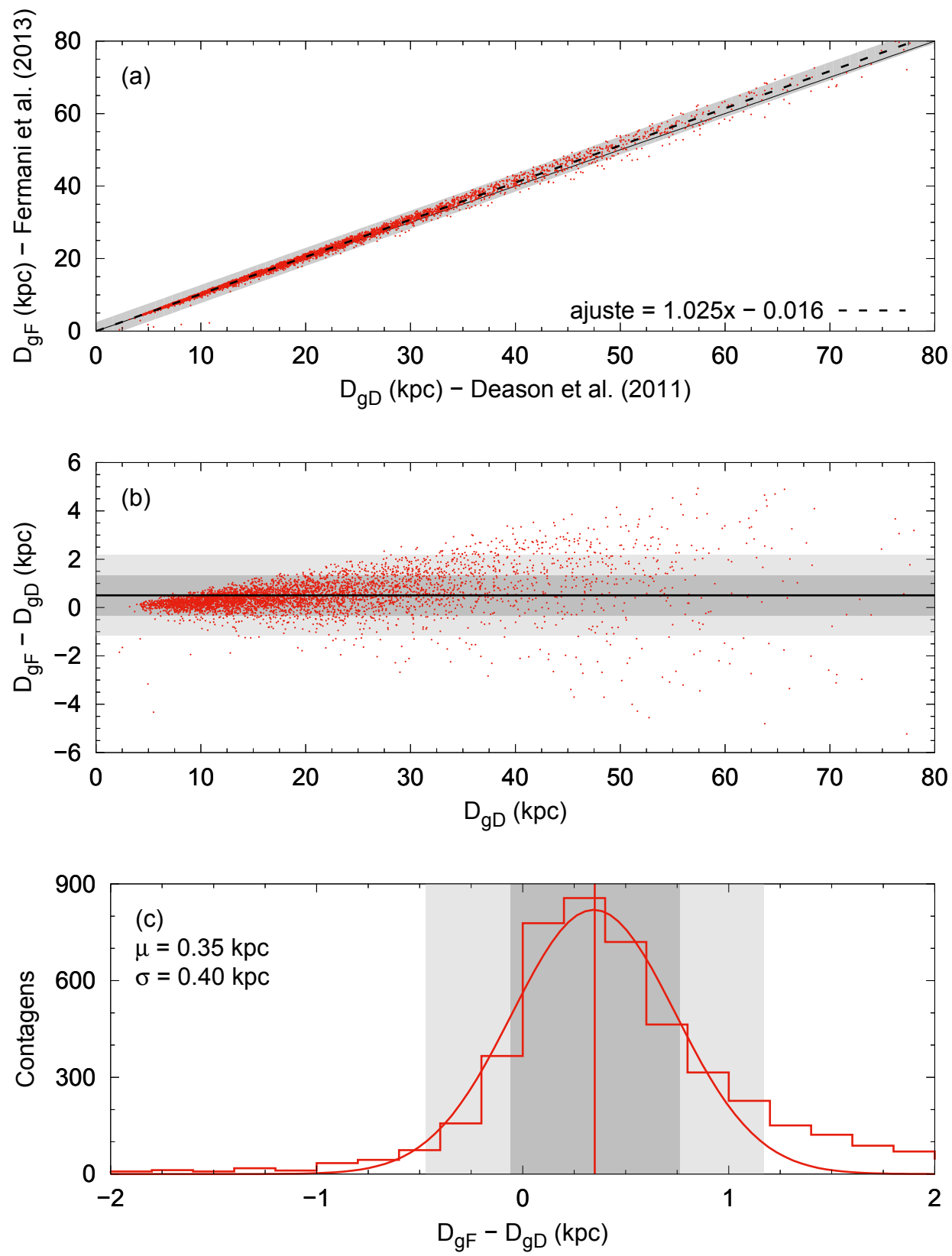

Figura 4.2: Painel (a): Comparação entre as distâncias estimadas com as calibrações de Deason et al. (2011) e Fermani e Schönrich (2013) para BHBs. A linha sólida (preta) representa o valor onde $\mathrm{D}_{\mathrm{gF}}=\mathrm{D}_{\mathrm{gD}}$. A linha tracejada é o ajuste linear aplicado aos dados e a região com a sombra cinza representa o limite de $\pm 3 \sigma$ do ajuste. Os painéis (b) e (c) mostram, respectivamente, os resíduos da distribuição e sua dispersão, representados por um ajuste gaussiano. A região cinza escura indica o limite em $1 \sigma(0.4)$ do valor médio $(\sim 0.35 \mathrm{kpc})$ da distribuição. A região cinza mais clara é o limite em $2 \sigma$ da média.

Desta maneira, a razão $\mathrm{F}_{\mathrm{BSS} / \mathrm{BHB}}$ no halo foi avaliada no intervalo de distâncias onde as contagens de ambas estrelas se mostram constantes, preferencialmente onde também possuam o maior número de objetos. Esse intervalo ocorre para distâncias heliocêntricas entre 


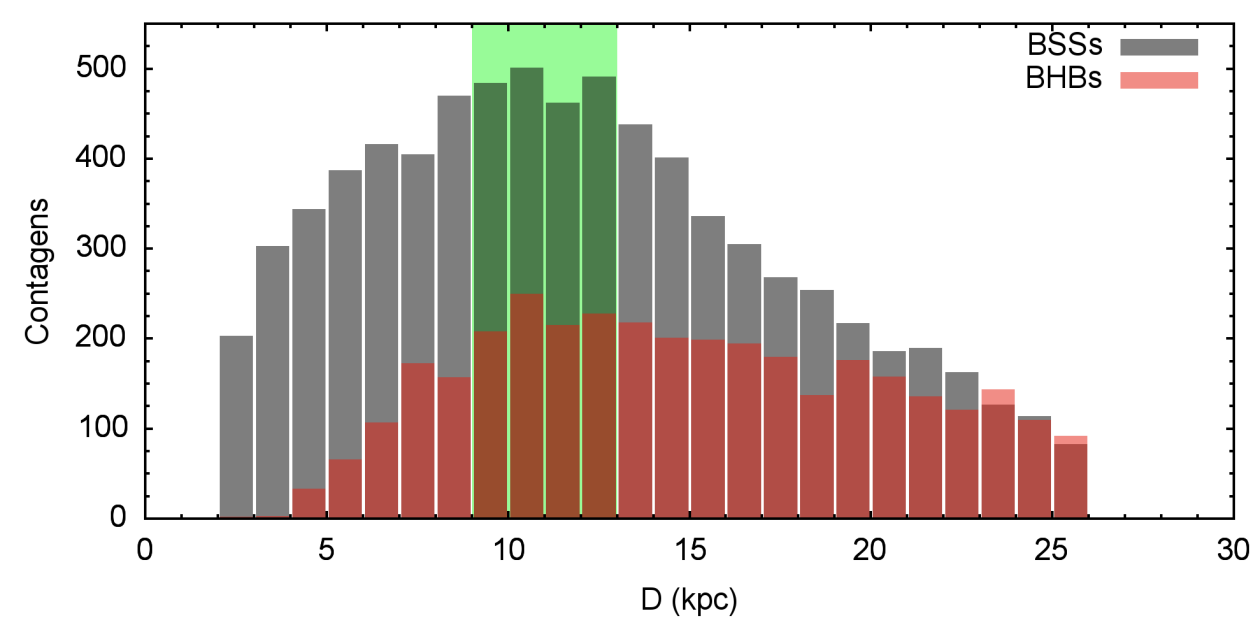

Figura 4.3: Distibruição de distâncias heliocêntricas de BSSs, vistas em cinza, usando a cabibração de Kinman et al. (1994) (Equação 4.3) e de BHBs, em vermelho, usando a calibração de Deason et al. (2011) (Equação 4.5). Para avaliar a frequência $\mathrm{F}_{\mathrm{BSS} / \mathrm{BHB}}$ no halo, foi considerado o intervalo de distâncias onde as contagens de ambas estrelas são as maiores possíveis, destacado pela área em verde. $\mathrm{O}$ valor médio para $\mathrm{F}_{\mathrm{BSS} / \mathrm{BHB}}$ obtido nesta região é igual a $2.15 \pm 0.13$, praticamente idêntico ao valor da frequência $F_{B S S / B H B}$ encontrada em aglomerados abertos e galáxia anãs próximas (2.24 \pm 0.17 : Momany et al., 2007).

9 e 13 kpc, como visto na Figura 4.3 (região destacada em verde). Nesse intervalo, o valor médio para $\mathrm{F}_{\mathrm{BSS} / \mathrm{BHB}}$ é de cerca de $2.15 \pm 0.13$, praticamente idêntico ao valor da frequência $\mathrm{F}_{\mathrm{BSS} / \mathrm{BHB}}$ encontrada em aglomerados abertos e galáxias anãs próximas (2.24 0.17 : Momany et al., 2007).

Sabendo que as estrelas azuis tardias são, em média, 2.15 vezes mais frequentes que as BHBs no halo galáctico, pode-se então, mesmo que de maneira grosseira, estimar a contribuição da luminosidade das BSSs neste ambiente. Admitindo que toda luminosidade do halo devida a estrelas de tipo A seja atribuída a BHBs e BSSs (pois anãs brancas de tipo A são muito menos luminosas), temos: $\mathrm{L}_{\text {TotalA }}=\mathrm{L}_{\mathrm{BHB}}+\mathrm{L}_{\mathrm{BSS}}$. Então, para 2.15 vezes mais BSSs que BHBs: $\mathrm{L}_{\text {TotalA }}=\left(1.0 \cdot \mathrm{L}_{\mathrm{BHB}}+2.15 \cdot \mathrm{L}_{\mathrm{BSS}}\right) / 3.15$, onde $\mathrm{L}_{\mathrm{BHB}} \sim 6.37 \cdot \mathrm{L}_{\mathrm{BSS}}$, a parcela de luminosidade do halo devida a estrelas de tipo A tem uma constribuição de aproximadamente 37\% correspondente às BSSs. Este valor pode ser importante para refinar os modelos de populações estelares da Galáxia (e de outras galáxias), em particular para os códigos que já incluem BSSs em seus modelos (Chen e Han, 2009; Conroy e Gunn, 2010; Xin et al., 2011; Zhang et al., 2012). 


\subsection{Cores e metalicidades}

Os importantes trabalhos de Preston et al. (1991b); Santucci et al. (2015b); Carollo et al. (2016) mostraram que existe uma variação de cores de BHBs com a distância ao centro galáctico. Essa variação ocorre de modo que, quanto mais longe elas estão, mais vermelhas elas aparentam ser. Depois de verificar que essa variação não ocorre devido ao efeito da metalicidade e também independe dos mapas de extinção adotados (Santucci et al., 2015b; Carollo et al., 2016), coube explicá-la como sendo uma variação de idade, da mesma forma que Preston et al. (1991b) fizeram. Segundo essa perspectiva, o halo galáctico parece ficar mais jovem de dentro para fora, em um gradiente de idade de $\sim 1-2$ bilhões de anos na região entre 0 kpc e 50 kpc de distância ao centro da Galáxia (Santucci et al., 2015b). Seria estranho que esse efeito fosse exclusividade de apenas um tipo estelar do halo. Assim, busca-se avaliar as cores das BSSs com a distância, com a finalidade de encontrar resultados análogos.

Inicialmente, deve-se avaliar a dependência das cores das BSSs com suas metalicidades, como feito com as BHBs em Santucci et al. (2015b). A Figura 4.4 mostra as distribuições de metalicidades para as BSSs (cinza) e BHBs (vermelho) reunidas na amostra espectroscópica. Através desta figura, pode-se ver que a distribuição de metalicidades das BSSs possui dispersão cerca de duas vezes maior que a distribuição de metalicidades das BHBs. Além disso, as BSSs estão centradas em um valor médio de $[\mathrm{Fe} / \mathrm{H}] \sim-1.4$, e as BHBs em $[\mathrm{Fe} / \mathrm{H}] \sim-1.8$.

As distribuições das cores $(g-r)_{0}$ de BHBs e BSSs são apresentadas na Figura 4.5, onde as BHBs apresentam um ligeiro enviesamento para cores mais azuis, e um enviesamento ainda maior para as BSSs, por conta do corte imposto em $(g-r)_{0}=0.02$, feito no início da seleção fotométrica. Por esta razão, todas as comparações de tendências das cores feitas neste trabalho levam em consideração medianas ao invés de médias.

Conhecidas as distribuições de cores e metalicidades das amostras espectroscópicas, verificou-se então a dependência entre essas grandezas, como pode ser visto na Figura 4.6. As BHBs (pontos vermelhos), assim como descrito por Deason et al. (2011) e Santucci et al. (2015b), não mostraram relação forte entre suas cores e metalicidades. Entretanto o mesmo não ocorre para estrelas BSSs (pontos pretos), onde foi indentificada uma dependência da cor com a metalicidade, com um comportamento bem descrito por uma função de segundo 


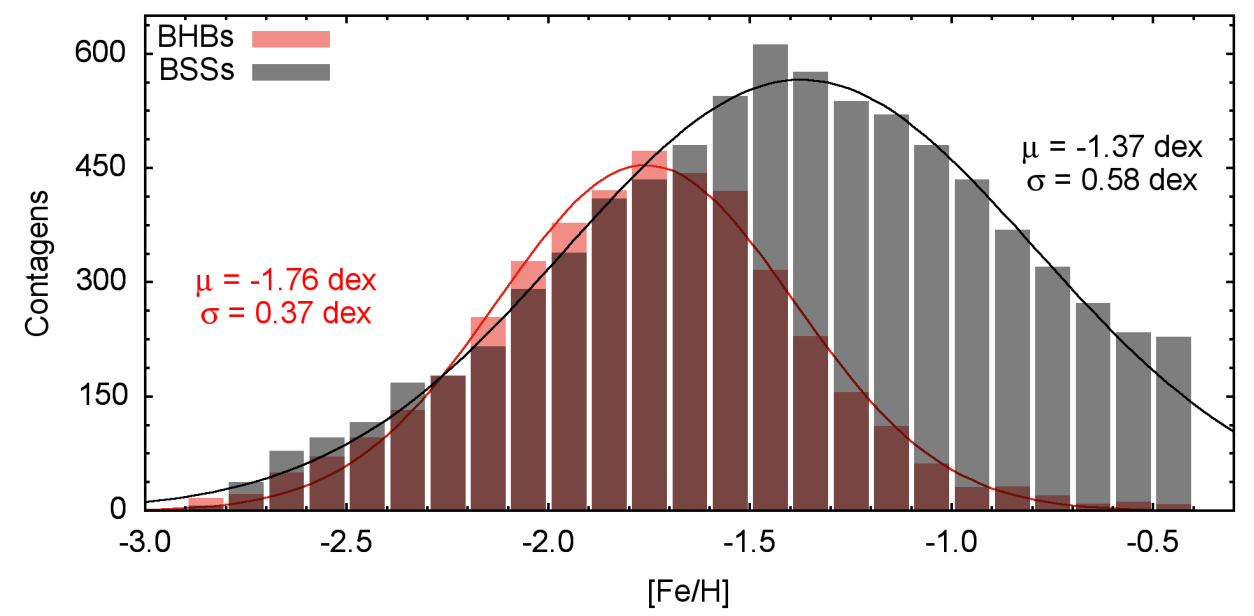

Figura 4.4: Distribruições de metalicidades de BSSs (cinza) e BHBs (vermelho). As curvas gaussianas ajustadas em ambas distribuições fornecem os valores centrais dos picos $(\mu)$ e suas dispersões $(\sigma)$, em preto para as BSS e em vermelho para as BHBs.

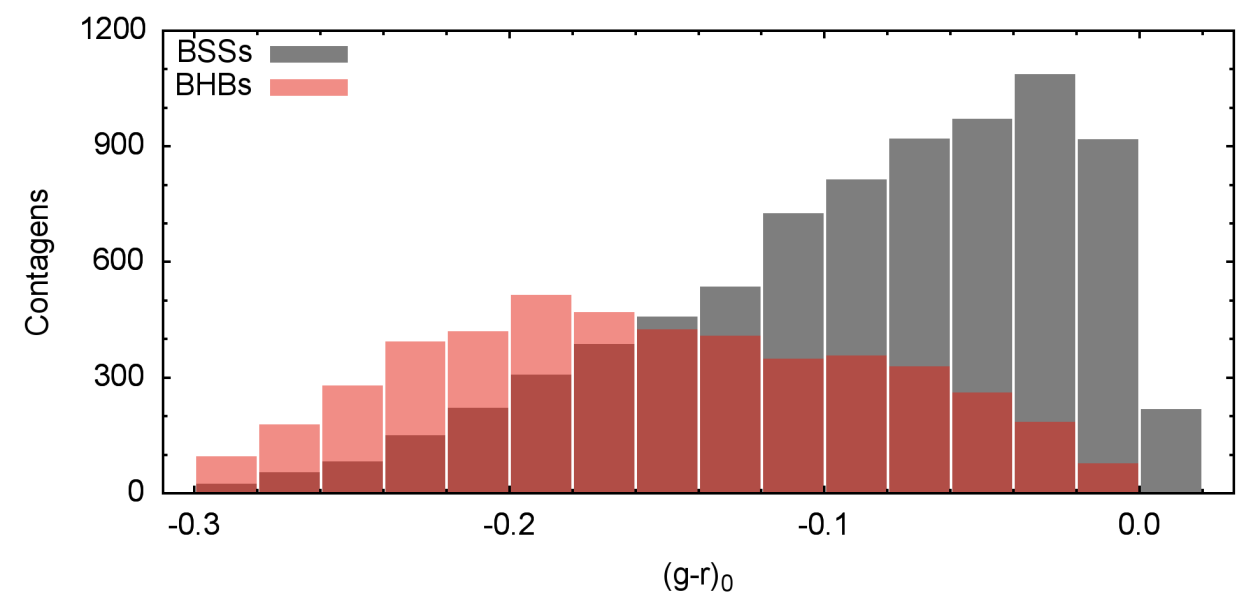

Figura 4.5: Distribruições de cores $(g-r)_{0}$ para BHBs (em vermelho) e BSSs (em cinza). A distribuição das BHBs apresenta um leve enviesamento para cores mais azuis. As BSSs, por conta do corte imposto em $(g-r)_{0}=0.02$ feito no início da seleção fotométrica, possuem um enviesamento ainda maior.

grau, com coeficientes apresentados na legenda da Figura 4.6.

Conhecendo a dependência da relação metalicidade-cor para as BSSs, é possível verificar sua influência nos resultados quando distâncias e cores são comparadas. Visando este fim, as cores das BSSs foram corrigidas de acordo com suas metalicidades. O resultado também é apresentado na Figura 4.6, através dos pontos em cinza, ficando praticamente constantes em torno de $(g-r)_{0} \sim-0.073$. Esta correção foi feita utilizando como referência o ponto máximo da função ajustada sobre as BSSs. Os valores foram "normalizados" de maneira 


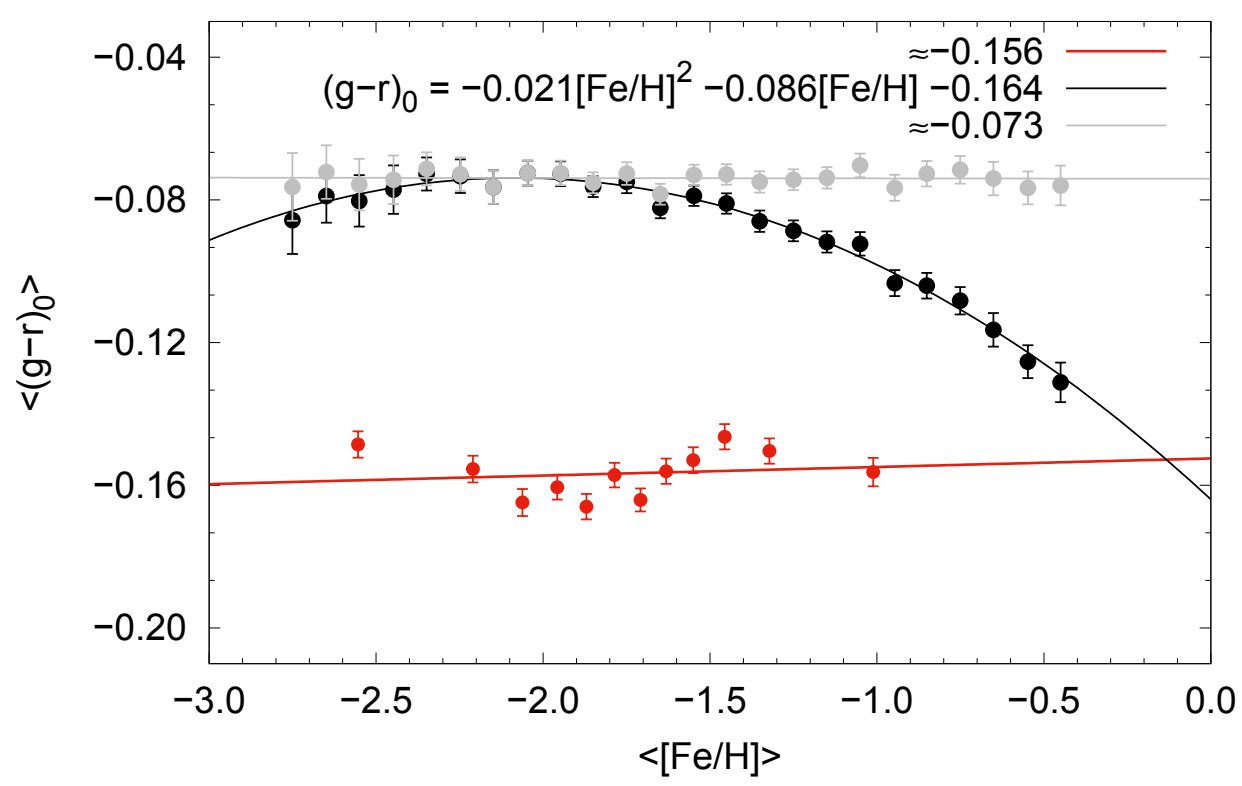

Figura 4.6: Relação $[\mathrm{Fe} / \mathrm{H}] \mathrm{vs}(g-r)_{0}$ para BHBs (pontos vermelhos) e BSSs (pontos pretos). Verifica-se que, assim como descrito por Deason et al. (2011) e Santucci et al. (2015b), não há relação evidente entre a metalicidade e a cor das BHBs, que possuem cores praticamente constantes $(\sim-0.156)$ no intervalo de metalicidades estudado. Entretanto, o mesmo não ocorre para as BSSs, as quais apresentam dependência da cor com a metalicidade, cujo comportamento pode ser descrito por uma função de segundo grau, com coeficientes exibidos na legenda da figura. Os pontos em cinza são BSSs que tiveram suas cores corrigidas dessa dependência com a metalicidade, usando a relação 4.9, e agora apresentam-se praticamente constantes em torno de $(g-r)_{0} \sim-0.073$.

a ficarem próximos de $\sim-0.076$, para qualquer metalicidade. A função resultante destas imposições pode ser vista na relação abaixo:

$$
(g-r)_{0_{C}}=0.088+(g-r)_{0}+0.086 \cdot[\mathrm{Fe} / \mathrm{H}]+0.021 \cdot[\mathrm{Fe} / \mathrm{H}]^{2} .
$$

\subsubsection{Variações de cor com a distância}

O comportamento das cores das BSSs em função da distância ao centro galáctico podem ser apreciados na Figura 4.7. Nessa figura, são comparadas também as diversas calibrações de distâncias previamente discutidas, assim como a influência da metalicidade na cor das BSSs para o resultado final.

Todas as calibrações adotadas mostram que as BSSs ficam mais azuladas com a distância ao centro galáctico, ao mesmo tempo que as BHBs ficam mais avermelhadas, conforme 


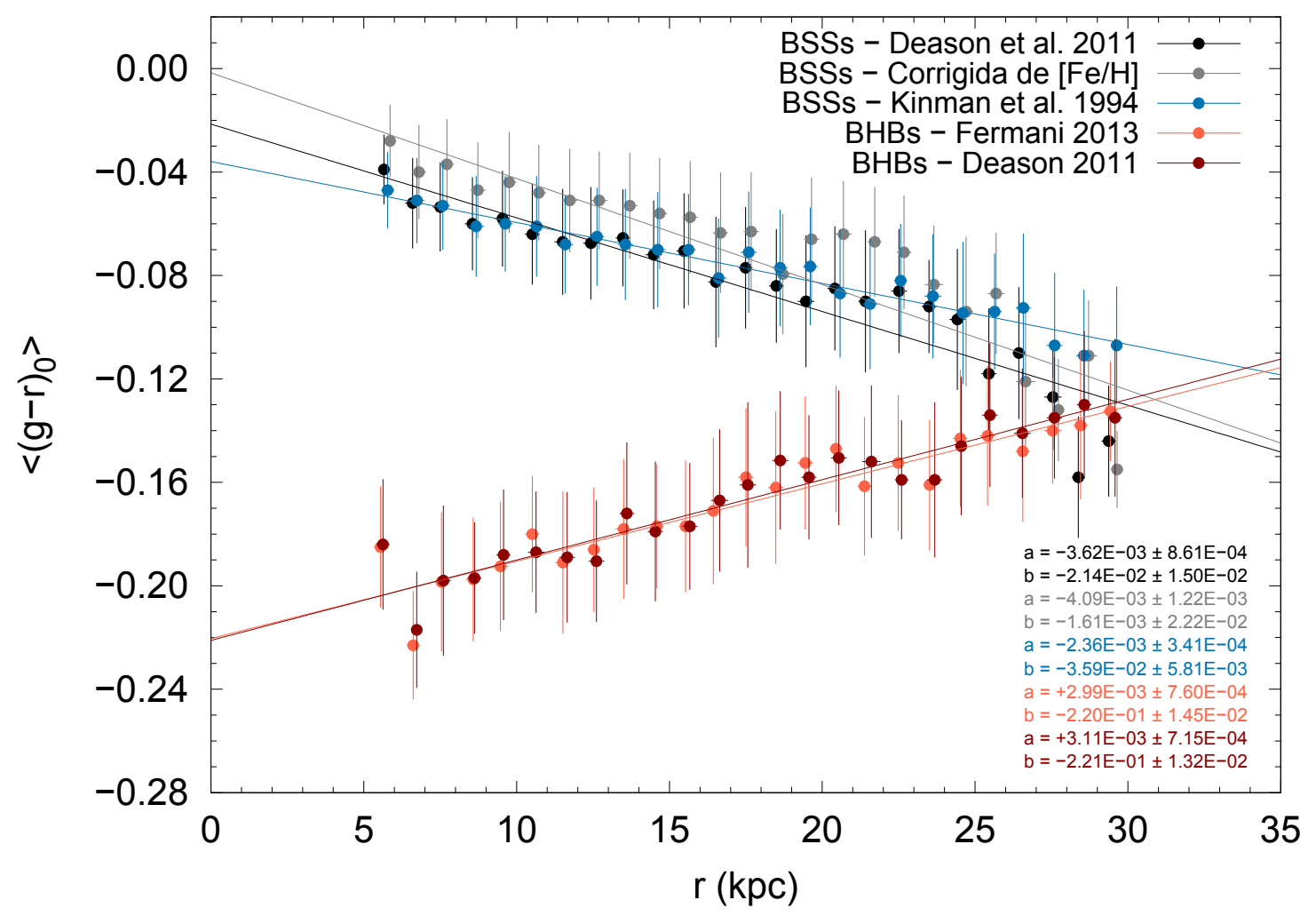

Figura 4.7: Relação entre o índice de cor mediano das BSSs e médio das BHBs em relação a distância ao centro galáctico (r), a cada kpc. Nota-se que, independentemente da calibração de distância adotada, BSSs se tornam mais azuis com a distância, enquanto que as BHBs ficam mais vermelhas. A calibração de distância para BSSs usando a equação 4.4 (Deason et al., 2011) é mostrada em pontos pretos. Os pontos cinza são BSSs que tiveram distâncias (e cores) calculadas com a combinação das Equações 4.4 e 4.9, portanto corrigidas do desvio de cor associado a metalicidade. Os pontos azuis representam as BSSs com distâncias estimadas segundo a relação 4.3 (Kinman et al., 1994). Os coeficientes dos ajustes podem ser vistos no canto inferior direito da figura e seguem o mesmo esquema de cor descrito por suas distribuições.

visto nos dados em vermelho. A maior variação da cor com a distância foi verificada para a calibração que usa distâncias corrigidas do efeito de cor causado pela metalicidade (feita usando uma combinação das Equações 4.4 e 4.9), representada pelos pontos cinza. Já a menor variação da cor com a distância foi verificada com a utilização da calibração 4.3, amostrada pelos pontos azuis, que considera metalicidade e cores na estimativa da magnitude absoluta. A calibração de distâncias proposta por Deason et al. (2011), equação 4.4, é representada pelos pontos pretos.

O efeito da metalicidade na cor também foi considerado na calibração 4.3 e o resultado encontrado foi um coeficiente angular de $-3.11 \pm 0.57 .10^{-3}$ dex $/ \mathrm{kpc}$, que é coerente com 
todos os valores descritos nos outros ajustes em $3 \sigma$ (ver os parâmetros no canto inferior direito da Figura 4.7 para mais detalhes).

Para BHBs, da mesma maneira que Santucci et al. (2015a) descreveram, não houve qualquer mudança no resultado da variação de cor das BHBs com a distância ao usar a Equação 4.6, que tem dependência da metalicidade.

Assim como feito por Preston et al. (1991a) e Santucci et al. (2015b) para BHBs, também foi avaliado o gradiente de cor com a distância para diversos intervalos de metalicidade na amostra de BSSs, como mostra a Figura 4.8. O painel superior esquerdo da Figura 4.8 mostra a mesma distribuição de metalicidades das BSSs espectroscópicas vistas na Figura 4.4, mas desta vez colorida de acordo com intervalos de metalicidade. As cores dos intervalos são mantidas nos demais painéis para facilitar a associação do gradiente de cor analisado. Esses paineis mostram a relação da cor mediana das BSSs com a distância ao centro da Galáxia, onde os pontos coloridos são resultado da adoção da Equação 4.3 para calibração das distâncias. Os pontos pretos foram calculados usando a Equação 4.4 e os pontos cinza são resultados obtidos para distâncias que combinaram as equações Equações 4.4 e 4.9. Pode-se notar que as BSSs ficam mais azuladas com a distância em todos os intervalos de metalicidade adotados. Fazendo a média dos coeficiente angulares de todos painéis da Figura 4.8, obtêm-se o gradiente de cor $\left\langle(g-r)_{0}\right\rangle / r=-3.3 \pm 0.7 \cdot 10^{-3}$ dex/kpc. Este valor foi adotado para as análises seguintes deste trabalho, pois trata-se do valor mais representativo para o halo galáctico, e é compatível com todos os ajustes feitos anteriormente.

Estes resultados mostram que, mesmo que não exista informação sobre a metalicidade das BSSs, ainda assim é possível verificar que suas cores ficam mais azuis com a distância ao centro da Galáxia, e que, além disso, o desvio de cor acontece para qualquer intervalo de metalicidade. Ou seja, o gradiente de cor das BSSs em função da distância ao centro da Galáxia é, também, independente de [Fe/H], assim como verificado para as BHBs (Santucci et al., 2015b).

Sendo assim, o fenômeno da variação de cor com a distância foi avaliado também com as amostras fotométricas selecionadas no fim do capítulo anterior. Essa análise é mostrada na Figura 4.9, que compara as variações de cor com as distâncias galactocêntricas, usando BHBs e BSSs tanto espectroscópicas como fotométricas. As distâncias adotadas nesta figura foram calculadas utilizando calibrações de magnitudes absolutas baseadas somente 
em cores (Deason et al., 2011) para todas as amostras.

A Figura 4.9 mostra que os gradientes de cor observados nas amostras fotométricas são menores que os vistos nas amostras espectroscópicas, especialmente para as BSSs. Esses resultados podem ser explicados por duas razões, (i) isto ocorre porque os intervalos de cor adotados na seleção fotométrica de ambos os tipos estelares são menores que os intervalos de cor adotados para as amostras espectroscópicas; (ii) a distribuição de cores $(g-r)_{0}$ das BSSs não é gaussiana (ver Figuras 4.5 e 3.7), de modo que as BSSs do lado mais vermelho do intervalo $(g-r)_{0}$ sejam preferencialmente selecionadas nas restrições fotométricas.

A visão detalhada da variação de cor das BSSs no halo galáctico é apresentada no Capítulo 5 através da técnica dos mapas de idade (Santucci et al., 2015b; Carollo et al., 2016). Tal técnica será avaliada somente com a amostra espectroscópica de BSSs, pois estas estrelas se distribuem em um intervalo maior de cores revelando mais detalhes nos mapas. 

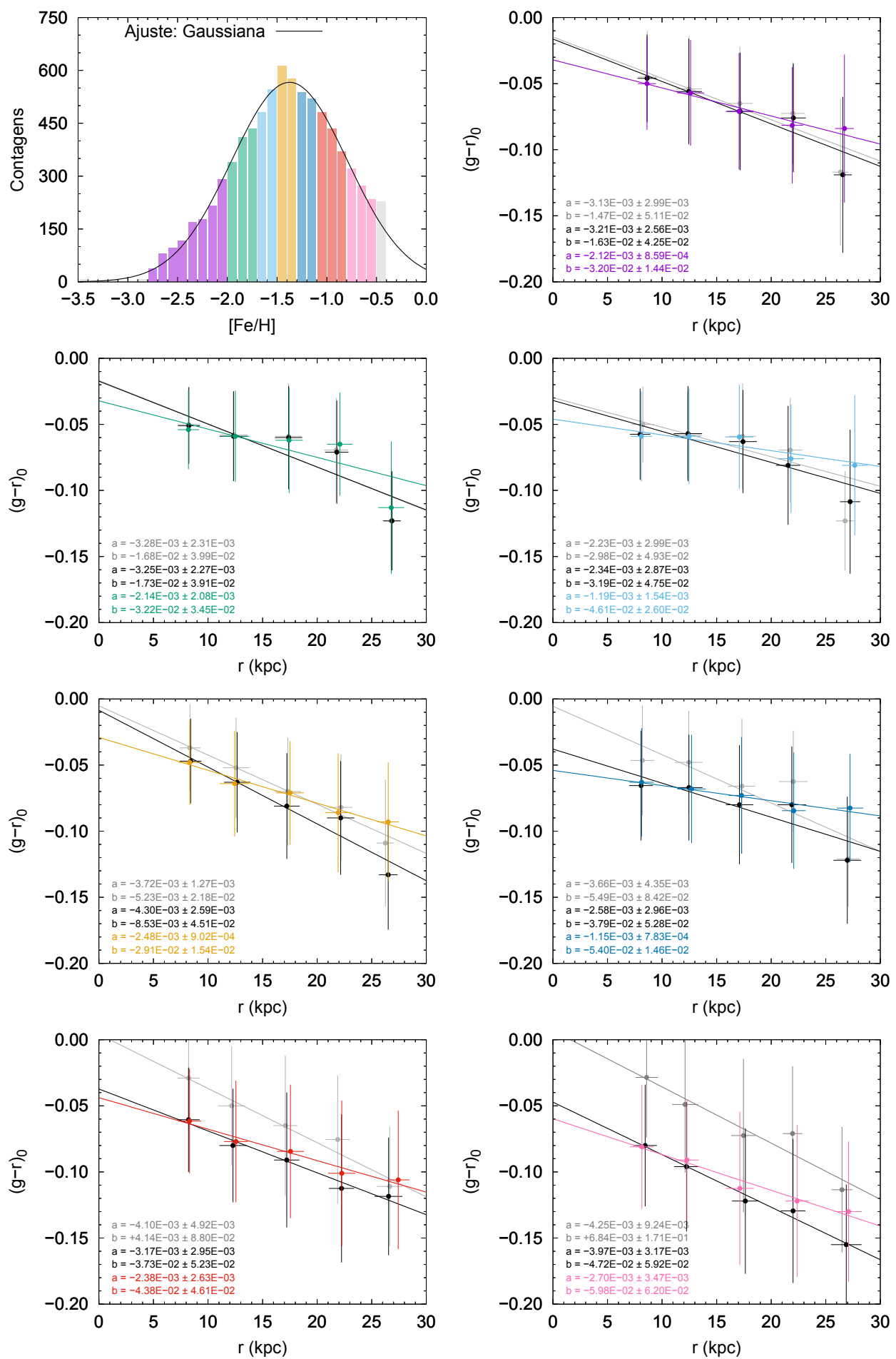

Figura 4.8: No painel superior esquerdo mostra-se a distribuição de metalicidades das BSSs, onde as várias cores representam os 7 intervalos considerados para análise nos outros painéis. As cores foram mantidas nos demais painéis para facilitar a associação com os intervalos de metalicidade avaliados. Os pontos coloridos são resultado da variação de cor (mediana) das BSSs com a distânca utilizando a Equação 4.3 para calibração das distâncias. Os pontos pretos foram calculados usando a Equação 4.4 e os pontos cinzas-claros são resultados vistos para distâncias que combinaram as equações Equações 4.4 e 4.9 . 


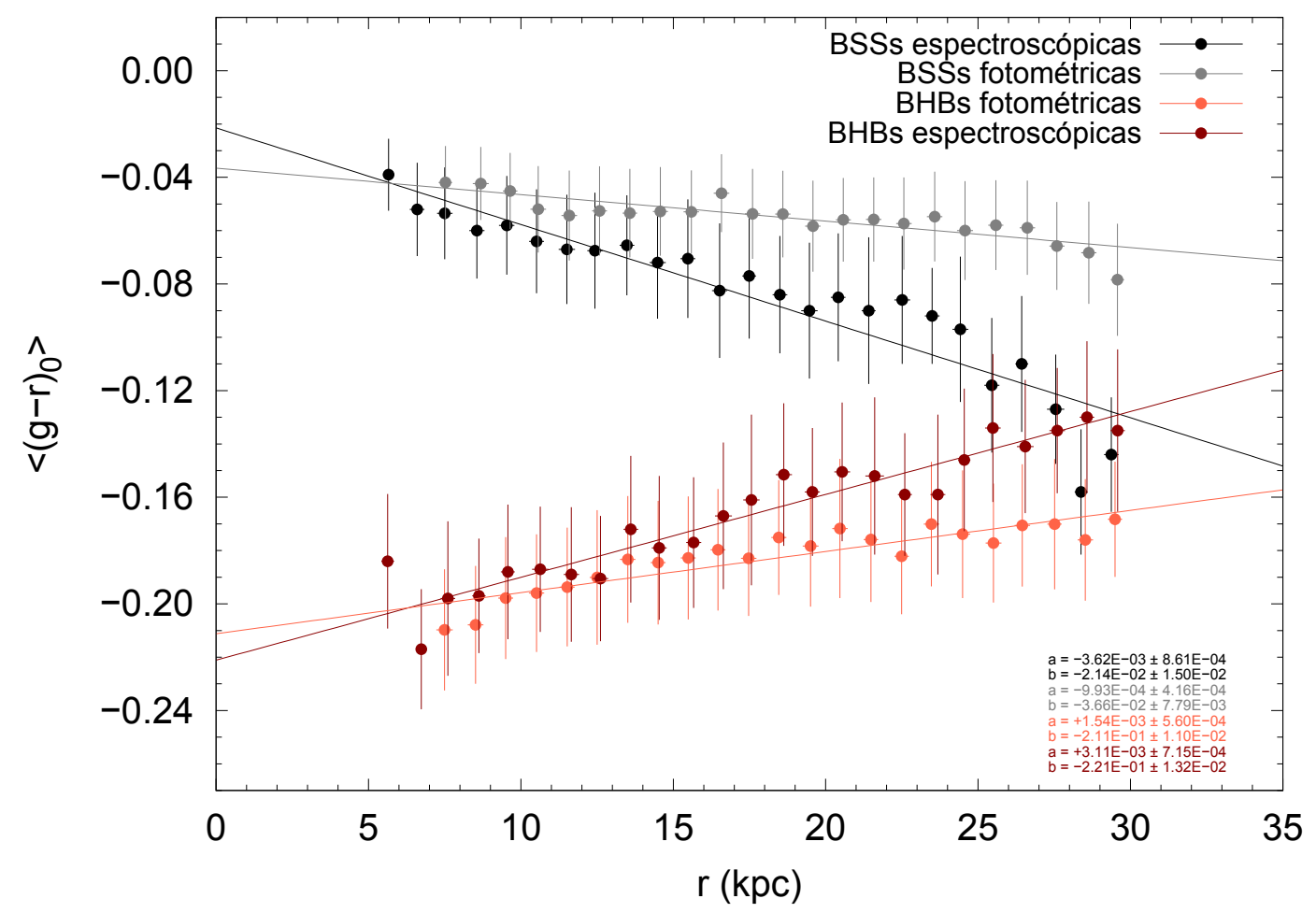

Figura 4.9: Variações de cor com a distância galactocêntrica, usando BHBs e BSSs tanto espectroscópicas como fotométricas, coloridas conforme visto na legenda da figura. As distâncias adotadas nesta figura foram calculadas usando calibrações de magnitudes absolutas baseadas somente em cores (Deason et al., 2011). A figura revela que os gradientes de cor das amostras fotométricas são mais sutis que os vistos nas amostras espectroscópicas. 
Capítulo 5

\section{Mapas}

Seguindo os trabalhos de Preston et al. (1991a) e Santucci et al. (2015b) que utilizam BHBs no halo galáctico, este capítulo mostra que o desvio de cor observado nas estrelas azuis tardias também pode estar atrelado às variações de idade em suas populações.

\subsection{Relações entre cores, metalicidades e idades}

Dentre as várias opções de modelos evolutivos e isócronas disponíveis na literatura (Girardi et al., 2000; Salasnich et al., 2000; Lejeune e Schaerer, 2001; Yi et al., 2003; Bertelli et al., 2008; Bressan et al., 2012; Dell'Omodarmeme e Valle, 2015) foram escolhidos os modelos YZVAR de Bertelli et al. (2008) para a análise das BSSs, pois eles cobrem amplos intervalos de massas $\left(0.15 \mathrm{M}_{\odot}-2.50 \mathrm{M}_{\odot}\right)$ e metalicidades $(0.0001 \leq \mathrm{Z} \leq 0.070$ - equivalentes à $-2.3 \leq[\mathrm{Fe} / \mathrm{H}] \leq+0.6)$. Além disso, eles possuem fotometria no sistema $U B V R I$ e são de livre acesso através da internet.

O principal mecanismo proposto para a formação das BSSs é a transferência de massa entre estrelas de um sistema binário (Boffin et al., 2014) e não existe, até o momento, uma grade de modelos dedicada a descrever a trajetória evolutiva desses sistemas. Por essa razão, todas as associações feitas entre modelos e propriedades observacionais das BSSs neste trabalho são baseadas na evolução de estrelas individuais, de tipo espectral A, pobres em metais e de sequência principal.

Várias trajetórias evolutivas para estrelas de sequência principal passam pela região $\mathrm{T}_{\text {eff }}$ vs $\log (\mathrm{g})$ que as BSSs ocupam, como mostram as Figuras 5.1 e 5.2, para $[\mathrm{Fe} / \mathrm{H}]$ constante e massa constante, respectivamente. Ao se comparar essas figuras, nota-se que muitas curvas podem representar uma mesma estrela, pois a posição e a evolução na sequência 
principal dependem, basicamente, da massa e da metalicidade inicial da estrela (Bertelli et al., 2008).

Para representar as BSSs, foram escolhidas trajetórias evolutivas com massas entre 0.8-1.8 $\mathrm{M}_{\odot}$, com passos de 0.1 dex, para 6 metalicidades $([\mathrm{Fe} / \mathrm{H}])$ diferentes: $-2.3,-1.7$, $-1.3,-1.0,-0.7$ e -0.4 , equivalentes à distribuição de metalicidades das BSSs espectroscópicas. A princípio, a abundância inicial de Hélio (Y) foi considerada a mesma em todos os modelos, e igual a 0.23 .

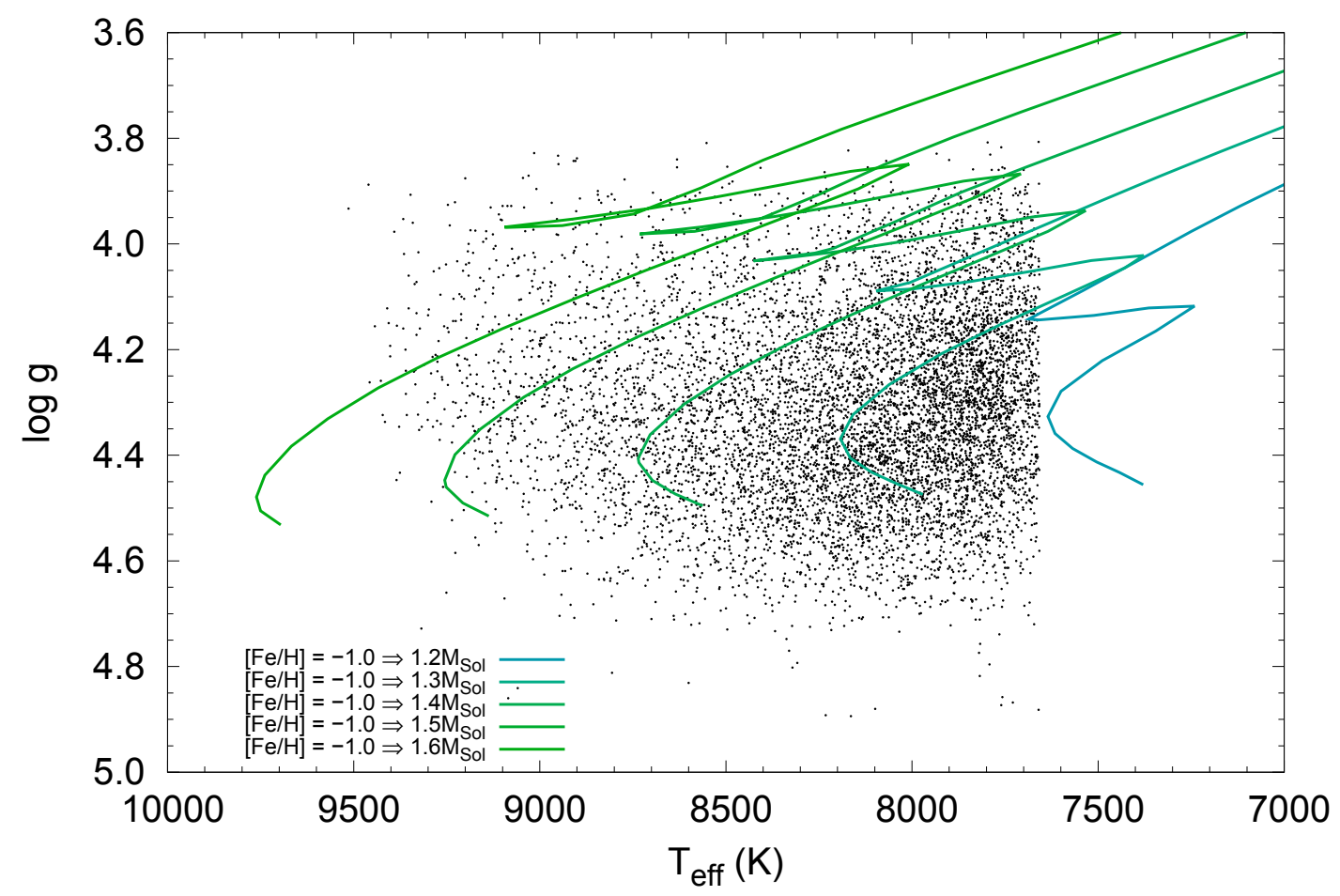

Figura 5.1: Região do plano $\mathrm{T}_{\text {eff }}$ vs $\log (\mathrm{g})$ ocupada por BSSs (pontos pretos). Sobrepostas a elas estão as trajetórias evolutivas YZVAR (Bertelli et al., 2008), para metalicidades constantes $([\mathrm{Fe} / \mathrm{H}]=-1.0)$ e diferentes massas $(1.2-1.6 \mathrm{M} \odot)$ com passos de $0.1 \mathrm{M}_{\odot}$. Para mais detalhes, veja a legenda localizada canto inferior esquerdo da figura.

As trajetórias consideradas não têm índices de cor diretamente associados às fases evolutivas. Para acessar essas propriedades nos modelos é necessário utilizar isócronas. O ponto adotado para obter as cores foi a saída da sequência principal ("turnoff"). Assim, isócronas com idades dos turnoffs foram geradas para obter os índices de cor dos modelos.

O turnoff foi especialmente escolhido como referência pois possui $\log (\mathrm{g})$ entre $4.2 \leq$ $\log (\mathrm{g}) \leq 4.5$, típicos das BSSs espectroscópicas. Além disso, também fornece uma referência para idade máxima possível de uma BSS na sequência principal. Esse instante foi definido 
através do ponto de inflexão das curvas evolutivas, ou seja, em seus limites mais quentes (exemplificados na Figura 5.2 através de círculos vermelhos).

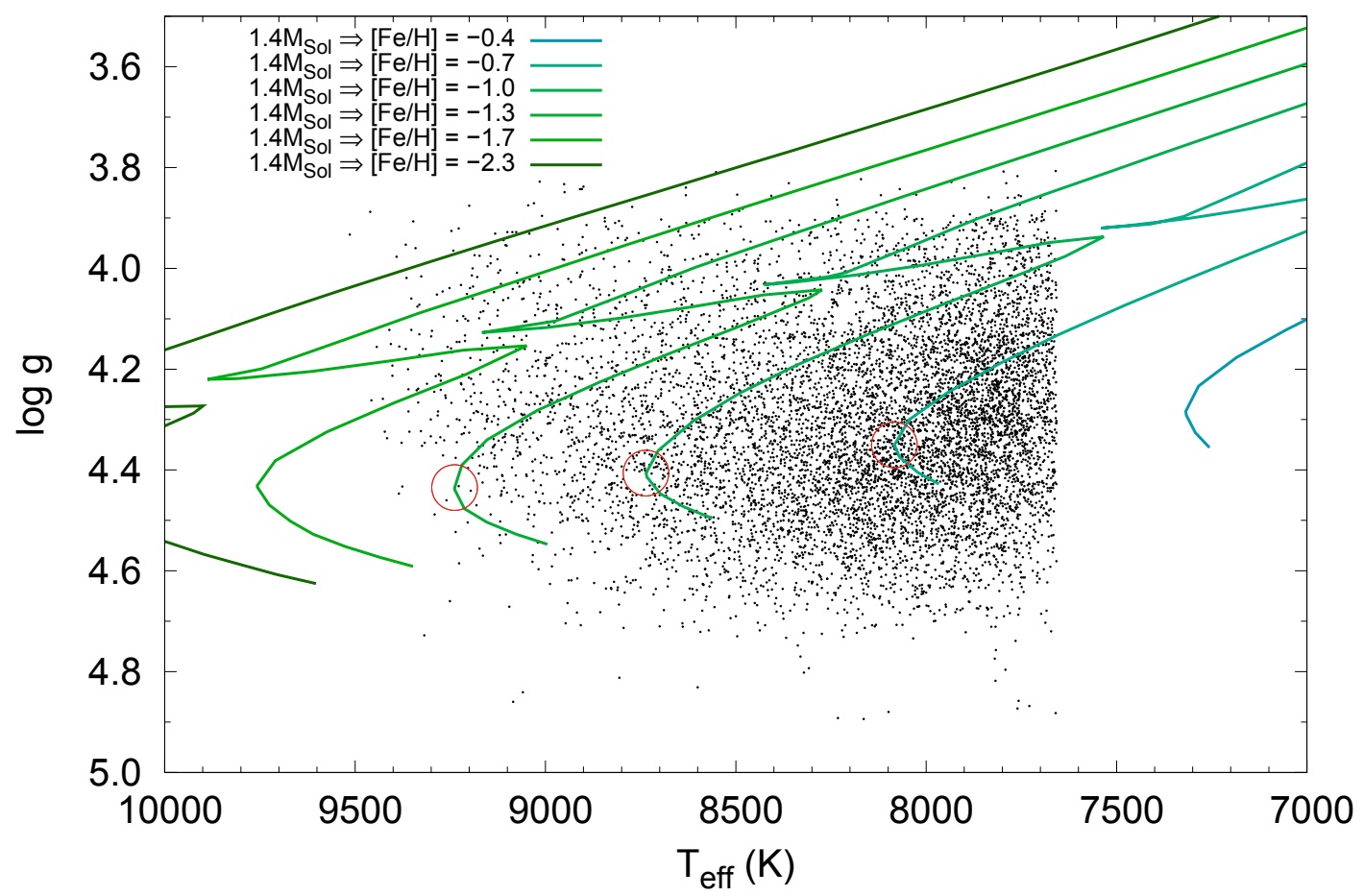

Figura 5.2: Região do plano $\mathrm{T}_{\text {eff }}$ vs $\log (\mathrm{g})$ ocupada por BSSs (pontos pretos). Sobrepostas a elas estão as curvas evolutivas YZVAR (Bertelli et al., 2008) para massas constantes (1.4 $\mathrm{M} \odot)$ e diferentes metalicidades, cujos detalhes podem ser vistos na legenda, localizada canto superior esquerdo da figura. Os círculos vermelhos representam os pontos onde os índices de cor são obtidos através de isócronas.

As cores fornecidas por cada isócrona foram convertidas do sistema Jonhson ( UBVRI) para o sistema fotométrico do SDSS usando a relação 4.2, e comparadas com suas respectivas idades. Os resultados obtidos podem ser vistos na Figura 5.3, que compara cores e metalicidades com a idade equivalente da saída da sequência principal, em bilhões de anos. As tendências vistas nessa figura possuem metalicidades constantes e estão coloridas de acordo com os intervalos definidos na Figura 4.8.

Nota-se através da Figura 5.3 que a variação de cor $(g-r)_{0}$ máxima ocorre quase sempre em um intervalo de 0.3 massas solares. O limite definido pelas linhas horizontais tracejadas indica o intervalo de cor da amostra espectroscópica e a linha vertical é uma referência para localizar a idade igual a zero. A massa de cada modelo é vista ao lado dos pontos. Modelos com $(g-r)_{0}<-0.2$ não foram considerados pois suas temperaturas efetivas ultrapassavam 
10000 K, ou seja, são muito maiores que os valores das BSSs espectroscópicas.

Os modelos usados até então consideram a abundância inicial de Hélio (Y) igual a 0.23. Para avaliar o impacto nos resultados ao adotar abundâncias maiores de Y, foram obtidas as cores de modelos com Y variando de 0.23 até 0.26 , para a metalicidade $[\mathrm{Fe} / \mathrm{H}]=-1.0$. Apesar dos índices de cor mostrarem-se sistematicamente (e ligeiramente) mais azuis (em 0.02 dex) ao longo do intervalo em Y avaliado, a variação de cor total foi exatamanete a mesma no intervalo de massas entre 1.3-1.6 $\mathrm{M}_{\odot}$. Entretanto, apesar da variação de cor não possuir alteração, o mesmo não ocorre para a variação de idade associada a ela. Nesse caso, a variação de idade dos modelos torna-se até $\sim 20 \%$ menor, indo de $\Delta \mathrm{t}_{9}=1.3$ Gano $(\mathrm{Y}=0.23)$ até $\Delta \mathrm{t}_{9}=1.1$ Gano $(\mathrm{Y}=0.26)$, no intervalo de massas entre 1.3-1.6 $\mathrm{M}_{\odot}$. Portanto, este efeito mostra que a variação de idade do halo será menor quanto maior for a abundância inicial de Hélio considerada nos modelos.

Com base nas tendências observadas na Figura 5.3, pode-se notar que cada metalicidade possui um coeficiente angular diferente para a relação idade-cor (linhas pontilhadas coloridas). Assim, foi adotado o valor médio de todos esses coeficientes como representativo da relação cor-idade total das BSSs no halo. Essa média foi ponderada pelo número de pontos de cada tendência dentro da janela de cor $(g-r)_{0}$, resultando em $\Delta \mathrm{t}_{9} / \Delta(g-r)_{0}$ $=10.3 \pm 3.4$ Gano/dex.

Combinando o gradiente de cor das BSSs no halo $\left(-3.3 \pm 0.7 \cdot 10^{-3} \mathrm{dex} / \mathrm{kpc}\right)$, com o valor médio da variação cor-idade dos modelos ( 10.3 \pm 3.4 Gano/dex $)$, obtém-se a variação de idade do halo em função a distância galactocêntrica $\left(\Delta t_{9}\right)$ como sendo $-0.034 \pm 0.002$ Gano/kpc.

Definida a variação de idade do halo, resta agora considerar o ponto inicial para contagem do tempo. O ponto zero adotado para a variação de cor das BSSs é o mesmo que foi definido em Santucci et al. (2015b): 13.5 Ganos, que assume que a formação estelar começou rapidamente após o Big Bang, sendo consistente com a recente datação da estrela pobre em metais HD 140283 (VandenBerg et al., 2014).

Através da Figura 5.3 também é possível atribuir idades máximas para cada BSS. Na figura encontram-se disponíveis informações de metalicidades, cores e suas idades equivalentes. Os dois primeiros $\left([\mathrm{Fe} / \mathrm{H}]\right.$ e $\left.(g-r)_{0}\right)$ são parâmetros observáveis da amostra espectroscópica, sendo portanto possível construir uma relação matemática que indique as idades. Utilizando o código EUREQA (Schmidt e Lipson, 2009), obteve-se uma estimativa 


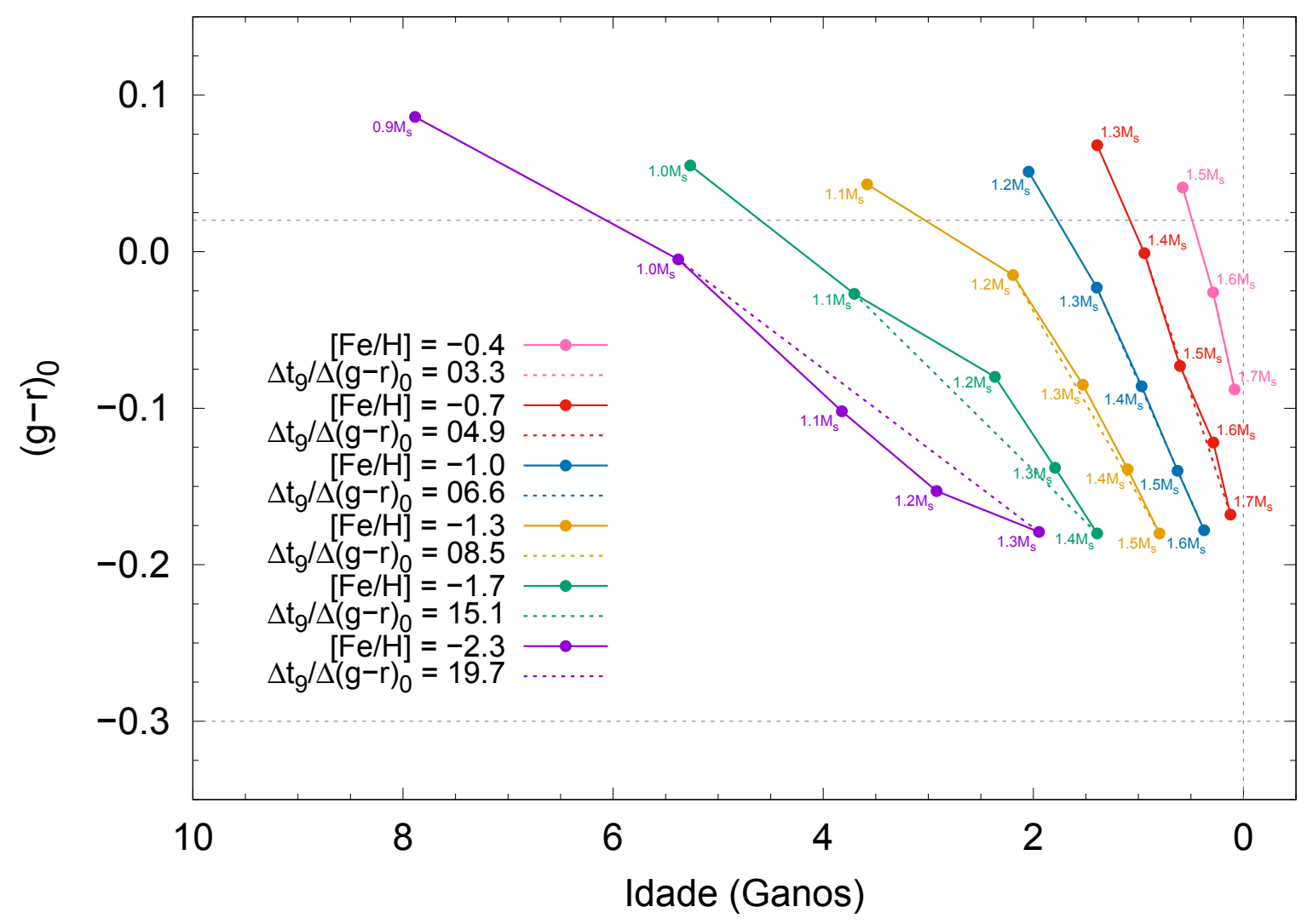

Figura 5.3: Diagrama de idades vs cores para modelos de estrelas de sequência principal, com $\mathrm{Y}=0.23$. As linhas horizontais tracejadas representam o limite de índice de cor da amostra de BSSs. Cada linha colorida representa uma metalicidade diferente, seguindo a divisão feita na distribuição de metalicidades das BSSs (ver Figura 4.8). Os valores vistos ao lado dos pontos mostram as massas de cada modelo. Os índices de cor e idades foram obtidos no ponto de saída da sequência principal, como destacado na Figura 5.2. $\Delta$ t $_{9}$ é o intervalo de tempo em bilhões de anos associado a variação de cor de cada tendência.

da idade máxima que uma estrela de tipo A pobre em metais teria na sequência principal, explicitada segundo a relação 5.1:

$$
\Delta t_{9}=-[\mathrm{Fe} / \mathrm{H}]-6.97 \cdot[\mathrm{Fe} / \mathrm{H}] \cdot(g-r)_{0}+0.597 \cdot[\mathrm{Fe} / H]^{2} .
$$

onde $\Delta \mathrm{t}_{9}$ é a idade em bilhões de anos.

Como não há confirmação observacional para binaridade de nenhuma BSSs da amostra, a massa total do (provável) sistema estelar do qual elas fazem parte é, a princípio, completamente desconhecida, bem como as estimativas de suas idades totais. Mesmo assim, os parâmetros atmosféricos da amostra espectroscópica mostram que, de fato, BSSs são estrelas quentes de sequência principal, pobres em metais. Logo, ao aplicar a Equação 5.1 
às BSSs obtém-se uma idade máxima para cada uma na sequência principal, e ao mesmo tempo, uma idade mínima para o seu sistema.

Usando a Equação 5.1, pode-se construir um gradiente de idade para o halo através das idades individuais atribuídas às BSSs, conforme ilustram os pontos verdes da Figura 5.4 , obtendo $\sim-0.070 \pm 0.002$ Gano/kpc. Para comparar o gradiente de idade obtido através desssa relação com outros gradientes já estimados, foi acrescido o valor de 10.5 Ganos ao coeficiente linear inicial do ajuste ( 3 Ganos). Desse modo, todos os gradientes de idade-distância obtidos para o halo galáctico possuem agora o mesmo ponto zero de idade (13.5 Ganos), conforme pode ser visto na Figura 5.4.

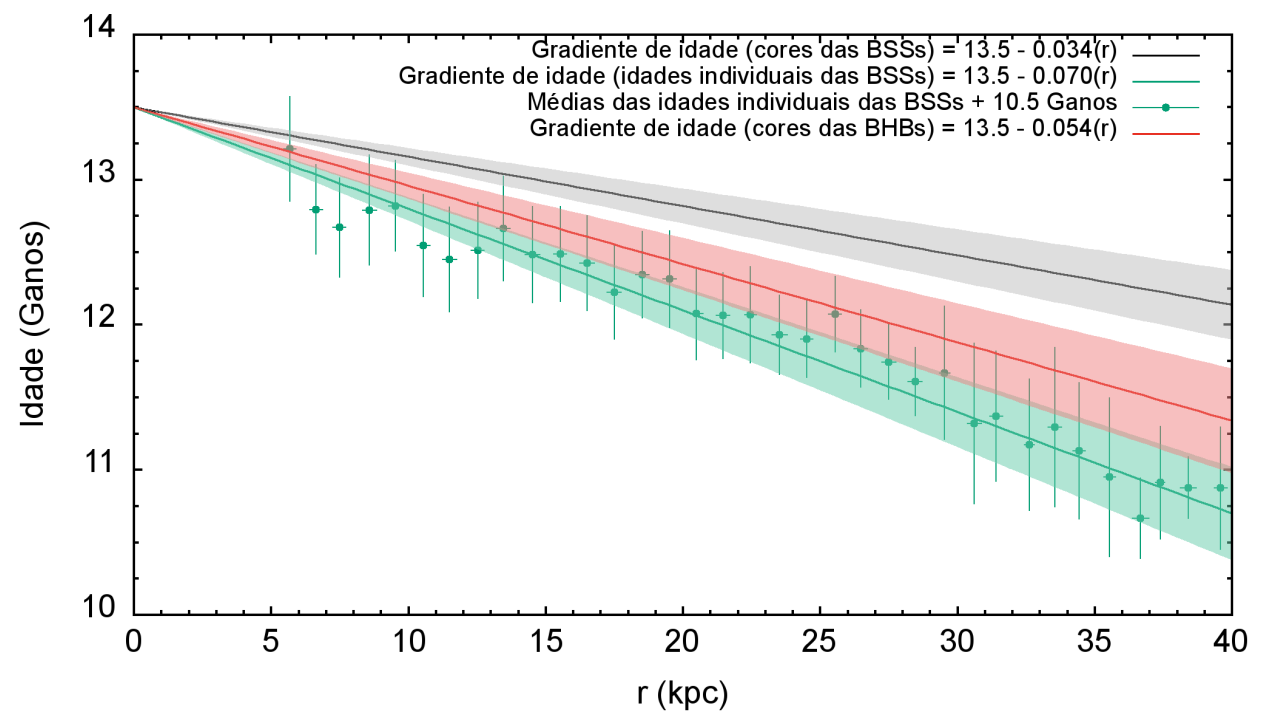

Figura 5.4: Comparação entre os diversos gradientes de idade obtidos para o halo em função da distância galactocêntrica. A linha preta representa o gradiente considerando a média dos ajustes da Figura 4.8. A linha verde representa o gradiente obtido com as idades individuais das BSSs (pontos verdes), segundo a Equação 5.1. A linha vermelha é o gradiente obtido por Santucci et al. (2015b), usando BHBs no halo. As áreas claras sombreadas limitam a região $3 \sigma$ de cada ajuste.

A Figura 5.4 mostra que o gradiente de idade obtido com a Equação 5.1 é duas vezes maior que o gradiente fornecido através das cores das BSSs no halo, não sendo compatíveis dentro de $3 \sigma$ (ver a intersecção das regiões sombreadas). Entretanto, ele se mostra compatível com o gradiente de idade encontrado para as cores das BHBs (Santucci et al., $2015 b)$.

Essa discrepância pode ser resultado da natureza do processo de formação das BSSs. Nota-se na Figura 4.6 que a dependência da cor com a metalicidade para estas estrelas 
é inversa ao que seria esperado, pois os objetos mais pobres se tornam cada vez mais avermelhados. Juntamente com esse fenômeno, deve-se ter em mente que BHBs e BSSs se tornam cada vez mais pobres em metais conforme ficam mais distantes do centro galáctico (como visto na Figura 5.5). Esse efeito inesperado da relação cor-metalicidade das BSSs parece atrapalhar o gradiente de cor observado no halo e, consequentemente, o seu gradiente de idade associado. Para contornar esse fenômeno, as cores das BSSs foram corrigidas desse efeito, tendo como resultado um gradiente de cor maior (Figura 4.7).

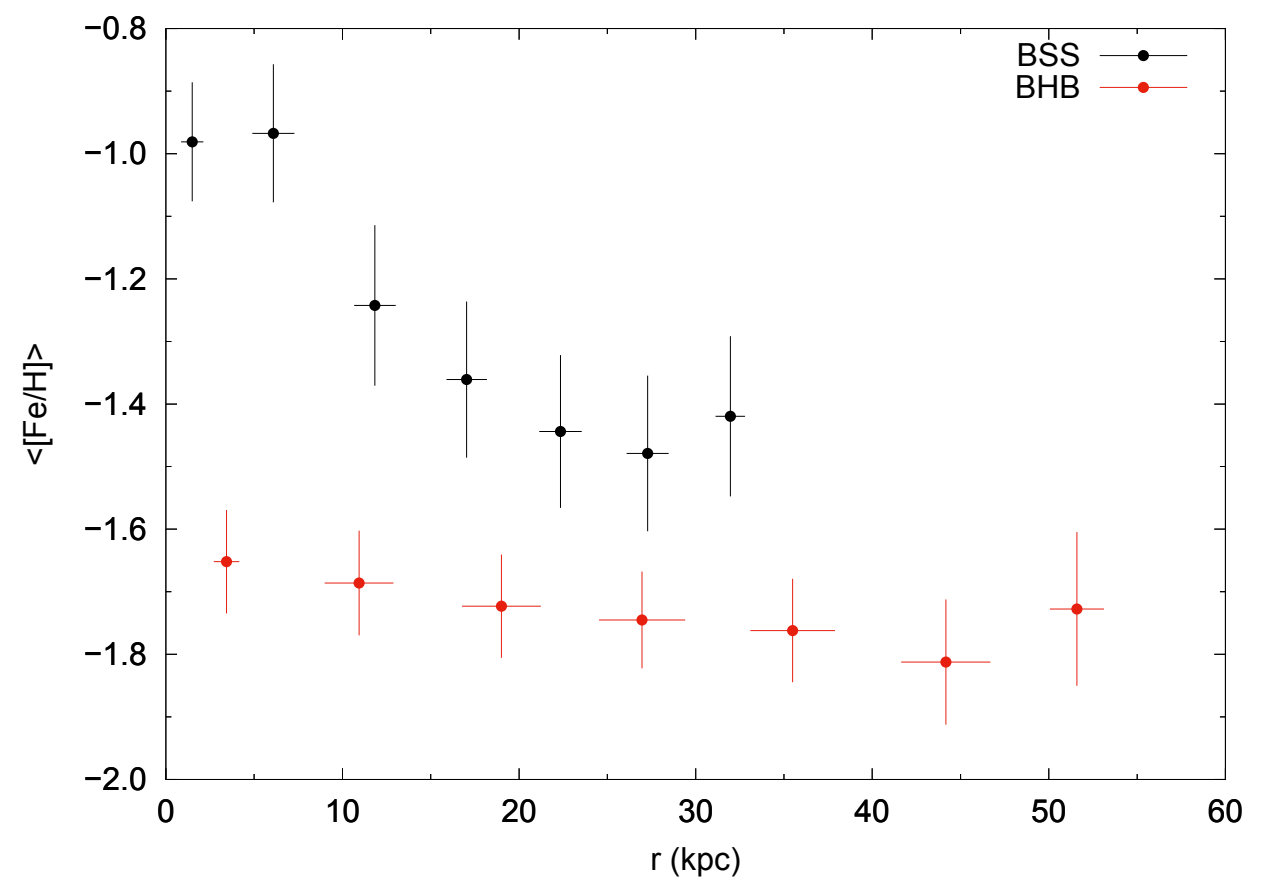

Figura 5.5: Variação da metalicidade $([\mathrm{Fe} / \mathrm{H}])$ em função da distância ao centro galáctico (em kpc) para BHBs (pontos vermelhos) e BSSs (pontos pretos). Nota-se que ambas as classes apresentam-se cada vez mais pobres em metais conforme as distâncias aumentam.

Estas constatações mostram que são necessários modelos evolutivos específicos para as BSSs. Os resultados poderiam ser melhor comparados se uma escala de cor-idade adequada a esses objetos estivesse disponível.

Mesmo que os dois gradientes para idade do halo estimados com as BSSs sejam diferentes (e não concordantes entre si em $3 \sigma$ ), seus resultados apontam para o mesmo caminho que resultados anteriores obtidos por Preston et al. (1991a) e Santucci et al. (2015b). Em todos estes gradientes o halo se torna cada vez mais jovem com a distância ao centro galáctico, confirmando o que é previsto por modelos hierárquicos modernos de formação de galáxias (White e Springel, 2000). 
O efeito da variação de cor-idade no halo parece ser tão evidente que, mesmo para o menor gradiente de idade encontrado usando as BSSs, pode ser notado com facilidade através dos mapas de idade apresentados a seguir.

\subsection{Mapas de idade do halo usando BSSs}

Utilizando a técnica descrita inicialmente por Santucci et al. (2015b), foram construídos mapas de idade do halo em coordenadas galácticas XYZ (Equação 4.8), utilizando a calibração de magnitudes absolutas dada pela relação 4.3, construídas com cores e metalicidades das BSSs. O gradiente de cor-idade adotado na escala dos mapas é o estimado na seção anterior $\left(\Delta \mathrm{t}_{9} / \Delta(g-r)_{0}=10.3 \pm 3.4 \mathrm{Gano} / \mathrm{dex}\right)$.

Os mapas de cor-idade construídos para o halo galáctico são apresentados nas Figuras 5.6, 5.7 e 5.8, e exibem diferentes pontos de vista do halo galáctico, segundo os planos XY, $\mathrm{XZ}$, e YZ, respectivamente.

Cada mapa possui dois painéis que mostram a mesma região espacial. Os painéis do lado esquerdo mostram as regiões onde as cores médias $\left(<(g-r)_{0}>\right)$ das BSSs foram calculadas, considerando áreas de $1 \mathrm{kpc}^{2}$. Nesses painéis, os quadrados coloridos contém ao menos 3 BSSs, enquanto os pontos são regiões com uma ou duas estrelas. Os valores médios das cores de cada quadrado são vistos como linhas verticais pretas na barra superior dos mapas. Além destes valores, a barra também mostra linhas vermelhas que representam a mediana de cada distribuição de médias, juntamente com o limite $2 \sigma$ delas, correspondendo a área preenchida com a cor cinza. A área cinza da Figura 5.7 é a base de referência para a escala das barras coloridas, as quais destacam a variação $<(g-r)_{0}>$ encontrada. As idades associadas aos índices de cor são vistas entre parênteses em bilhões de anos. Os painéis do lado direito dos mapas mostram suavizações gaussianas dos painéis esquerdos, feitas apenas com os quadrados coloridos. As suavizações adotam passos de dados "2 a 2", dessa maneira, mesmo que existam pontos discrepantes nos mapas, eles acabam sendo suavizados pelo ambiente ao seu redor.

Todos os mapas mostram flutuações de cor-idade complexas e não homogêneas. Entretanto, dois aspectos estão sempre presentes: (i) o gradiente de idade que torna o halo mais jovem do centro para fora que, segundo a escala de cor-idade adotada, é de aproximadamente 1 bilhão de anos, desde o centro da Galáxia até cerca de 30 kpc de distância; 


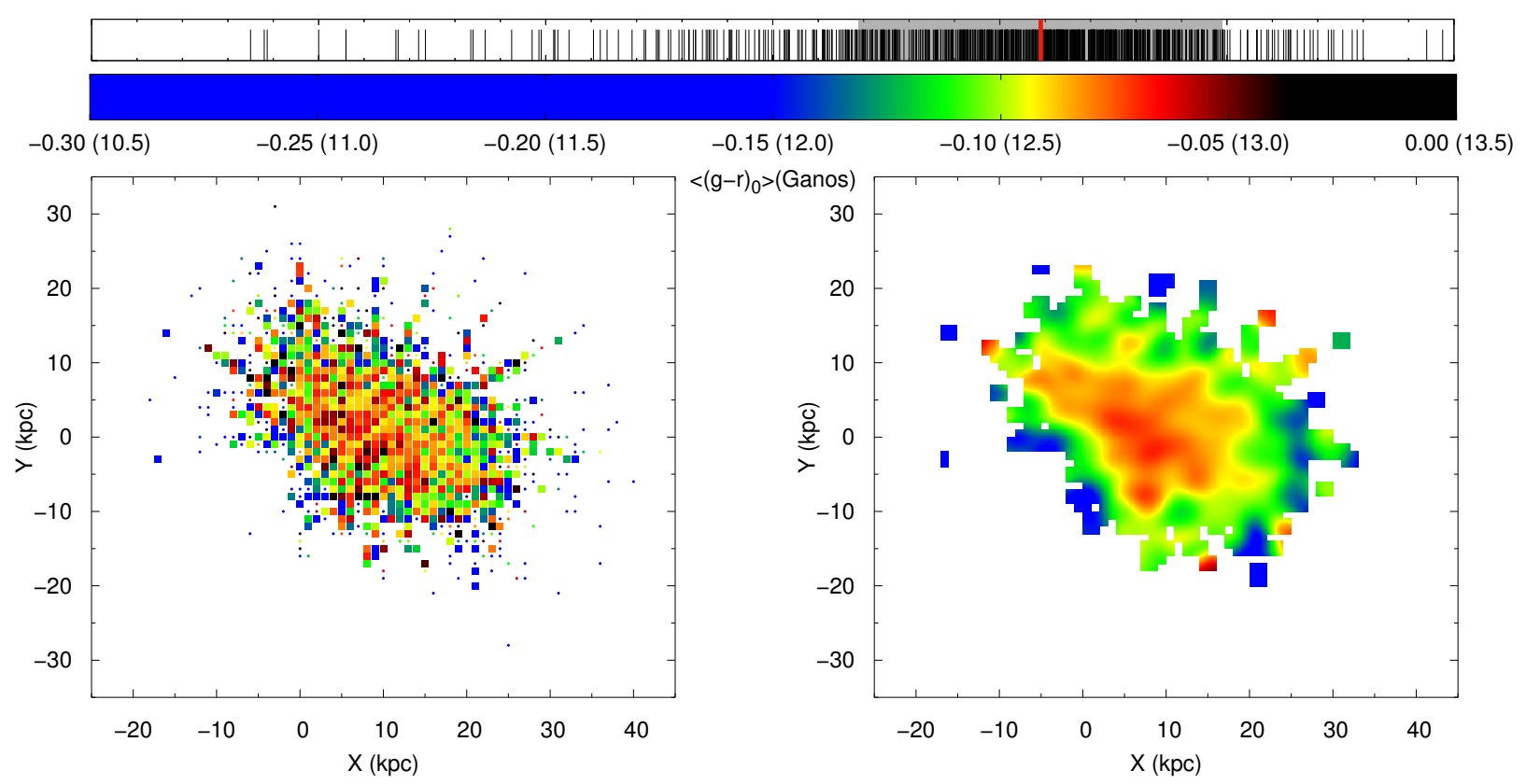

Figura 5.6: Mapa de idade do halo da Galáxia visto no plano de coordenadas galácticas XY. As distâncias foram calculadas usando a relação 4.3 e ambos painéis mostram a mesma região espacial. No painel esquerdo estão identificadas regiões onde as cores médias $\left(<(g-r)_{0}>\right)$ das BSSs foram medidas, considerando passos de $1 \mathrm{kpc}^{2}$. Nesse painel, os quadrados mostram as regiões onde estão presentes ao menos $3 \mathrm{BSSs}$, e os pontos são regiões com 2 ou menos estrelas. Cada quadrado fornece um valor médio de cor, correspondente a uma linha vertical preta na barra superior da figura. Além das médias de todos os quadrados do painel esquerdo, essa barra mostra uma linha vermelha representando a mediana dos valores dessas médias, além de uma região cinza indicando o limite $2 \sigma$ dela. A escala colorida destaca a variação $<(g-r)_{0}>$ encontrada em diferentes ambientes do halo e sua idade equivalente em bilhões de anos (valor entre parênteses). O painel direito mostra uma suavização gaussiana do painel esquerdo, feita apenas com os quadrados em intervalos de dados de 2 em 2.

(ii) Uma nítida concentração de objetos mais velhos sempre internos a um raio de $15 \mathrm{kpc}$ do centro da Galáxia.

A posição preferencial de estrelas mais velhas nas regiões centrais dos mapas é predita por muitos modelos modernos de formação da Galáxia (Bullock e Johnston, 2005; Cooper et al., 2010; Tumlinson, 2010). É relevante notar também que essa região antiga se estende até a vizinhança solar, justificando a busca pelas estrelas mais velhas da Galáxia dentre as estrelas mais brilhantes dos levantamentos de dados (Schlaufman e Casey, 2014).

As diversas flutuações de cores existentes em todos os mapas não indicam, de maneira nenhuma, variações da densidade de objetos. Isso é interessante pois os mapas de idade podem ser usados como ferramentas de identificação de subestruturas baseadas em contraste de cor-idade, muito úteis quando não há, necessariamente, uma sobredensidade de 


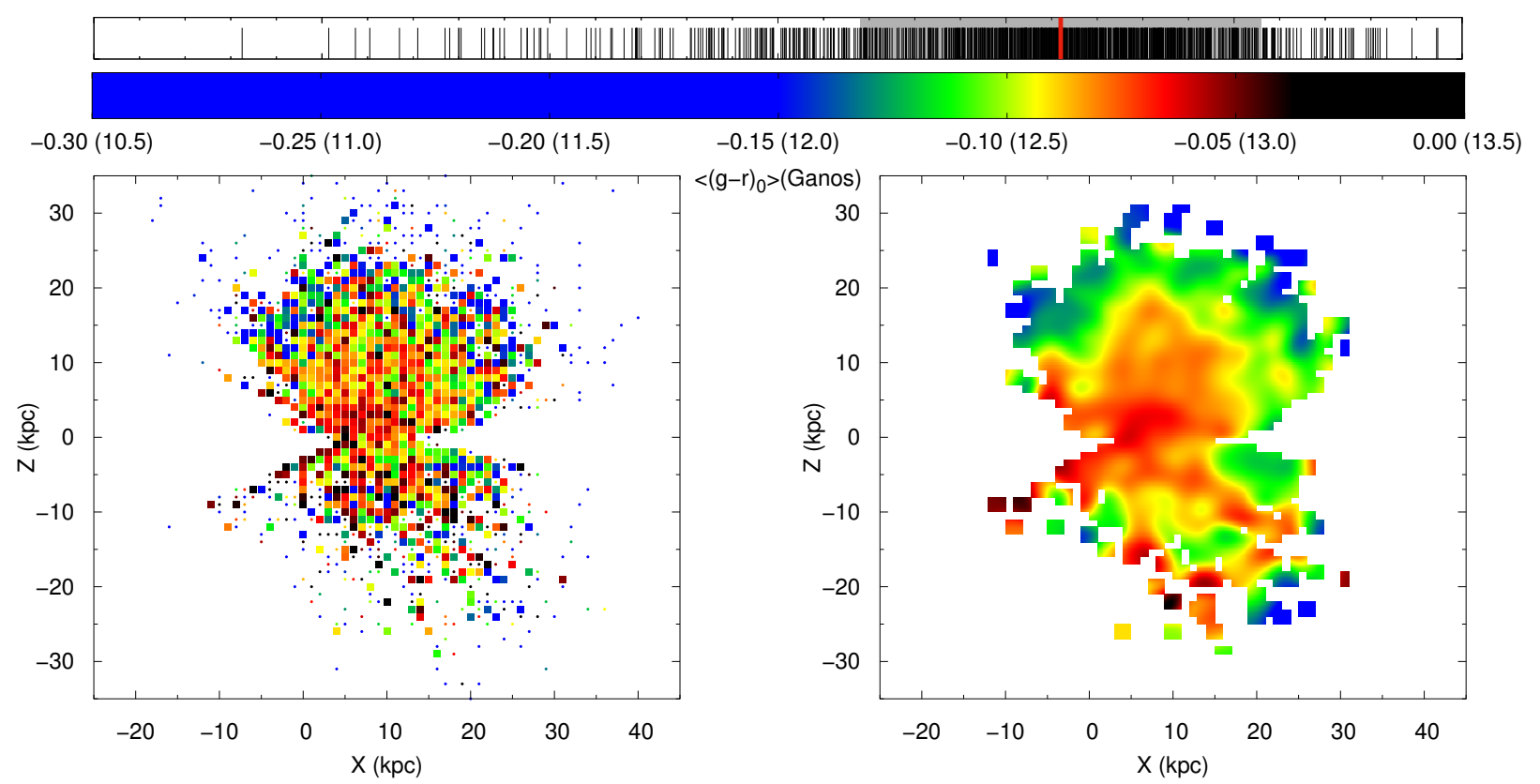

Figura 5.7: Mapa de idade do halo da Galáxia visto no plano de coordenadas galácticas XZ. É nítida a presença de um gradiente de idade ( 1 bilhão de anos), que vai da região central da Galáxia, rejuvenescendo até $\sim 30 \mathrm{kpc}$ de distância. Em todos os mapas pode ser vista uma nítida concentração de "estrelas mais velhas" em um raio de 15kpc do centro da Galáxia. A escala de cor desta figura foi adotada como padrão para todos os mapas.

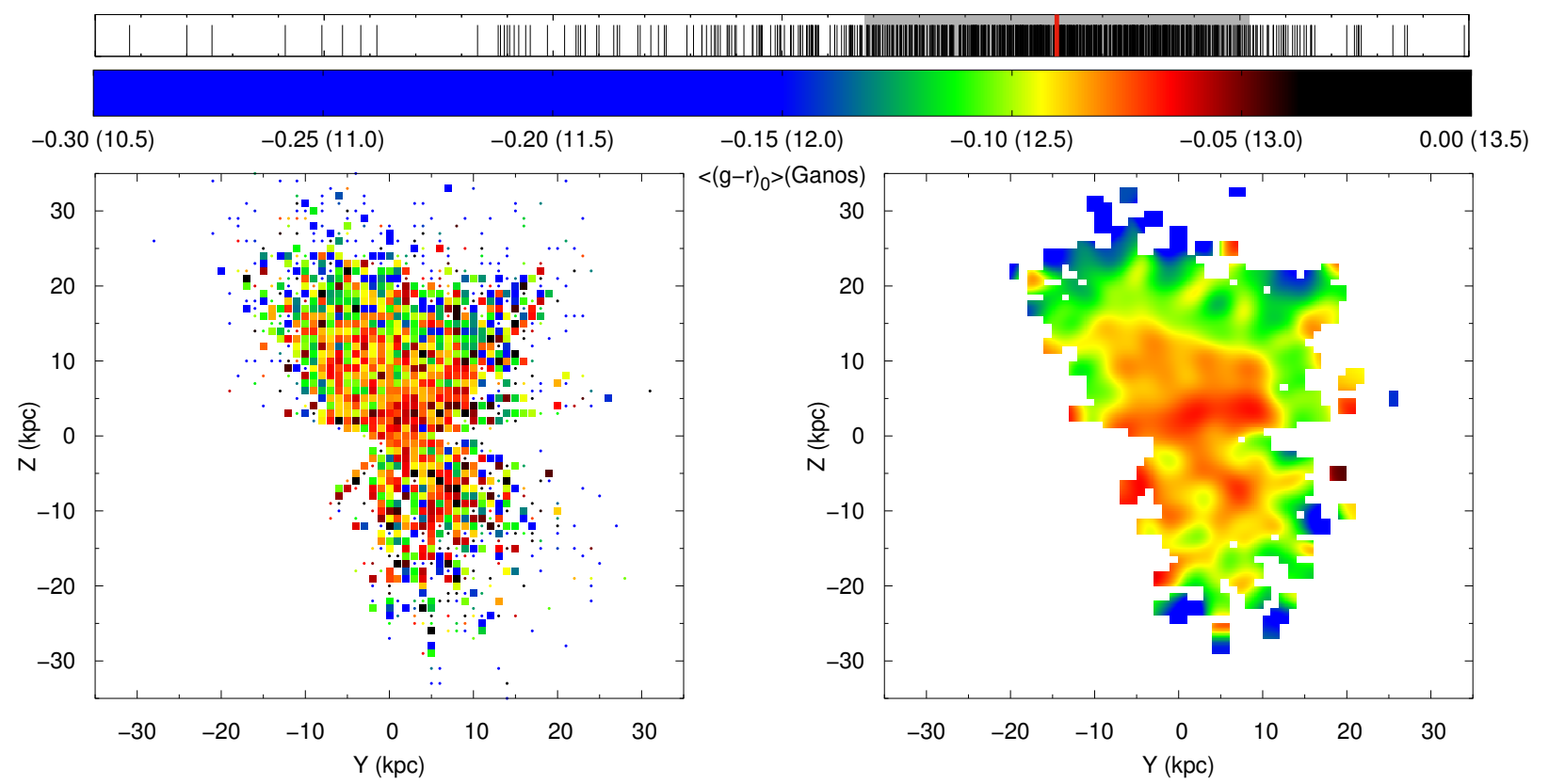

Figura 5.8: Mapa de idade do halo da Galáxia visto no plano de coordenadas galácticas YZ. Através do mapa, assim como nos demais, é possível ver diversas (e nítidas) flutuações de cores-idades, as quais podem estar associadas à presença de subestruturas no halo. 
objetos a ser avaliada (Santucci et al., 2015b; Carollo et al., 2016). Essas flutuações de cor, que aumentam a complexidade dos mapas, podem ser resultado da passagem de uma população mais jovem por um ambiente mais velho, ou mesmo do contrário.

Na tentativa de buscar mais informações sobre a natureza das flutuações de cores observadas nos mapas de idade, foram comparadas suas posições com as localizações centrais de subestruturas já identificadas no halo, com distâncias e coordenadas encontradas na literatura (Newberg e Carlin, 2016).

\subsection{Identificação de subestruturas no halo galáctico}

Conforme visto na Tabela 1.1, são muitas as subestruturas já identificadas no halo galáctico. Através das distâncias centrais e das janelas de localização em coordenadas celestes, vistas na Tabela 1.1, foram estimadas suas posições centrais em coordenadas galácticas XYZ (kpc), usando a Equação 4.8. Devido à limitação de distância dos mapas feitos com BSSs, nenhuma subestrutura com distância heliocêntrica maior que $35 \mathrm{kpc}$ pode ser identificada.

Todas as subestruturas da Tabela 1.1 com posições acessíveis via mapas de cor-idade estão graficadas na Figura 5.9. Os valores de suas coordenadas galácticas centrais (XYZ em kpc) podem ser consultados na Tabela 5.1. É importante ressaltar que, a princípio, somente os valores centrais das subestruturas são usados para identificá-las nos mapas. Sua caracterização detalhada exige um trabalho muito mais cuidadoso, que está em andamento mas não é apresentado neste trabalho. A intenção dessa análise é mostrar que os mapas podem ser usados para identificá-las visualmente, através do contraste de cor-idade. Ao final desta seção, pode ser visto que mesmo esse critério simples de comparação (posições centrais) também apresenta boa concordância quantitativa.

A Figura 5.9 foi construída usando as mesmas regiões espaciais dos mapas de coridade. Ela mostra que muitas componentes possuem posições superpostas, alguma em mais de um plano de visada. Além disso, a figura mostra também que as buscas por subestruturas usando grandes mapeamentos de dados, como o SDSS, tornaram o halo muito mais complexo e dinâmico. As regiões púrpuras da figura destacam as posições centrais das subestruturas compiladas por Newberg e Carlin (2016), e as regiões cinzas mostram três regiões da corrente de Sagitário, que foram escolhidas segundo observações 

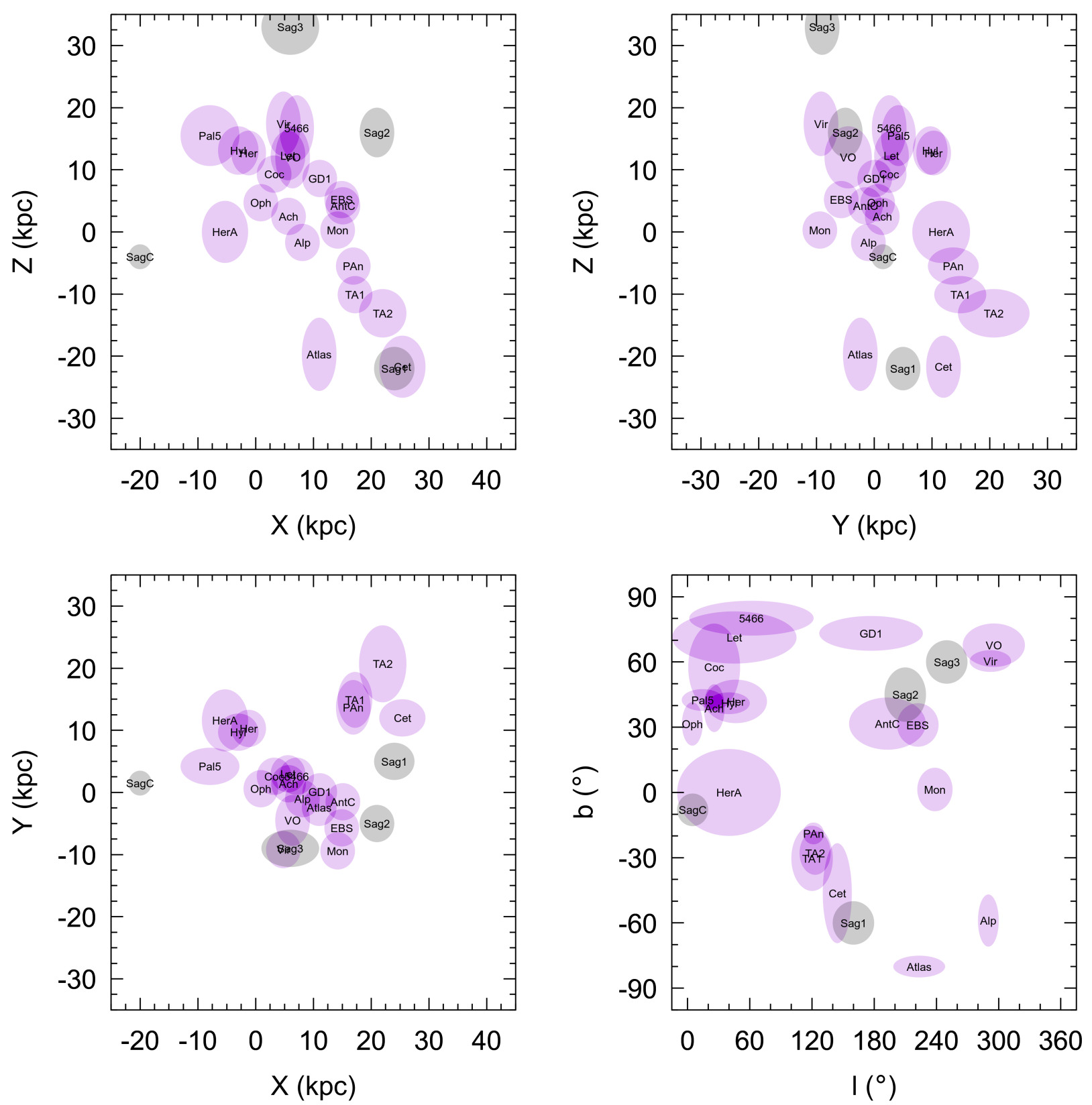

Figura 5.9: Posições galácticas (XYZ em kpc) e celestes (l,b em graus) das subestruturas presentes na Tabela 5.1. Tais subestruturas estão presentes nas regiões espaciais alcançadas pelos mapas de cor-idade. Os nomes das subestruturas estão centrados em áreas coloridas (cor púrpura) para facilitar suas identificações (estas áreas não representam seus limites espaciais). Foram escolhidas 3 posições da corrente de Sagitário (em cinza escuro), baseadas em observações do trabalho de Slater et al. (2013), para efeitos de comparação nos mapas. Como curiosidade, foi identicada a posição galáxia anã de Sagitário, progenitora da corrente de Sagitário, vista com o nome de "SagC".

de Slater et al. (2013). Todas as regiões graficadas possuem tamanhos exagerados para ajudar a destacar suas posições e não representam seus limites espaciais no halo. A posição 
da galáxia progenitora da corrente de Sagitário é identificada na Figura com "SagC". A corrente de Sagitário é a subestrutura mais distante que o mapa pode correlacionar, já que está no limite de alcance das distâncias fornecidas pelas BSSs. Ao todo, 22 subestruturas distintas são vistas na Figura 5.9. Suas posições centrais foram então superpostas aos mapas de cor-idade, conforme visto nas Figuras 5.10, 5.11 e 5.12.

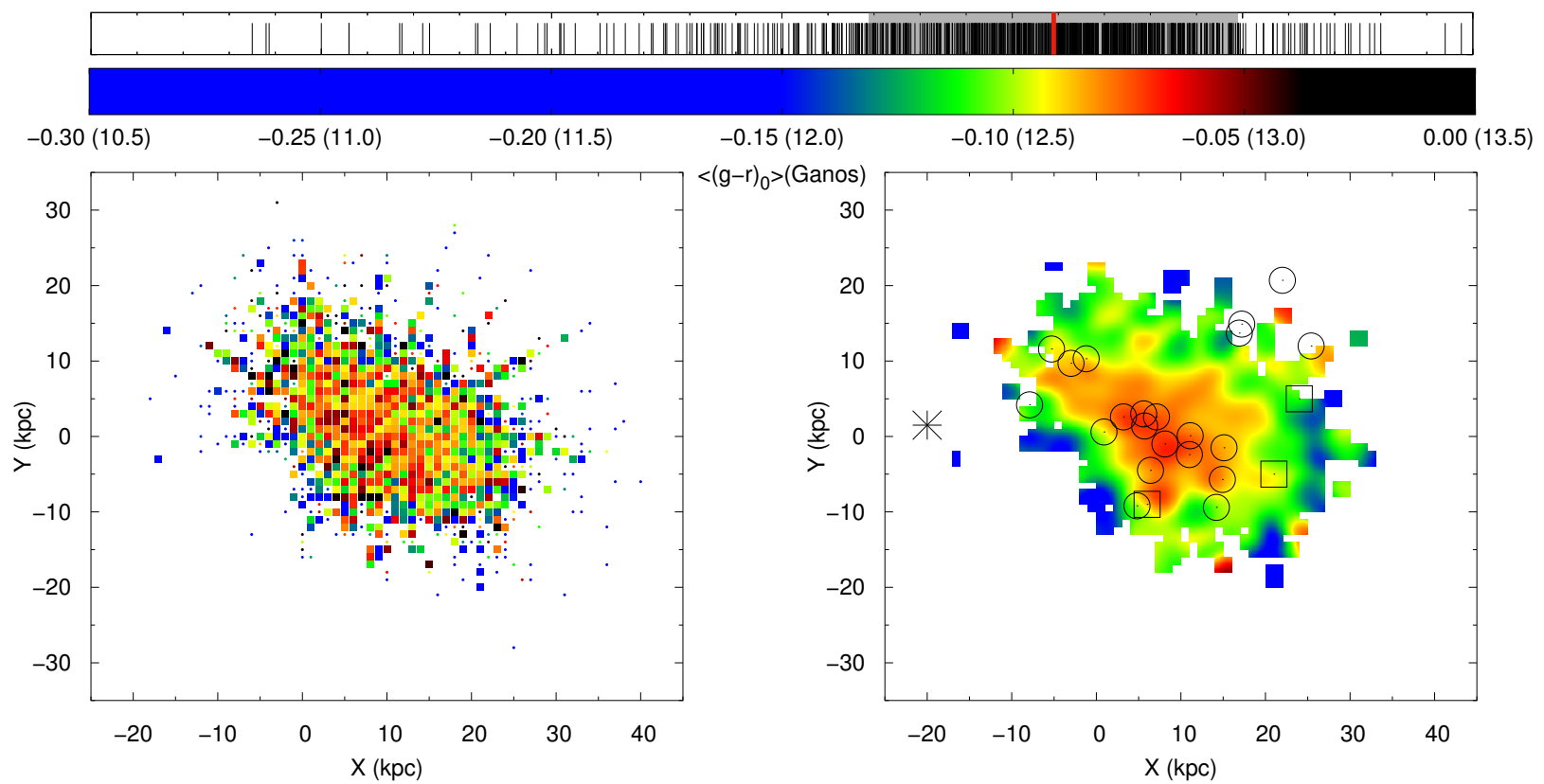

Figura 5.10: Combinação das posições centrais das subestruturas da Figura 5.9 com o mapa de idade do halo visto no plano XY. Os quadrados marcam as 3 posições escolhidas para a corrente de Sagitário (Slater et al., 2013). Os círculos marcam todas as subestruturas compiladas por Newberg e Carlin (2016), presentes nas áreas dos mapas. A posição da galáxia anã de Sagitário está marcada com um asterisco (Slater et al., 2013). Várias flutuações/extensões de cor coincidem com as posições centrais das subestruturas comparadas.

Nota-se, por inspeção visual, que muitas subestruturas possuem posições centrais coincidentes com flutuações/extensões de cores dos mapas. Segundo esse critério visual, as subestruturas Cet, Sag2, Sag3, HerA, Her, Hyl, EBS, Coc e Alp podem ser associadas com deformações de cor-idade no mapa apresentado na Figura 5.10. Já na Figura 5.11, além de algumas das estruturas já citadas, outras subestruturas se tornam mais evidentes, como é o caso de Atlas, TA1, TA2, Mon, Ach, 5466, Vir e Oph. Por fim, na Figura 5.12, mais duas subestruturas diferentes são vistas em flutuações/extensões de cores: Sag1, PAn. As subestruturas AntC, GD1, Let, Vir e Pal5 apresentam-se mais evidentes no mapa da Figura 5.10 do que nos outros. Mesmo assim, não são tão evidentes quanto as outras detecções feitas. Isso pode significar que, apesar serem encontradas por contrate de densi- 
dade, elas não parecem ter idades diferentes do ambiente em que estão no momento. Todas estas identificações visuais foram baseadas em extensões, deformações ou concentrações de ambientes mais velhos no halo (portanto mais avermelhados).

Além disso, as comparações visuais baseadas em posições centrais das subestruturas podem atrapalhar suas identificações, como o caso de HerA (ver Figura 5.11). Essa subestrututa possui coordenadas centrais $\mathrm{X}=-5 \mathrm{kpc}$ e $\mathrm{Z}=0 \mathrm{kpc}$, mas esta região não é amostrada por BSSs no mapa. Entretanto, a subestrutura está presente, pois é uma nuvem enorme que se estende de $\mathrm{b}=-50^{\circ}$ até $\mathrm{b}=+50^{\circ}$, sendo vista através de duas grandes manchas vermelhas perpendiculares ao disco, na direção de sua posição central. Portanto, nem sempre as posições centrais das correntes (ou mesmo das nuvens) são as melhores para identificá-las nos mapas, pois elas podem estar fora da região amostrada, ou podem ser a região menos importante (ou evidente) da subestrutura. Essas razões também podem ser os motivos de AntC, GD1, Let, Vir e Pal5 não terem sido identificadas obviamente.

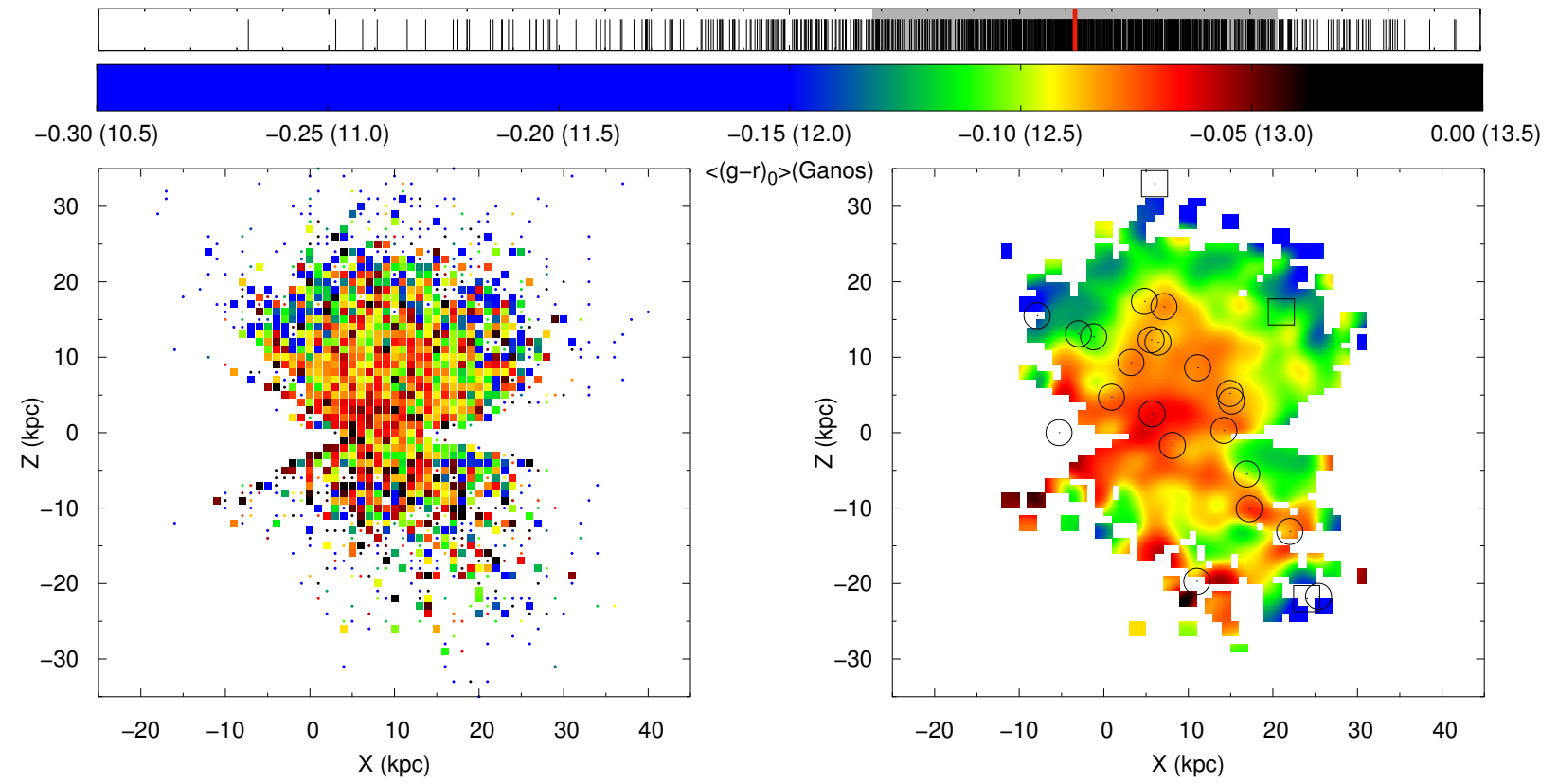

Figura 5.11: Combinação das posições centrais das subestruturas da Figura 5.9 com o mapa de idade do halo visto no plano XZ. Novamente, várias flutuações/extensões de cor coincidem com as posições de subestruturas. A nuvem HerA não possui BSSs na sua posição central $(\mathrm{X}=-5 \mathrm{kpc}$ e $\mathrm{Z}=0 \mathrm{kpc})$, mas ela está presente no mapa e é facilmente visível, pois se estende de $\mathrm{b}=-50^{\circ}$ até $\mathrm{b}=+50^{\circ}$. Note que existem duas flutuações de cor, bem avermelhadas, perpendiculares ao disco galáctico, na direção da sua posição central.

É interessante notar que a maioria das subestruturas mapeadas na figuras puderam ser encontradas preferecialmente nos planos XY e XZ. Entretanto, o mapa do plano YZ 
(Figura 5.12) também fornece informações interessantes sobre o halo, pois é neste plano que as subestruturas Sag1, Atlas e PAn ficam mais evidentes. Além disso, esse plano também mostra flutuações de cor intensas que ainda não possuem subestruturas associadas, como visto nas regiões $(\mathrm{Y}, \mathrm{Z})$ iguais a $(-5,-8),(+8,+4),(+15,+15)$ e $(-15,+10)$.

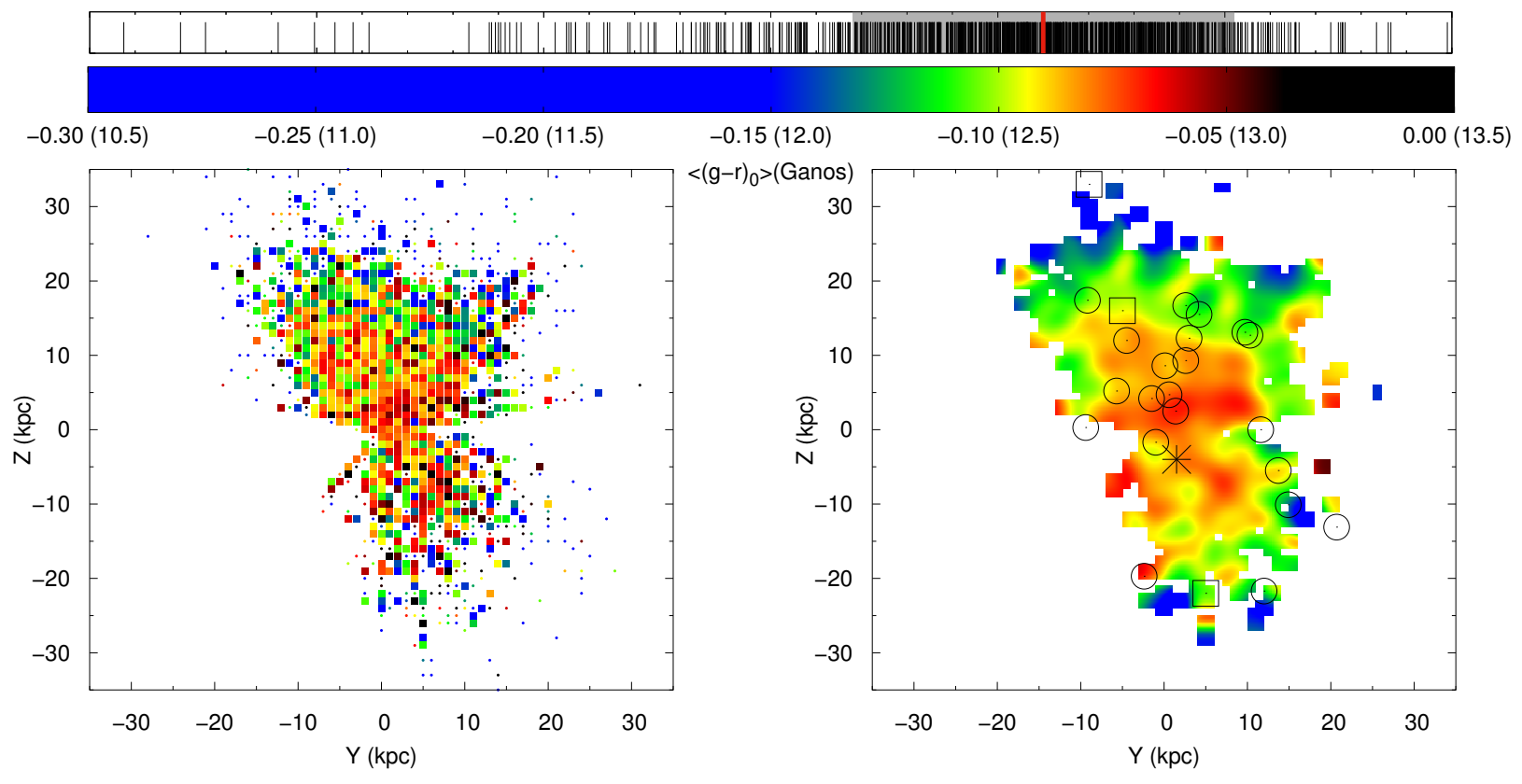

Figura 5.12: Combinação das posições centrais das subestruturas da Figura 5.9 com o mapa de idade do halo visto no plano YZ. Neste plano de visada da Galáxia são vistas muitas flutuações de cor intensas que não possuem estruturas associadas, como nas regiões (Y,Z) iguais a $(-5,-8),(+8,+4),(+15,+15)$ e $(-15,+10)$.

Essas sugestões de novas subestruturas, assim como as outras identificações visuais feitas, ainda devem ser avaliadas cuidadosamente e individualmente. Mapas de cor-idade específicos dessas regiões estão em construção e fazem parte de uma extensão deste trabalho. Nessa "tomografia" de cor-idade do halo, a confirmação de cada subestrutura deve ser feita através de mapas em todos os planos de visada. Além disso, suas regiões contrastantes devem possuir parâmetros químicos e cinemáticos compatíveis com os valores encontrados na literatura, quando disponíveis.

Para simplificar e resumir o poder dessa técnica, e ao mesmo tempo fornecer uma ideia das comparações que estarão presentes na extensão deste trabalho, foram calculadas as medianas das velocidades heliocêntricas e metalicidades das BSSs nas regiões centrais definidas. Os valores obtidos foram comparados com outros disponíveis na literatura (Newberg e Carlin, 2016) e apresentados na Tabela 5.1. Para selecionar as BSSs nas regiões 
centrais, foram adotados os limites de $1 \sigma$ dos erros de cada coordenada galáctica XYZ, cujos valores também estão presentes na Tabela 5.1. Nessa tabela, a coluna 1 fornece o nome abreviado da subestrutura (veja o nome completo na Tabela 1.1). As colunas 3 e 5 mostram, respectivamente, metalicidades $([\mathrm{Fe} / \mathrm{H}])$ e velocidades radiais heliocêntricas (em $\mathrm{km} / \mathrm{s}$ ) da subestrutura disponíveis na literatura (Newberg e Carlin, 2016). As colunas 4 e 6 mostram, respectivamente, metalicidades $([\mathrm{Fe} / \mathrm{H}])$ e velocidades radiais heliocêntricas (em $\mathrm{km} / \mathrm{s}$ ) medianas de BSSs nas regiões centrais adotadas. As colunas 7, 8 e 9 mostram, respectivamente, os valores centrais de cada subestrutura, juntamente com suas margens de erro. A coluna 2 mostra o número de BSSs presentes dentro das regiões centrais avaliadas.

Das 22 subestruturas consideradas, $17(\sim 77 \%)$ foram identificadas visualmente através do contraste de cor-idade. Ainda dentre as 22, 15 possuem velocidades radiais medidas na literatura, sendo que $13(\sim 87 \%)$ são compatíveis com os valores das BSSs em $2 \sigma$. Comparando-se as metalicidades das 22 subestruturas, 19 ( $\sim 86 \%)$ possuem valores que estão de acordo com as BSSs dentro de um intervalo de $2 \sigma$. Esses números mostram que, a princípio, a calibração de magnitude absoluta adotada para as BSSs mostra-se confiável para traçar distâncias no halo. Além disso, quando se compara identificações visuais, metalicidades e velocidades, $9(\sim 60 \%)$ subestruturas dentre 15 das que possuem todos os parâmetros comparados disponíveis concordam em $2 \sigma$. Essa fração é relativamente alta dada a simplicidade das comparações adotadas.

Assim, tais resultados mostram que a técnica parece ter uma aplicabilidade promissora para explorar o halo em busca de subestruturas e, certamente, trará grandes avanços à área se aplicada a outros levantamentos de dados. 
Tabela 5.1 - Resumo e comparação entre os parâmetros físicos das subestruturas publicados na literatura Newberg e Carlin (2016), com os valores obtidos neste trabalho usando as BSSs. A coluna 1 fornece o nome abreviado da componente (apresentado por completo na Tabela 1.1). As colunas 3 e 5 mostram, respectivamente, metalicidades $([\mathrm{Fe} / \mathrm{H}])$ e velocidades radiais heliocêntricas $(\mathrm{em} \mathrm{km} / \mathrm{s})$ de membros das subestruturas já estimados na literatura. As colunas 4 e 6 mostram, respectivamente, metalicidades $([\mathrm{Fe} / \mathrm{H}])$ e velocidades radiais heliocêntricas $(\mathrm{em} \mathrm{km} / \mathrm{s})$ de membros das subestruturas estimadas por este trabalho, usando as BSSs. As colunas 7, 8 e 9 mostram, respectivamente, os valores centrais de cada subestrutura, e suas margens de erro, usados para calcular as metalicidades e velocidades das colunas 4 e 6. A coluna 2 mostra o número de objetos encontrados nas posições centrais XYZ das subestrutura, dentro de suas margens de erro (ver colunas 7, 8 e 9).

\begin{tabular}{|c|c|c|c|c|c|c|c|c|}
\hline Nome & $\#$ & {$[\mathrm{Fe} / \mathrm{H}]$} & {$[\mathrm{Fe} / \mathrm{H}]$} & $\mathrm{V}_{\odot}(\mathrm{km} / \mathrm{s})$ & $\mathrm{V}_{\odot}(\mathrm{km} / \mathrm{s})$ & $\mathrm{X}$ & $\mathrm{Y}$ & $\mathrm{Z}$ \\
- & - & literatura & BSSs & literatura & BSSs & $(\mathrm{kpc})$ & $(\mathrm{kpc})$ & $(\mathrm{kpc})$ \\
\hline Sag1 & 33 & $-1.15,-0.4$ & $-1.17 \pm 0.53$ & $-200,+200$ & $-149 \pm 15$ & $24.0 \pm 6.0$ & $5.0 \pm 3.0$ & $-22.0 \pm 5.0$ \\
Sag2 & 7 & $-1.15,-0.4$ & $-1.39 \pm 0.57$ & $-200,+200$ & $-98 \pm 35$ & $21.0 \pm 3.0$ & $-5.0 \pm 3.0$ & $-16.0 \pm 5.0$ \\
Sag3 & 9 & $-1.15,-0.4$ & $-1.01 \pm 0.52$ & $-200,+200$ & $86 \pm 56$ & $6.0 \pm 5.0$ & $-9.0 \pm 4.0$ & $33.0 \pm 6.0$ \\
\hline Vir & 36 & -1.8 & $-1.56 \pm 0.45$ & 128 & $112 \pm 104$ & $4.8 \pm 2.0$ & $-9.2 \pm 2.0$ & $17.4 \pm 5.0$ \\
Pal5 & 13 & -1.4 & $-1.21 \pm 0.40$ & -55 & $-27 \pm 80$ & $-7.9 \pm 3.0$ & $4.2 \pm 2.0$ & $15.5 \pm 3.0$ \\
Mon & 15 & -0.8 & $-1.08 \pm 0.23$ & 100 & $114 \pm 9$ & $14.2 \pm 2.0$ & $-9.4 \pm 2.0$ & $0.3 \pm 3.0$ \\
5466 & 20 & -2.2 & $-1.77 \pm 0.45$ & 108 & $18 \pm 92$ & $7.1 \pm 2.0$ & $2.6 \pm 2.0$ & $16.7 \pm 3.0$ \\
GD1 & 51 & -2.1 & $-1.70 \pm 0.55$ & $-200,+100$ & $-108 \pm 93$ & $11.1 \pm 1.5$ & $0.1 \pm 1.5$ & $8.6 \pm 1.5$ \\
AntC & 28 & -1.0 & $-1.34 \pm 0.48$ & $+050,+090$ & $36 \pm 27$ & $15.1 \pm 1.0$ & $-1.5 \pm 1.0$ & $4.2 \pm 1.0$ \\
EBS & 33 & -1.8 & $-1.53 \pm 0.51$ & $+071,+085$ & $86 \pm 42$ & $14.9 \pm 1.5$ & $-5.7 \pm 1.0$ & $5.2 \pm 1.0$ \\
Ach & 26 & $-1.7(?)$ & $-1.41 \pm 0.32$ & - & $-75 \pm 53$ & $5.7 \pm 1.0$ & $1.4 \pm 1.0$ & $2.5 \pm 1.0$ \\
Coc & 20 & $-1.7(?)$ & $-1.67 \pm 0.70$ & - & $-114 \pm 81$ & $3.2 \pm 1.5$ & $2.6 \pm 1.5$ & $9.3 \pm 1.5$ \\
Let & 24 & $-1.7(?)$ & $-1.63 \pm 0.45$ & - & $-106 \pm 83$ & $5.6 \pm 1.5$ & $3.0 \pm 1.5$ & $12.3 \pm 2.5$ \\
Cet & 12 & -2.1 & $-1.22 \pm 0.46$ & $-200,-160$ & $-170 \pm 31$ & $25.4 \pm 6.0$ & $12.0 \pm 4.0$ & $-21.7 \pm 8.0$ \\
Alp & 15 & $-1.0(?)$ & $-1.48 \pm 0.52$ & - & $-11 \pm 46$ & $8.1 \pm 1.5$ & $-1.0 \pm 2.0$ & $-1.7 \pm 2.0$ \\
Atlas & 12 & $-1.4(?)$ & $-1.31 \pm 0.43$ & - & $-98 \pm 55$ & $11.0 \pm 5.0$ & $-2.4 \pm 3.5$ & $-19.7 \pm 5.0$ \\
PAn & 18 & $-1.5(?)$ & $-0.98 \pm 0.42$ & 127 & $-102 \pm 28$ & $16.9 \pm 3.5$ & $13.7 \pm 4.0$ & $-5.5 \pm 2.5$ \\
Her & 81 & $-2.3(?)$ & $-1.28 \pm 0.41$ & - & $-99 \pm 103$ & $-1.2 \pm 2.0$ & $10.3 \pm 2.0$ & $12.7 \pm 2.0$ \\
Hyl & 16 & $-2.3(?)$ & $-1.36 \pm 0.57$ & - & $-109 \pm 50$ & $-3.0 \pm 2.0$ & $9.7 \pm 2.0$ & $13.1 \pm 2.0$ \\
Oph & 11 & -2.0 & $-1.72 \pm 0.42$ & 290 & $56 \pm 137$ & $0.9 \pm 1.5$ & $0.6 \pm 1.5$ & $4.7 \pm 1.5$ \\
\hline TA1 & 22 & -0.6 & $-1.45 \pm 0.41$ & $-200,-50$ & $-142 \pm 115$ & $17.2 \pm 4.0$ & $14.9 \pm 5.0$ & $-10.1 \pm 4.0$ \\
HerA & 17 & $-2.2,-1.4$ & $-1.00 \pm 0.35$ & $-130,-120$ & $-141 \pm 89$ & $-5.3 \pm 3.0$ & $11.6 \pm 3.0$ & $0.0 \pm 9$ \\
VO & 30 & $-2.0,-1.0$ & $-1.74 \pm 0.49$ & $+200,+360$ & $117 \pm 77$ & $6.4 \pm 1.5$ & $-4.5 \pm 1.5$ & $12 \pm 1.5$ \\
TA2 & 4 & -0.6 & $-1.00 \pm 0.49$ & $-200,-50$ & $-110 \pm 6$ & $22 \pm 5.0$ & $20.7 \pm 6.0$ & $-13.1 \pm 5.0$ \\
\hline
\end{tabular}


Capítulo 6

\section{Considerações finais}

\subsection{Interpretação dos resultados}

Um gradiente de idade mostrando que estrelas mais velhas da Galáxia estão concentradas predominantemente em seu centro, como encontrado neste trabalho, é consistente com o modelo cosmológico $\Lambda \mathrm{CDM}$ ("lambda cold dark matter") de formação de estruturas, onde os progenitores mais velhos do halo estão concentrados em suas regiões mais centrais. Essa concentração é resultado do processo de formação de "dentro para fora" dos halos galácticos, os quais são constituídos por progenitores primordiais em suas regiões centrais, enquanto que as regiões mais externas são construídas preferencialmente a partir de sub-halos que se virializam e se fundem tempos depois (White e Springel, 2000).

Segundo esses autores, as estrelas mais velhas do Universo deveriam ser atualmente encontradas nos núcleos de galáxias centrais de grandes aglomerados de galáxias. No caso da Via Láctea, a região mais adequada para se encontrar as primeiras estrelas do Universo seria seu bojo e/ou regiões muito internas do halo. Por esta razão, pouca correlação entre idade e metalicidade é esperada para o halo galáctico.

Considerando esse cenário, vários objetos mais velhos da Galáxia podem exibir altas metalicidades, pois os "esferóides" centrais primordiais de estrelas que se formam nos modelos, antes e juntamente com o halo, já passaram por episódios de evolução química. Assim, espera-se que as estrelas mais velhas e com enriquecimento químico mais elevado sejam encontradas preferencialmente nas regiões centrais da Galáxia ( $r<5-15$ kpc), enquanto que as estrelas mais pobres estejam preferencialmente localizadas em regiões cada vez mais distantes do centro galáctico (White e Springel, 2000). Ambos os resultados foram verificados neste trabalho, através do gradiente de cor-idade do halo e das distribuições de 
metalicidades observadas.

Ainda de acordo com White e Springel (2000), o esferóide antigo da Via Láctea, de raio entre $5 \mathrm{kpc}$ a $15 \mathrm{kpc}$ do seu centro, ainda pode conter informações a respeito do seu histórico de formação, pois ainda poderiam ser observadas até centenas de correntes "frias" resultantes da fusão de sub-halos primordiais. Indícios dessas predições poder ser vistos nos mapas de cor-idade criados neste trabalho, já que essa região central antiga é observada em todos os planos de visada e, além disso, nota-se que é uma estrutura muito complexa, repleta de inomogeneidades de cores-idades.

Entretanto, mesmo que esse cenário coincida qualitativamente com os mapas gerados por este trabalho, cabe lembrar que a escala de cor-idade adotada segue modelos de estrelas na sequência principal, sem acréscimo de massa ao longo de sua evolução. Portanto, uma comparação mais direta com modelos que atentem para a natureza das BSSs ainda se faz necessária. Isso poderia ser melhorado com uma grade de modelos de sequência principal que considerem atmosferas enriquecidas, com abundâncias químicas diferentes de sua composição original central. Esses valores de enriquecimento químico poderiam se basear em abundâncias químicas de BSSs medidas em aglomerados globulares (Ferraro et al., 2006), ou mesmo em estrelas jovens do disco galáctico que foram vítimas do mesmo processo de transferências de massa, como Sirius e Prócion (Adelman, 2004). Tais modelos, mais semelhantes ao que seriam as BSSs, poderiam explicar a tendência desses objetos serem mais avermelhados para metalicidades mais baixas. Também é possível que essas variações nas cores sejam resultado de processos físicos ainda desconhecidos destes objetos. Ao mesmo tempo, é difícil imaginar como isso teria correlação com a distância ao centro galáctico.

\subsection{Conclusões}

Este trabalho utilizou 8001 estrelas azuis tardias provenientes da base de dados do SDSS, selecionadas segundo várias restrições fotométricas e espectroscópicas. Esses objetos apresentaram um gradiente de cor em função de suas distâncias ao centro da Galáxia, fenômeno que foi relacionado com suas idades, usadas para produzir mapas de cor-idade do halo galáctico. Esses mapas mostraram que as estrelas mais velhas da Galáxia estão preferencialmente localizadas na região mais interna do halo $(\mathrm{r}<10-15 \mathrm{kpc}$ ). Além disso, eles 
também confirmaram que o halo possui uma grande complexidade estrutural, descatada por muitas flutuações de cor-idade. Várias dessas flutuações foram conectadas à presença de subestruturas já identificadas no halo, onde cerca de $\sim 60 \%$ delas possuem parâmetros físicos que concordam com valores da literatura em até $2 \sigma$.

A variação de idade observada no halo juntamente com a localização e a extensão de seu esferóide central antigo $(\mathrm{r}<10-15 \mathrm{kpc})$, confirmam e estendem os resultados anteriores de Preston et al. (1991a), Santucci et al. (2015b) e Carollo et al. (2016), através de uma nova classe de objetos: as estrelas azuis tardias. Esses resultados são consistentes com as predições de modelos hierárquicos de formação de Galáxia (White e Springel, 2000; Font et al., 2006; Cooper et al., 2010).

Além disso, a frequência de estrelas azuis tardias observada no halo galáctico, $\mathrm{F}_{\mathrm{BSS} / \mathrm{BHB}}$ $=2.15 \pm 0.13$, concorda perfeitamente com a frequência de BSSs em galáxias anãs próximas $\left(\mathrm{F}_{\mathrm{BSS} / \mathrm{BHB}}=2.24 \pm 0.17\right.$ : Momany et al., 2007), sugerindo também que o halo parece ter sido construído através da fusão destes sistemas menores.

\subsection{Perspectivas}

A técnica de mapas de cor-idade possui um potencial enorme ainda é difícil de ser predito em detalhes. Ela pode ser usada tanto com BHBs (Santucci et al., 2015b), como também com BSSs, e provavelmente com qualquer tipo estelar que possua variações de idade acessíveis através de suas cores.

Até o momento, nenhuma base de dados além do SDSS foi usada para construção desses mapas. A técnica é acessível até mesmo para amostras puramente fotométricas (Carollo et al., 2016), onde se obtém resultados equivalentes.

O levantamento de dados J-PLUS (Cenarro et al., 2015), e seu equivalente no hemisfério Sul (S-PLUS), fornecerão dados fotométricos em regiões do céu diferentes do SDSS. Além dos filtros de banda larga usados, eles também possuem filtros estreitos centrados exatamente nas linhas da série de Balmer do Hidrogênio, que são as características espectrais comumente usadas para a separação de BHBs e BSSs. Novos mapeamentos de dados como LAMOST ("Large Sky Area Multi-Object Fibre Spectroscopic Telescope": Zhao et al., 2012), PAn-STARRS ("Panoramic Survey Telescope \& Rapid Response System": Vickers et al., 2014), Dark Energy Survey (Li et al., 2016), DESI ("Dark Energy Spectroscopic Instru- 
ment": DESI Collaboration et al., 2016) e o LSST ("Large Synoptic Survey Telescope": Oluseyi et al., 2011) também se mostram promissores para a aplicação da técnica.

Apesar da informação espectrofotométrica ser importante, o conhecimento das distâncias dos objetos é fundamental. Os mapas feitos até então utilizam distâncias que estão sempre atreladas às cores e/ou abundâncias dos objetos (que também variam com a distância). Por esta razão, a informação astrométrica permite que as cores das estrelas sejam avaliadas de maneira completamente independente das suas distâncias, tornando os dados fornecidos pelo GAIA (Perryman et al., 2001; Jordi, 2015), fundamentais para o entendimento da formação e evolução da Galáxia (Jurić e Ivezić, 2011; Ivezić et al., 2015). 


\section{Referências Bibliográficas}

Adelman S. J., The physical properties of normal A stars. In The A-Star Puzzle, vol. 224 of IAU Symposium, 2004, p. 1

Aihara H., Allende Prieto C., An D., Anderson S. F., Aubourg É., Balbinot E., Beers T. C., Berlind A. A., Bickerton S. J., Bizyaev D., Blanton M. R. et. al., The Eighth Data Release of the Sloan Digital Sky Survey: First Data from SDSS-III, ApJS, 2011, vol. 193 , p. 29

Allende Prieto C., Sivarani T., Beers T. C., Lee Y. S., Koesterke L., Shetrone M., Sneden C., Lambert D. L., Wilhelm R. et. al., The SEGUE Stellar Parameter Pipeline. III. Comparison with High-Resolution Spectroscopy of SDSS/SEGUE Field Stars, AJ, 2008, vol. 136 , p. 2070

An D., Johnson J. A., Clem J. L., Yanny B., Rockosi C. M., Morrison H. L., Harding P., Gunn J. E. et. al.., Galactic Globular and Open Clusters in the Sloan Digital Sky Survey. I. Crowded-Field Photometry and Cluster Fiducial Sequences in ugriz, ApJS, 2008, vol. 179 , p. 326

Baade W., Galaxies and their Stellar Populations. (A Review of the Present State of Affairs), Ricerche Astronomiche, 1958, vol. 5, p. 3

Bailyn C. D., Blue Stragglers and Other Stellar Anomalies:Implications for the Dynamics of Globular Clusters, ARA\&A, 1995, vol. 33, p. 133

Beers T. C., Carollo D., Ivezić Ž., An D., Chiba M., Norris J. E., Freeman K. C., Lee Y. S. et. al., The Case for the Dual Halo of the Milky Way, ApJ, 2012, vol. 746, p. 34 
Beers T. C., Doinidis S. P., Griffin K. E., Preston G. W., Shectman S. A., Spectroscopy of hot stars in the Galactic halo, AJ, 1992, vol. 103, p. 267

Beers T. C., Kage J. A., Preston G. W., Shectman S. A., Estimation of stellar metal abundance. I - Calibration of the CA II K index, AJ, 1990, vol. 100, p. 849

Beers T. C., Rossi S., Norris J. E., Ryan S. G., Shefler T., Estimation of Stellar Metal Abundance. II. A Recalibration of the Ca II K Technique, and the Autocorrelation Function Method, AJ, 1999, vol. 117, p. 981

Belokurov V., Evans N. W., Irwin M. J., Hewett P. C., Wilkinson M. I., The Discovery of Tidal Tails around the Globular Cluster NGC 5466, ApJ, 2006, vol. 637, p. L29

Belokurov V., Evans N. W., Irwin M. J., Lynden-Bell D., Yanny B., Vidrih S. et. al., An Orphan in the "Field of Streams", ApJ, 2007, vol. 658, p. 337

Belokurov V., Zucker D. B., Evans N. W., Gilmore G., Vidrih S., Bramich D. M. et. al., The Field of Streams: Sagittarius and Its Siblings, ApJ, 2006, vol. 642, p. L137

Bernard E. J., Ferguson A. M. N., Schlafly E. F., Abbas M., Bell E. F., Deacon N. R., Martin N. F. et. al., Serendipitous discovery of a thin stellar stream near the Galactic

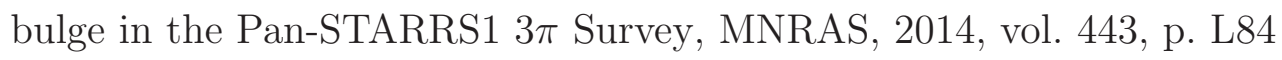

Bertelli G., Girardi L., Marigo P., Nasi E., Scaled solar tracks and isochrones in a large region of the Z-Y plane. I. From the ZAMS to the TP-AGB end for 0.15-2.5M stars, A\&A, 2008, vol. 484, p. 815

Boffin H. M. J., Carraro G., Beccari G., Ecology of Blue Straggler Stars, ArXiv e-prints, 2014

Bonaca A., Geha M., Kallivayalil N., A Cold Milky Way Stellar Stream in the Direction of Triangulum, ApJ, 2012, vol. 760, p. L6

Bonaca A., Jurić M., Ivezić Ž., Bizyaev D., Brewington H., Malanushenko E., Malanushenko V., Oravetz D., Pan K., Shelden A., Simmons A., Snedden S., Update on the Nature of Virgo Overdensity, AJ, 2012, vol. 143, p. 105 
Bressan A., Marigo P., Girardi L., Salasnich B., Dal Cero C., Rubele S., Nanni A., PARSEC: stellar tracks and isochrones with the PAdova and TRieste Stellar Evolution Code, MNRAS, 2012, vol. 427, p. 127

Brink T. G., Mateo M., Martínez-Delgado D., Radial Velocities of Galactic Halo Stars in Virgo, AJ, 2010, vol. 140, p. 1337

Bullock J. S., Johnston K. V., Tracing Galaxy Formation with Stellar Halos. I. Methods, ApJ, 2005, vol. 635, p. 931

Carlberg R. G., Grillmair C. J., Gaps in the GD-1 Star Stream, ApJ, 2013, vol. 768, p. 171

Carlin J. L., Grillmair C. J., Muñoz R. R., Nidever D. L., Majewski S. R., Kinematics and Metallicities in the Boötes III Stellar Overdensity: A Disrupted Dwarf Galaxy?, ApJ, 2009, vol. 702, p. L9

Carlin J. L., Yam W., Casetti-Dinescu D. I., Willett B. A., Newberg H. J., Majewski S. R., Girard T. M., The Origin of the Virgo Stellar Substructure, ApJ, 2012, vol. 753, p. 145

Carney B. W., Latham D. W., Laird J. B., Metal-poor Field Blue Stragglers: More Evidence for Mass Transfer, AJ, 2005, vol. 129, p. 466

Carney B. W., Latham D. W., Laird J. B., Grant C. E., Morse J. A., A Survey of ProperMotion Stars. XIV. Spectroscopic Binaries among Metal-poor Field Blue Stragglers, AJ, 2001, vol. 122, p. 3419

Carollo D., Beers T. C., Chiba M., Norris J. E., Freeman K. C., Lee Y. S., Ivezić Ž., Rockosi C. M., Yanny B., Structure and Kinematics of the Stellar Halos and Thick Disks of the Milky Way Based on Calibration Stars from Sloan Digital Sky Survey DR7, ApJ, 2010, vol. 712 , p. 692

Carollo D., Beers T. C., Placco V. M., Santucci R. M., Denissenkov P., Tissera P. B., Lentner G., Rossi S., Lee Y. S., Tumlinson J., The age structure of the Milky Way's halo, ArXiv e-prints, 2016 
Casetti-Dinescu D. I., Girard T. M., Majewski S. R., Vivas A. K., Wilhelm R., Carlin J. L., Beers T. C., van Altena W. F., Proper Motions in Kapteyn Selected Area 103: A Preliminary Orbit for the Virgo Stellar Stream, ApJ, 2009, vol. 701, p. L29

Casey A. R., Da Costa G., Keller S. C., Maunder E., Hunting the Parent of the Orphan Stream: Identifying Stream Members from Low-resolution Spectroscopy, ApJ, 2013, vol. 764 , p. 39

Casey A. R., Keller S. C., Da Costa G., Frebel A., Maunder E., Hunting the Parent of the Orphan Stream. II. The First High-resolution Spectroscopic Study, ApJ, 2014, vol. 784, p. 19

Cenarro J., Marin-Franch A., Moles M., Cristobal-Hornillos D., Mendes de Oliveira C., Sodre L., J-PLUS: The Javalambre Photometric Local Universe Survey, IAU General Assembly, 2015, vol. 22, p. 2257478

Chen X., Han Z., Primordial binary evolution and blue stragglers, MNRAS, 2009, vol. 395, p. 1822

Clarkson W. I., Sahu K. C., Anderson J., Rich R. M., Smith T. E., Brown T. M., Bond H. E., Livio M., Minniti D., Renzini A., Zoccali M., The First Detection of Blue Straggler Stars in the Milky Way Bulge, ApJ, 2011, vol. 735, p. 37

Clewley L., Warren S. J., Hewett P. C., Norris J. E., Peterson R. C., Evans N. W., Distant field blue horizontal branch stars and the mass of the Galaxy - I. Classification of halo A-type stars, MNRAS, 2002, vol. 337, p. 87

Conroy C., Gunn J. E., FSPS: Flexible Stellar Population Synthesis, Astrophysics Source Code Library, 2010, p. 10043

Cooper A. P., Cole S., Frenk C. S., White S. D. M., Helly J., Benson A. J., De Lucia G., Helmi A., Jenkins A., Navarro J. F., Springel V., Wang J., Galactic stellar haloes in the CDM model, MNRAS, 2010, vol. 406, p. 744

de Marchi F., de Angeli F., Piotto G., Carraro G., Davies M. B., Search and analysis of blue straggler stars in open clusters, A\&A, 2006, vol. 459, p. 489 
De Silva G. M., Freeman K. C., Bland-Hawthorn J., Martell S., de Boer E. W., Asplund M., Keller S., Sharma S., Zucker D. B., Zwitter T., Anguiano B. et. al., The GALAH survey: scientific motivation, MNRAS, 2015, vol. 449, p. 2604

Deason A. J., Belokurov V., Evans N. W., The Milky Way stellar halo out to $40 \mathrm{kpc}$ : squashed, broken but smooth, MNRAS, 2011

Deason A. J., Belokurov V., Evans N. W., Koposov S. E., Cooke R. J., Peñarrubia J., Laporte C. F. P., Fellhauer M., Walker M. G., Olszewski E. W., The cold veil of the Milky Way stellar halo, MNRAS, 2012, vol. 425, p. 2840

Deason A. J., Belokurov V., Hamren K. M., Koposov S. E., Gilbert K. M., Beaton R. L., Dorman C. E., Guhathakurta P., Majewski S. R., Cunningham E. C., TriAnd and its siblings: satellites of satellites in the Milky Way halo, MNRAS, 2014, vol. 444, p. 3975

Dell'Omodarmeme M., Valle G., , 2015 StellaR: Stellar evolution tracks and isochrones tools Astrophysics Source Code Library

Demarque P., Woo J.-H., Kim Y.-C., Yi S. K., Y² Isochrones with an Improved Core Overshoot Treatment, ApJS, 2004, vol. 155, p. 667

DESI Collaboration Aghamousa A., Aguilar J., Ahlen S., Alam S., Allen L. E., Allende Prieto C., Annis J., Bailey S., Balland C., et al. The DESI Experiment Part I: Science,Targeting, and Survey Design, ArXiv e-prints, 2016

Duffau S., Vivas A. K., Zinn R., Méndez R. A., Ruiz M. T., A comprehensive view of the Virgo stellar stream, A\&A, 2014, vol. 566, p. A118

Eggen O. J., Freeman K. C., Rodgers A. W., Structure of the galaxy, Reports on Progress in Physics, 1973, vol. 36, p. 625

Eggen O. J., Lynden-Bell D., andage A. R., Evidence from the motions of old stars that the Galaxy collapsed., ApJ, 1962, vol. 136, p. 748

Fellhauer M., Evans N. W., Belokurov V., Zucker D. B., Yanny B., Wilkinson M. I., Gilmore G., Irwin M. J., Bramich D. M., Vidrih S., Hewett P., Beers T., Is Ursa Major II the progenitor of the Orphan Stream?, MNRAS, 2007, vol. 375, p. 1171 
Fermani F., Schönrich R., A new calibration for the Blue Horizontal Branch, MNRAS, 2013, vol. 430, p. 1294

Ferraro F. R., Sabbi E., Gratton R., Piotto G., Lanzoni B., Carretta E., Rood R. T., Sills A., Fusi Pecci F., Moehler S., Beccari G., Lucatello S., Compagni N., Discovery of Carbon/Oxygen-depleted Blue Straggler Stars in 47 Tucanae: The Chemical Signature of a Mass Transfer Formation Process, ApJ, 2006, vol. 647, p. L53

Font A. S., Johnston K. V., Bullock J. S., Robertson B. E., Chemical Abundance Distributions of Galactic Halos and Their Satellite Systems in a $\Lambda$ CDM Universe, ApJ, 2006, vol. 638 , p. 585

Freeman K., Bland-Hawthorn J., The New Galaxy: Signatures of Its Formation, ARA\&A, 2002, vol. 40, p. 487

Fuhrmann K., Bernkopf J., HR 4657 - evidence for a thick-disk field blue straggler, A\&A, 1999, vol. 347, p. 897

Fukugita M., Ichikawa T., Gunn J. E., Doi M., Shimasaku K., Schneider D. P., The Sloan Digital Sky Survey Photometric System, AJ, 1996, vol. 111, p. 1748

Fusi Pecci F., Ferraro F. R., Corsi C. E., Cacciari C., Buonanno R., On the blue stragglers and horizontal branch morphology in Galactic globular clusters - Some speculations and a new working scenario, AJ, 1992, vol. 104, p. 1831

Girardi L., Bressan A., Bertelli G., Chiosi C., Evolutionary tracks and isochrones for lowand intermediate-mass stars: From 0.15 to $7 \mathrm{M}_{\text {sun }}$, and from $\mathrm{Z}=0.0004$ to 0.03 , A\&AS, 2000, vol. 141, p. 371

Glaspey J. W., Pritchet C. J., Stetson P. B., Lithium in high velocity A and F stars: Constraints on the blue straggler phenomenon, AJ, 1994, vol. 108, p. 271

Gosnell N. M., Mathieu R. D., Geller A. M., Sills A., Leigh N., Knigge C., Implications for the Formation of Blue Straggler Stars from HST Ultraviolet Observations of NGC 188, ApJ, 2015, vol. 814, p. 163

Grillmair C. J., Substructure in Tidal Streams: Tributaries in the Anticenter Stream, ApJ, 2006, vol. 651, p. L29 
Grillmair C. J., Another Look at the Eastern Banded Structure: A Stellar Debris Stream and a Possible Progenitor, ApJ, 2011, vol. 738, p. 98

Grillmair C. J., Two New Halo Debris Streams in the Sloan Digital Sky Survey, ApJ, 2014, vol. 790, p. L10

Grillmair C. J., Carlin J. L., Majewski S. R., Fishing in Tidal Streams: New Radial Velocity and Proper Motion Constraints on the Orbit of the Anticenter Stream, ApJ, 2008, vol. 689, p. L117

Grillmair C. J., Cutri R., Masci F. J., Conrow T., Sesar B., Eisenhardt P. R. M., Wright E. L., Detection of a Nearby Halo Debris Stream in the WISE and 2MASS Surveys, ApJ, 2013, vol. 769, p. L23

Grillmair C. J., Johnson R., The Detection of a 45deg Tidal Stream Associated with the Globular Cluster NGC 5466, ApJ, 2006, vol. 639, p. L17

Gunn J. E., Carr M., Rockosi C., Sekiguchi M., Berry K., Elms B., de Haas E., Ivezić Ž., Knapp G., Lupton R., Pauls G. et. al., The Sloan Digital Sky Survey Photometric Camera, AJ, 1998, vol. 116, p. 3040

Gunn J. E., Siegmund W. A., Mannery E. J., Owen R. E., Hull C. L., Leger R. F., Carey L. N., Knapp G. R., York D. G., Boroski W. N., Kent S. M. et. al., The 2.5 m Telescope of the Sloan Digital Sky Survey, AJ, 2006, vol. 131, p. 2332

Hammersley P. L., López-Corredoira M., Modelling star counts in the Monoceros stream and the Galactic anti-centre, A\&A, 2011, vol. 527, p. A6

Harris W. E., A New Catalog of Globular Clusters in the Milky Way, ArXiv e-prints, 2010

Helmi A., Cooper A. P., White S. D. M., Cole S., Frenk C. S., Navarro J. F., Substructure in the Stellar Halos of the Aquarius Simulations, ApJ, 2011, vol. 733, p. L7

Hills J. G., Day C. A., Stellar Collisions in Globular Clusters, Astrophys. Lett., 1976, vol. 17, p. 87

Ibata R., Irwin M., Lewis G. F., Stolte A., Galactic Halo Substructure in the Sloan Digital Sky Survey: The Ancient Tidal Stream from the Sagittarius Dwarf Galaxy, ApJ, 2001, vol. 547, p. L133 
Ibata R., Lewis G. F., Irwin M., Totten E., Quinn T., Great Circle Tidal Streams: Evidence for a Nearly Spherical Massive Dark Halo around the Milky Way, ApJ, 2001, vol. 551, p. 294

Ibata R. A., Gilmore G., Irwin M. J., A dwarf satellite galaxy in Sagittarius, Nature, 1994, vol. 370, p. 194

Ibata R. A., Gilmore G., Irwin M. J., Sagittarius: the nearest dwarf galaxy, MNRAS, 1995, vol. 277 , p. 781

Ivezić Ž., Goldston J., Finlator K., Knapp G. R., Yanny B., McKay T. A., Amrose S., SDSS Collaboration Candidate RR Lyrae Stars Found in Sloan Digital Sky Survey Commissioning Data, AJ, 2000, vol. 120, p. 963

Ivezić Ž., Kahn S. M., Eliason P., The Gaia-LSST Synergy, ArXiv e-prints, 2015

Ivezić Ž., Lupton R. H., Schlegel D., Boroski B., Adelman-McCarthy J., Yanny B., Kent S., Stoughton C., Finkbeiner D., Padmanabhan N. et. al., SDSS data management and photometric quality assessment, Astronomische Nachrichten, 2004, vol. 325, p. 583

Ivezić Ž., Smith J. A., Miknaitis G., Lin H., Tucker D., Lupton R. H., Gunn J. E. et. al., Sloan Digital Sky Survey Standard Star Catalog for Stripe 82: The Dawn of Industrial 1\% Optical Photometry, AJ, 2007, vol. 134, p. 973

Jordi C., Gaia is now a reality. In Highlights of Spanish Astrophysics VIII , 2015, p. 390

Jurić M., Ivezić Ž., SDSS, LSST and Gaia: Lessons and Synergies. In EAS Publications Series, vol. 45 of EAS Publications Series, 2011, p. 281

Jurić M., Ivezić Ž., Brooks A., Lupton R. H., Schlegel D., Finkbeiner D. et. al.., The Milky Way Tomography with SDSS. I. Stellar Number Density Distribution, ApJ, 2008, vol. 673, p. 864

Kauffmann G., White S. D. M., Guiderdoni B., The Formation and Evolution of Galaxies Within Merging Dark Matter Haloes, MNRAS, 1993, vol. 264, p. 201

Kinman T. D., Suntzeff N. B., Kraft R. P., The structure of the galactic halo outside the solar circle as traced by the blue horizontal branch stars, AJ, 1994, vol. 108, p. 1722 
Klement R., Fuchs B., Rix H.-W., Identifying Stellar Streams in the First RAVE Public Data Release, ApJ, 2008, vol. 685, p. 261

Koposov S. E., Irwin M., Belokurov V., Gonzalez-Solares E., Yoldas A. K., Lewis J., Metcalfe N., Shanks T., Discovery of a cold stellar stream in the ATLAS DR1 data, MNRAS, 2014, vol. 442, p. L85

Koposov S. E., Rix H.-W., Hogg D. W., Constraining the Milky Way Potential with a Six-Dimensional Phase-Space Map of the GD-1 Stellar Stream, ApJ, 2010, vol. 712, p. 260

Küpper A. H. W., Lane R. R., Heggie D. C., More on the structure of tidal tails, MNRAS, 2012, vol. 420, p. 2700

Kuzma P. B., Da Costa G. S., Keller S. C., Maunder E., Palomar 5 and its tidal tails: a search for new members in the tidal stream, MNRAS, 2015, vol. 446, p. 3297

Larsen J. A., Cabanela J. E., Humphreys R. M., Mapping the Asymmetric Thick Disk. II. Distance, Size, and Mass of the Hercules Thick Disk Cloud, AJ, 2011, vol. 141, p. 130

Law D. R., Majewski S. R., The Sagittarius Dwarf Galaxy: A Model for Evolution in a Triaxial Milky Way Halo, ApJ, 2010, vol. 714, p. 229

Leaman R., VandenBerg D. A., Mendel J. T., The bifurcated age-metallicity relation of Milky Way globular clusters and its implications for the accretion history of the galaxy, MNRAS, 2013, vol. 436, p. 122

Lee Y. S., Beers T. C., Sivarani T., Johnson J. A., An D., Wilhelm R., Allende Prieto C. et. al., The SEGUE Stellar Parameter Pipeline. II. Validation with Galactic Globular and Open Clusters, AJ, 2008, vol. 136, p. 2050

Lee Y.-W., Demarque P., Zinn R., The horizontal-branch stars in globular clusters. 2: The second parameter phenomenon, ApJ, 1994, vol. 423, p. 248

Lejeune T., Schaerer D., Database of Geneva stellar evolution tracks and isochrones for $(\mathrm{UBV})_{J}(\mathrm{RI})_{C}$ JHKLL'M, HST-WFPC2, Geneva and Washington photometric systems, A\&A, 2001, vol. 366, p. 538 
Leonard P. J. T., Stellar collisions in globular clusters and the blue straggler problem, AJ, 1989, vol. 98 , p. 217

Leonard P. J. T., Blue Stragglers in Star Clusters. In The Origins, Evolution, and Destinies of Binary Stars in Clusters, vol. 90 of Astronomical Society of the Pacific Conference Series, 1996, p. 337

Li J., Newberg H. J., Carlin J. L., Deng L., Newby M., Willett B. A., Xu Y., Luo Z., On Rings and Streams in the Galactic Anti-Center, ApJ, 2012, vol. 757, p. 151

Li T. S., Balbinot E., Mondrik N., Marshall J. L., Yanny B., Bechtol K., Drlica-Wagner A., DES Collaboration Discovery of a Stellar Overdensity in Eridanus-Phoenix in the Dark Energy Survey, ApJ, 2016, vol. 817, p. 135

Lopez-Corredoira M., Moitinho A., Zaggia S., Momany Y., Carraro G., Hammersley P. L., Cabrera-Lavers A., Vazquez R. A., Comments on the "Monoceros" affair, ArXiv e-prints, 2012

LSST Science Collaboration Abell P. A., Allison J., Anderson S. F., Andrew J. R., Angel J. R. P., Armus L., Arnett D., Asztalos S. J., Axelrod T. S., et al. LSST Science Book, Version 2.0, ArXiv e-prints, 2009

Lupton R., Gunn J. E., Ivezić Z., Knapp G. R., Kent S., Yasuda N., The SDSS Imaging Pipelines. In Astronomical Data Analysis Software and Systems X , vol. 238 of Astronomical Society of the Pacific Conference Series, 2001, p. 269

Lux H., Read J. I., Lake G., Johnston K. V., NGC 5466: a unique probe of the Galactic halo shape, MNRAS, 2012, vol. 424, p. L16

Majewski S. R., Ostheimer J. C., Kunkel W. E., Patterson R. J., Exploring Halo Substructure with Giant Stars. I. Survey Description and Calibration of the Photometric Search Technique, AJ, 2000, vol. 120, p. 2550

Majewski S. R., Skrutskie M. F., Weinberg M. D., Ostheimer J. C., A Two Micron All Sky Survey View of the Sagittarius Dwarf Galaxy. I. Morphology of the Sagittarius Core and Tidal Arms, ApJ, 2003, vol. 599, p. 1082 
Mapelli M., Sigurdsson S., Colpi M., Ferraro F. R., Possenti A., Rood R. T., Sills A., Beccari G., The Contribution of Primordial Binaries to the Blue Straggler Population in 47 Tucanae, ApJ, 2004, vol. 605, p. L29

Marsteller B., Beers T. C., Christlieb N., Thom C., Horizontal-Branch Stars as Probes of Structure in the Halo of the Milky Way. In American Astronomical Society Meeting Abstracts , vol. 36 of Bulletin of the American Astronomical Society, 2004, p. 1377

Martin C., Carlin J. L., Newberg H. J., Grillmair C., Kinematic Discovery of a Stellar Stream Located in Pisces, ApJ, 2013, vol. 765, p. L39

Martin N. F., Ibata R. A., Conn B. C., Lewis G. F., Bellazzini M., Irwin M. J., McConnachie A. W., Why the Canis Major overdensity is not due to the Warp: analysis of its radial profile and velocities, MNRAS, 2004, vol. 355, p. L33

Martin N. F., Ibata R. A., Irwin M., Galactic Halo Stellar Structures in the TriangulumAndromeda Region, ApJ, 2007, vol. 668, p. L123

Martin N. F., Ibata R. A., Rich R. M., Collins M. L. M., Fardal M. A., Irwin M. J., Lewis G. F., McConnachie A. W., Babul A. et. al., The PAndAS Field of Streams: Stellar Structures in the Milky Way Halo toward Andromeda and Triangulum, ApJ, 2014, vol. 787 , p. 19

Martínez-Delgado D., Butler D. J., Rix H.-W., Franco V. I., Peñarrubia J., Alfaro E. J., Dinescu D. I., The Closest View of a Dwarf Galaxy: New Evidence on the Nature of the Canis Major Overdensity, ApJ, 2005, vol. 633, p. 205

Mastrobuono-Battisti A., Di Matteo P., Montuori M., Haywood M., Clumpy streams in a smooth dark halo: the case of Palomar 5, A\&A, 2012, vol. 546, p. L7

McConnachie A. W., The Observed Properties of Dwarf Galaxies in and around the Local Group, AJ, 2012, vol. 144, p. 4

McCrea W. H., The interpretation of the Schwarzschild metric and the release of gravitational energy, Astrophysica Norvegica, 1964, vol. 9, p. 89

Mihalas D. M., Stellar atmospheres., 1982 
Momany Y., Held E. V., Saviane I., Zaggia S., Rizzi L., Gullieuszik M., The blue plume population in dwarf spheroidal galaxies. Genuine blue stragglers or young stellar population?, A\&A, 2007, vol. 468, p. 973

Newberg H. J., Determining distances to stars statistically from photometry. In Advancing the Physics of Cosmic Distances, vol. 289 of IAU Symposium, 2013, p. 74

Newberg H. J., Carlin J. L., eds,, 2016 Tidal Streams in the Local Group and Beyond vol. 420 of Astrophysics and Space Science Library

Newberg H. J., Willett B. A., Yanny B., Xu Y., The Orbit of the Orphan Stream, ApJ, 2010, vol. 711, p. 32

Newberg H. J., Yanny B., Cole N., Beers T. C., Re Fiorentin P., Schneider D. P., Wilhelm R., The Overdensity in Virgo, Sagittarius Debris, and the Asymmetric Spheroid, ApJ, 2007, vol. 668, p. 221

Newberg H. J., Yanny B., Grebel E. K., Hennessy G., Ivezić Ž., Martinez-Delgado D., Odenkirchen M., Rix H.-W., Brinkmann J., Lamb D. Q., Schneider D. P., York D. G., Sagittarius Tidal Debris 90 Kiloparsecs from the Galactic Center, ApJ, 2003, vol. 596, p. L191

Newberg H. J., Yanny B., Rockosi C., Grebel E. K., Rix H.-W., Brinkmann J., Csabai I., Hennessy G., Hindsley R. B., Ibata R., Ivezić Z., Lamb D., Nash E. T., Odenkirchen M., Rave H. A., Schneider D. P., Smith J. A., Stolte A., York D. G., The Ghost of Sagittarius and Lumps in the Halo of the Milky Way, ApJ, 2002, vol. 569, p. 245

Newberg H. J., Yanny B., Willett B. A., Discovery of a New, Polar-Orbiting Debris Stream in the Milky Way Stellar Halo, ApJ, 2009, vol. 700, p. L61

Niederste-Ostholt M., Belokurov V., Evans N. W., Peñarrubia J., Re-Assembling the Sagittarius Dwarf Galaxy, ApJ, 2010, vol. 712, p. 516

Oluseyi H. M., Becker A. C., Culliton C. C., Furqan M., Hoadley K. L., Regencia P., Wells A. J., Jones L., Krughoff S., Sesar B., Jacoby S., LSST Observations of RR Lyrae Stars for Mapping the Galactic Halo. In Tracing the Ancestry of Galaxies , vol. 277 of IAU Symposium, 2011, p. 300 
Parada J., Richer H., Heyl J., Kalirai J., Goldsbury R., Dynamical Estimate of Post-mainsequence Stellar Masses in 47 Tucanae, ApJ, 2016, vol. 826, p. 88

Perryman M. A. C., de Boer K. S., Gilmore G., Høg E., Lattanzi M. G., Lindegren L., Luri X., Mignard F., Pace O., de Zeeuw P. T., GAIA: Composition, formation and evolution of the Galaxy, A\&A, 2001, vol. 369, p. 339

Pier J. R., AB stars in the southern galactic halo. II - Spectroscopy and radial velocities, ApJS, 1983, vol. 53, p. 791

Pier J. R., Munn J. A., Hindsley R. B., Hennessy G. S., Kent S. M., Lupton R. H., Ivezić Ž., Astrometric Calibration of the Sloan Digital Sky Survey, AJ, 2003, vol. 125, p. 1559

Piotto G., De Angeli F., King I. R., Djorgovski S. G., Bono G., Cassisi S., Meylan G., Recio-Blanco A., Rich R. M., Davies M. B., Relative Frequencies of Blue Stragglers in Galactic Globular Clusters: Constraints for the Formation Mechanisms, ApJ, 2004, vol. 604 , p. L109

Preston G. W., Field Blue Stragglers and Related Mass Transfer Issues, ArXiv e-prints, 2014

Preston G. W., Beers T. C., Shectman S. A., The space density and kinematics of blue metal-poor main sequence stars near the solar circle, AJ, 1994, vol. 108, p. 538

Preston G. W., Shectman S. A., Beers T. C., Detection of a galactic color gradient for blue horizontal-branch stars of the halo field and implications for the halo age and density distributions, ApJ, 1991a, vol. 375, p. 121

Preston G. W., Shectman S. A., Beers T. C., Photoelectric UBV photometry of stars selected in the HK objective-prism survey, ApJS, 1991b, vol. 76, p. 1001

Preston G. W., Sneden C., What Are These Blue Metal-Poor Stars?, AJ, 2000, vol. 120, p. 1014

Prior S. L., Da Costa G. S., Keller S. C., Murphy S. J., Extending the Virgo Stellar Stream with SEKBO Survey RR Lyrae Stars, ApJ, 2009, vol. 691, p. 306

Proctor R. A., Preliminary Paper on Certain Drifting Motions of the Stars, Proceedings of the Royal Society of London Series I, 1869, vol. 18, p. 169 
Rocha-Pinto H. J., Maciel W. J., Castilho B. V., Chromospherically Young, Kinematically Old Stars. In Astrophysical Ages and Times Scales, vol. 245 of Astronomical Society of the Pacific Conference Series, 2001, p. 364

Rocha-Pinto H. J., Majewski S. R., Skrutskie M. F., Crane J. D., Patterson R. J., Exploring Halo Substructure with Giant Stars: A Diffuse Star Cloud or Tidal Debris around the Milky Way in Triangulum-Andromeda, ApJ, 2004, vol. 615, p. 732

Ryan S. G., Beers T. C., Kajino T., Rosolankova K., Ultra-Lithium-deficient Halo Stars and Blue Stragglers: A Common Origin?, ApJ, 2001, vol. 547, p. 231

Ryan S. G., Gregory S. G., Kolb U., Beers T. C., Kajino T., Rapid Rotation of Ultra-Lidepleted Halo Stars and Their Association with Blue Stragglers, ApJ, 2002, vol. 571, p. 501

Salasnich B., Girardi L., Weiss A., Chiosi C., Evolutionary tracks and isochrones for alpha -enhanced stars, A\&A, 2000, vol. 361, p. 1023

Sales L. V., Helmi A., Starkenburg E., Morrison H. L., Engle E., Harding P., Mateo M., Olszewski E. W., Sivarani T., On the genealogy of the Orphan Stream, MNRAS, 2008, vol. 389, p. 1391

Sandage A. R., The color-magnitude diagram for the globular cluster M 3., AJ, 1953, vol. 58 , p. 61

Santucci R. M., Beers T. C., Placco V. M., Carollo D., Rossi S., Lee Y. S., Denissenkov P., Tumlinson J., Tissera P. B., Chronography of the Milky Way's Halo System with Field Blue Horizontal-Branch Stars, ApJ, 2015, vol. 813, p. L16

Santucci R. M., Placco V. M., Rossi S., Beers T. C., Reggiani H. M., Lee Y. S., Xue X.-X., Carollo D., The Frequency of Field Blue-Straggler Stars in the Thick Disk and Halo System of the Galaxy, ApJ, 2015, vol. 801, p. 116

Sarajedini A., A Survey of Galactic Globular Clusters for Blue Straggler Stars. In Blue Stragglers, vol. 53 of Astronomical Society of the Pacific Conference Series, 1993, p. 14

Sarajedini A., Globular Cluster Photometry near the Turnoff: Blue Stragglers, Relative Ages, and the Horizontal Branch, PASP, 1994, vol. 106, p. 205 
Schlaufman K. C., Casey A. R., The Best and Brightest Metal-poor Stars, ApJ, 2014, vol. 797 , p. 13

Schlegel D. J., Finkbeiner D. P., Davis M., Maps of Dust Infrared Emission for Use in Estimation of Reddening and Cosmic Microwave Background Radiation Foregrounds, ApJ, 1998, vol. 500, p. 525

Schmidt M., Lipson H., Distilling free-form natural laws from experimental data., Science (New York, N.Y.), 2009, vol. 324, p. 81

Searle L., Zinn R., Compositions of halo clusters and the formation of the galactic halo, ApJ, 1978, vol. 225, p. 357

Sersic J. L., Atlas de galaxias australes, 1968

Sesar B., Bovy J., Bernard E. J., Caldwell N., Cohen J. G., Fouesneau M., et al. The Nature and Orbit of the Ophiuchus Stream, ApJ, 2015, vol. 809, p. 59

Sesar B., Grillmair C. J., Cohen J. G., Bellm E. C., Bhalerao V. B., Levitan D., Laher R. R., Ofek E. O., Surace J. A., Tang S., Waszczak A., Kulkarni S. R., Prince T. A., Tracing the Orphan Stream to 55 kpc with RR Lyrae Stars, ApJ, 2013, vol. 776, p. 26

Sesar B., Ivezić Ž., Grammer S. H., Morgan D. P., Becker A. C., Jurić M., De Lee N., Annis J., Beers T. C., Fan X., Lupton R. H., Gunn J. E., Knapp G. R., Jiang L., Jester S., Johnston D. E., Lampeitl H., Light Curve Templates and Galactic Distribution of RR Lyrae Stars from Sloan Digital Sky Survey Stripe 82, ApJ, 2010, vol. 708, p. 717

Sesar B., Ivezić Ž., Lupton R. H., Jurić M., Gunn J. E., Knapp G. R. et. al.., Exploring the Variable Sky with the Sloan Digital Sky Survey, AJ, 2007, vol. 134, p. 2236

Sesar B., Vivas A. K., Duffau S., Ivezić Ž., Halo Velocity Groups in the Pisces Overdensity, ApJ, 2010, vol. 717, p. 133

Shanks T., Metcalfe N., Chehade B., Findlay J. R., Irwin M. J., Gonzalez-Solares E., Lewis J. R., Yoldas A. K., Mann R. G., Read M. A., Sutorius E. T. W., Voutsinas S., The VLT Survey Telescope ATLAS, MNRAS, 2015, vol. 451, p. 4238 
Sharma S., Johnston K. V., Majewski S. R., Muñoz R. R., Carlberg J. K., Bullock J., Group Finding in the Stellar Halo Using M-giants in the Two Micron All Sky Survey: An Extended View of the Pisces Overdensity?, ApJ, 2010, vol. 722, p. 750

Sheffield A. A., Johnston K. V., Majewski S. R., Damke G., Richardson W., Beaton R., Rocha-Pinto H. J., Exploring Halo Substructure with Giant Stars. XIV. The Nature of the Triangulum-Andromeda Stellar Features, ApJ, 2014, vol. 793, p. 62

Simion I. T., Belokurov V., Irwin M., Koposov S. E., Strong RR Lyrae excess in the Hercules-Aquila Cloud, MNRAS, 2014, vol. 440, p. 161

Sirko E., Goodman J., Knapp G. R., Brinkmann J., Ivezić Ž., Knerr E. J., Schlegel D., Schneider D. P., York D. G., Blue Horizontal-Branch Stars in the Sloan Digital Sky Survey. I. Sample Selection and Structure in the Galactic Halo, AJ, 2004, vol. 127, p. 899

Slater C. T., Bell E. F., Schlafly E. F., Jurić M., Martin N. F., Rix H.-W., Bernard E. J., Burgett W. S., Chambers K. C., Finkbeiner D. P., Goldman B., Kaiser N., Magnier E. A., Morganson E. P., Price P. A., Tonry J. L., A Pan-STARRS1 View of the Bifurcated Sagittarius Stream, ApJ, 2013, vol. 762, p. 6

Smith M. C., Kinematically Detected Halo Streams. In Astrophysics and Space Science Library , vol. 420 of Astrophysics and Space Science Library, 2016, p. 113

Springel V., White S. D. M., Jenkins A., Frenk C. S., Yoshida N., Gao L., Navarro J., Thacker R., Croton D., Helly J., Peacock J. A., Cole S., Thomas P., Couchman H., Evrard A., Colberg J., Pearce F., Simulations of the formation, evolution and clustering of galaxies and quasars, Nature, 2005, vol. 435, p. 629

Stoughton C., Lupton R. H., Bernardi M., Blanton M. R., Burles S., Castander F. J., Connolly A. J., Eisenstein D. J., Frieman J. A., Hennessy G. S. et. al.., Sloan Digital Sky Survey: Early Data Release, AJ, 2002, vol. 123, p. 485

Stryker L. L., Blue stragglers, PASP, 1993, vol. 105, p. 1081

Tucker D. L., Kent S., Richmond M. W., Annis J., Smith J. A., Allam S. S., Rodgers C. T., Stute J. L., Adelman-McCarthy J. K., Brinkmann J. et. al., The Sloan Digital 
Sky Survey monitor telescope pipeline, Astronomische Nachrichten, 2006, vol. 327, p. 821

Tumlinson J., Chemical Evolution in Hierarchical Models of Cosmic Structure. II. The Formation of the Milky Way Stellar Halo and the Distribution of the Oldest Stars, ApJ, 2010, vol. 708, p. 1398

VandenBerg D. A., Bond H. E., Nelan E. P., Nissen P. E., Schaefer G. H., Harmer D., Three Ancient Halo Subgiants: Precise Parallaxes, Compositions, Ages, and Implications for Globular Clusters, ApJ, 2014, vol. 792, p. 110

Vickers J. J., Huxor A. P., Grebel E. K., Blue Horizontal Branch Stars in Pan-STARRS. In EAS Publications Series , vol. 67 of EAS Publications Series, 2014, p. 183

Vivas A. K., Jaffé Y. L., Zinn R., Winnick R., Duffau S., Mateu C., Spectroscopy of Bright Quest RR Lyrae Stars: Velocity Substructures Toward Virgo, AJ, 2008, vol. 136, p. 1645

Vivas A. K., Zinn R., Andrews P., Bailyn C., Baltay C., Coppi P., Ellman N., Girard T., Rabinowitz D., Schaefer B. et. al., The QUEST RR Lyrae Survey: Confirmation of the Clump at 50 Kiloparsecs and Other Overdensities in the Outer Halo, ApJ, 2001, vol. 554 , p. L33

Watkins L. L., Evans N. W., Belokurov V., Smith M. C., Hewett P. C., Bramich D. M., Gilmore G. F., Irwin M. J., Vidrih S., Wyrzykowski Ł., Zucker D. B., Substructure revealed by RRLyraes in SDSS Stripe 82, MNRAS, 2009, vol. 398, p. 1757

White S. D. M., Springel V., Where Are the First Stars Now?. In The First Stars , 2000, p. 327

Wilhelm R., Beers T. C., Sommer-Larsen J., Pier J. R., Layden A. C., Flynn C., Rossi S., Christensen P. R., Spectroscopy of Hot Stars in the Galactic Halo. III. Analysis of a Large Sample of Field Horizontal-Branch and Other A-Type Stars, AJ, 1999, vol. 117, p. 2329

Willett B. A., Newberg H. J., Zhang H., Yanny B., Beers T. C., An Orbit Fit for the Grillmair Dionatos Cold Stellar Stream, ApJ, 2009, vol. 697, p. 207 
Xin Y., Deng L., de Grijs R., Kroupa P., Simple stellar population models including blue stragglers, MNRAS, 2011, vol. 411, p. 761

Xue X. X., Rix H. W., Zhao G., Re Fiorentin P., Naab T., Steinmetz M., van den Bosch F. C., Beers T. C., Lee Y. S., Bell E. F. et. al., The Milky Way's Circular Velocity Curve to $60 \mathrm{kpc}$ and an Estimate of the Dark Matter Halo Mass from the Kinematics of 2400 SDSS Blue Horizontal-Branch Stars, ApJ, 2008, vol. 684, p. 1143

Yam W., Carlin J. L., Newberg H. J., Dumas J., O’Malley E., Newby M., Martin C., Update on the Cetus Polar Stream and Its Progenitor, ApJ, 2013, vol. 776, p. 133

Yanny B., Newberg H. J., Johnson J. A., Lee Y. S., Beers T. C., Bizyaev D., Brewington H., Fiorentin P. R., Harding P., Malanushenko E., Malanushenko V., Oravetz D., Pan K., Simmons A., Snedden S., Tracing Sagittarius Structure with SDSS and SEGUE Imaging and Spectroscopy, ApJ, 2009, vol. 700, p. 1282

Yanny B., Newberg H. J., Kent S., Laurent-Muehleisen S. A., Pier J. R., Richards G. T., Stoughton C. et. al., Identification of A-colored Stars and Structure in the Halo of the Milky Way from Sloan Digital Sky Survey Commissioning Data, ApJ, 2000, vol. 540, p. 825

Yanny B., Rockosi C., Newberg H. J., Knapp G. R., Adelman-McCarthy J. K., Alcorn B., Allam S. et. al., SEGUE: A Spectroscopic Survey of 240,000 Stars with g = 14-20, AJ, 2009, vol. 137 , p. 4377

Yi S. K., Demarque P., Kim Y.-C., The $\mathrm{Y}^{2}$ Isochrones and Stellar Evolution Tracks. In Extragalactic Globular Cluster Systems , 2003, p. 255

York D. G., Adelman J., Anderson Jr. J. E., Anderson S. F., Annis J., Bahcall N. A., Bakken J. A., Barkhouser R., Bastian S., Berman E. et. al., The Sloan Digital Sky Survey: Technical Summary, AJ, 2000, vol. 120, p. 1579

Zhang Y., Han Z., Liu J., Zhang F., Kang X., Testing three derivative methods of stellar population synthesis models, MNRAS, 2012, vol. 421, p. 1678

Zhao C., Newberg H. J., Transformation from SDSS Photometric System to JohnsonMorgan-Cousins System in HK Survey, ArXiv:0612034, 2006 
Zhao G., Zhao Y.-H., Chu Y.-Q., Jing Y.-P., Deng L.-C., LAMOST spectral survey: An overview, Research in Astronomy and Astrophysics, 2012, vol. 12, p. 723 